Portland State University

PDXScholar

Fall 9-11-2018

\title{
Ecology and Population Dynamics of Salmonids in the Columbia River: Response of Fishes to Anthropogenic Change in a Large Riverscape
}

Timothy Sean Elder

Portland State University

Follow this and additional works at: https://pdxscholar.library.pdx.edu/open_access_etds

Part of the Ecology and Evolutionary Biology Commons, and the Environmental Sciences Commons Let us know how access to this document benefits you.

Recommended Citation

Elder, Timothy Sean, "Ecology and Population Dynamics of Salmonids in the Columbia River: Response of Fishes to Anthropogenic Change in a Large Riverscape" (2018). Dissertations and Theses. Paper 4635. https://doi.org/10.15760/etd.6519

This Dissertation is brought to you for free and open access. It has been accepted for inclusion in Dissertations and Theses by an authorized administrator of PDXScholar. Please contact us if we can make this document more accessible: pdxscholar@pdx.edu. 
Ecology and Population Dynamics of Salmonids in the Columbia River: Response of Fishes to Anthropogenic Change in a Large Riverscape

by

Timothy Sean Elder

A dissertation submitted in partial fulfillment of the requirements for the degree of

\author{
Doctor of Philosophy \\ in \\ Environmental Sciences and Resources
}

Dissertation Committee:

Angela Strecker, Chair

Valerie Kelly

Yangdong Pan

Michael Murphy

Portland State University

2018 


\begin{abstract}
Freshwater ecosystems and the species that reside therein are disproportionately imperiled compared to terrestrial systems. Over the past 150 years, the Columbia River basin in the western United States has gone from one of the most productive and abundant salmon watersheds in the world, to having just a small fraction of its former salmon abundance. The cause of declines in salmon productivity and abundance are related to overlapping and confounding stressors including changes in large-scale climatic patterns and anthropogenic alterations within and adjacent to the Columbia River. Four main anthropogenic stressors have been identified as the leading causes of salmonid declines: commercial harvest of adult salmon, hydroelectric power generation and associated reservoirs, habitat loss due to impassible dams and restricted access to historical habitat, and hatchery production.

My dissertation broadly examined how salmon ecology and population dynamics have been influenced by anthropogenic alterations occurring within the Columbia River basin. This dissertation addresses three main questions: Do the hydroelectric dams on the Lower Columbia River represent a pulse- or press-type ecological disturbance to migrating Chinook salmon (Oncorhynchus tshawytscha) and steelhead (O. mykiss) and what are the biotic and abiotic factors that most influence the survival of fish passing multiple dams (Chapter 2)? How do wild and hatchery fish differ in regards to the precocious life-history strategy, and which variables influence this strategy across environments (freshwater to marine) and life stages (egg to adult; Chapter 3)? What are
\end{abstract}


the morphological differences between wild and hatchery salmonids and how much of that variation is attributable to rearing-environment (Chapter 4)?

I found that high outflow volumes led to involuntary spill in 2011 and created an environment of supersaturated dissolved gas concentrations. In this environment, migrating smolt survival was strongly influenced by barometric pressure, fish velocity and water temperature. The effect of these variables on survival was compounded by multiple dam passages compared to fish passing a single dam. Despite spatial isolation between dams in the Lower Columbia River hydrosystem, migrating smolt appear to experience cumulative effects akin to an ecological press disturbance. In general, Chinook salmon and steelhead respond similarly in terms of survival rates and responses to altered environmental conditions. Management actions that limit dissolved gas concentrations in years of high flow will benefit migrating salmonids during this life stage.

Both biotic and environmental factors affect precociousness in hatchery and wild Chinook salmon, across freshwater and marine environments. Wild fish are influenced by density-dependent processes in freshwater, as well as marine conditions that promote growth. Wild Chinook have the highest probability of precocious maturation when large smolt $(>150 \mathrm{~mm})$ experience productive marine environments within the first several months of ocean residence. Precocious hatchery fish are broadly influenced by conditions experienced during freshwater residency, outmigration, and in marine habitats. There was no interaction between the size of hatchery fish and environmental variables, suggesting that these fish attained the size required to mature precociously prior to 
migration. These results indicate that hatchery Chinook salmon do not respond to the same environmental cues that determine life history transitions as wild Chinook salmon, likely as a result of different physiological conditions and environmental exposures during early life stages. There are ecological and economic consequences to the precocious life history strategy including reduced marine-derived nutrients entering freshwater ecosystems and a loss of investment for fish intended for the adult fishery. There are significant differences in body shape between wild and hatchery origin Chinook salmon and steelhead that can be partially explained by rearing environment and variables influenced by smoltification. Hatchery fish of both species are significantly larger (i.e. centroid size, length, weight) than wild fish but have comparable or lower condition factor. In general, hatchery fish have smaller heads and longer, thinner tails (i.e. fusiform) compared to wild fish. Allometric trajectories (i.e. shape change with size) indicate that the shape of wild and hatchery fish are significantly different at small and large sizes. Wild and hatchery Chinook salmon became more morphologically different as size increased, while steelhead became more similar. The overall amount of shape variation was not significantly different between wild and hatchery Chinook salmon. This finding suggests that regardless of significant differences in the way shapes vary, hatchery Chinook have not lost overall shape variation. Total amount of shape variation was significantly greater in wild compared to hatchery steelhead, indicating that hatcheries may have a homogenizing effect on steelhead shape. I recommend a coordinated effort between federal, state and tribal hatcheries to incorporate elements of the natural rearing environment into conventional hatcheries. These elements include in- 
water structure that promotes the burst swimming mode, increased water velocities to increase dorsal-ventral distance, under-water feeding apparatus that reduce surface feeding behavior, overhead cover and mimicked predators to teach escape behavior.

Major advancements have been made in identifying and ameliorating negative effects of anthropogenic alterations within the Columbia Basin, however, many wild populations continue to decline. My research suggests that the physical (i.e. weirs and bypass structures) and operational alterations (i.e. voluntary spill) to the lower Columbia hydrosystem have substantially improved conditions for migrating smolt compared to past years, but involuntary spill during years of high flow continue to create deleterious conditions for migrating smolt. Riverscape-scale management strategies that recognize biotic and abiotic connectivity between dams (i.e. press disturbance) will benefit migrating smolt. My research indicates that hatchery fish are not currently equal or adequate replacements for wild fish. Hatcheries vary greatly in their stated goals and desired outcomes and several coordinated changes to general hatchery practices may help produce fish that are more similar to wild fish in morphology and life histories: 1) Change the goals of production away from producing as many, large individuals as possible, to producing fish that resemble the target wild populations they are intended to support; 2) Alter the hatchery environment to reflect the rearing environments in which salmon evolved and into which they will be released; and 3) Reduce the annual number of hatchery fish released into the Columbia Basin for the sole purpose of harvest. Recovering and rehabilitating critical and diverse habitats utilized by salmonids at each 
life stage (spawning, rearing, migration, estuary and marine) remains crucial for wild population success into the future. 


\section{Acknowledgements}

I would like to extend my deepest gratitude to my adviser Angela Strecker. Angela has provided me with seven years of great advice, support, council and lots of help with grammar. I continue to be impressed with her dedication to her students and our department. I am thankful for my committee members Valerie Kelly, Michael Murphy and Yangdong Pan who provided guidance, support, great conversations, and really tough comprehensive exam questions. To all the members of the Strecker Lab: Ariana Chiapella, Meredith Jordan, Jeff Brittain, Sam Cimino, Amelia Johnson, Crysta Gantz, Brian McGann and Meredith Holgerson who listened over and over to the same presentations and only occasionally fell asleep. Thanks to Joey Peters and Matthew Duveneck, two great scientists who made it all look so easy. Special thanks to Steve Braun, whose belief that it is not enough to just study the natural world but that you have to get out and enjoy it, helped remind me to play. Thanks to all the past and present members of the Association of Environmental Science Students (AESS). You guys have been my community and some of my favorite memories from graduate school involve not talking about science at happy hour. Thanks to James Hiam for all the support and time spent out in the wilds. You changed the direction of my path and many others.

I would like to thank the staff of the Pacific Northwest National Laboratory Bonneville Office, and the Pacific States Marine Fisheries Commission, especially Christa Woodley, Mark Weiland and Gene Ploskey. I was a botanist before I met them. Thanks to M. Brad Eppard at the US Army Corps of Engineers. I would like to thank PTAGIS and all the folks throughout the Columbia River Basin that have contributed 
countless hours, hard work and high-quality data to this database. Thanks for funding support from the National Science Foundation's Cascades to Coast GK-12 program (0948041) and the Edward D. and Olive C. Bushby Scholarship.

Huge thanks to my family for all the encouragement and love that they have given me (not just over the past 7 years). I am extremely lucky to have you all in my life and I hope this dissertation will help you understand what I've been doing with my life. To my parents: I cannot thank you enough. I have felt loved and supported by you in all my endeavors.

Finally, thanks to my amazing partner Katherine. She has loved, encouraged and believed in me. Her patience and understanding when I was stressed out, preoccupied or needed to talk about statistics has been a tremendous gift. I continue to be so amazed by you and I am excited for the next chapter of our life together. 


\section{Table of Contents}

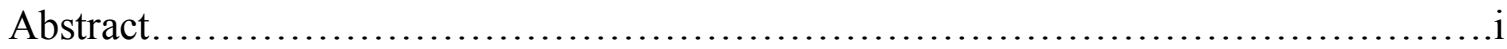

Acknowledgements............................................................. vi

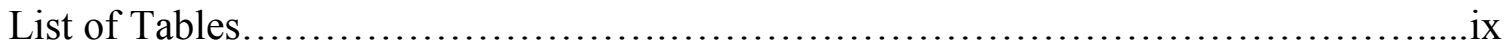

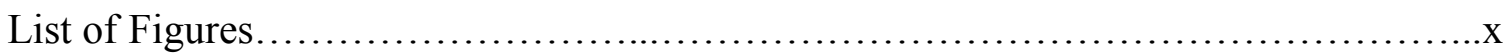

Chapter 1

Salmon Ecology and Population Dynamics in the Columbia River Basin................1

Chapter 2

Factors Influencing the Survival of Outmigrating Juvenile Salmonids through Multiple Dam Passages: An Individual-Based Approach.................................... 34

Chapter 3

Productive marine phases and density dependence influence early maturation in Chinook

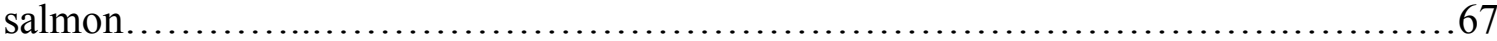

Chapter 4

Morphometric differences between wild and hatchery salmonids: Effects of rearing environment and smoltification............................................... 110

Chapter 5

Conclusion.

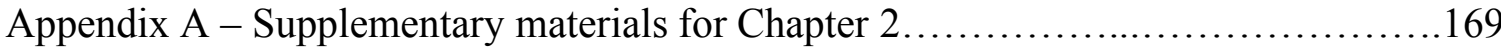

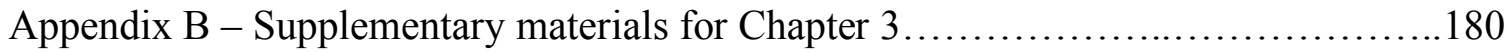

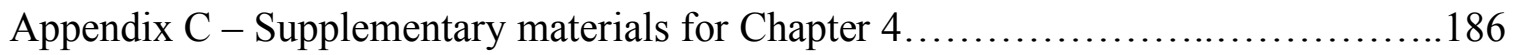




\section{List of Tables}

Chapter 2 Tables

Table 2.1: Dam passage experience and survival estimates for Chinook salmon and

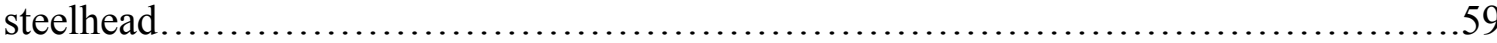

Table 2.2: Evaluation of random forest models for classification of Chinook salmon and steelhead survival for fish passing 1,2 , and 3 dams................................. 60

\section{Chapter 3 Tables}

Table 3.1: A priori predictions of the influence of freshwater, nearshore marine and offshore marine variables on precocious maturation in Chinook salmon................ 100

Table 3.2: Evaluation of random forest and artificial neural network models for classification of wild and hatchery precocious fish.

\section{Chapter 4 Tables}

Table 4.1: Summary statistics for wild and hatchery juvenile Chinook salmon and steelhead showing centroid size, length $(\mathrm{mm})$, weight $(\mathrm{g})$ and condition factor....

Table 4.2: Model comparison of shape variation as a function of size, fish origin and the interaction of size and origin in Chinook salmon and steelhead.

Table 4.3: Redundancy analysis of shape variation and selected predictor variables for

Chinook salmon and steelhead............................................ 142 


\section{List of Figures}

\section{$\underline{\text { Chapter } 1 \text { Figures }}$}

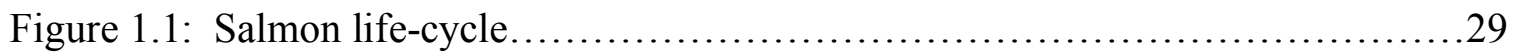

Figure 1.2: Chinook salmon smolt ............................................ 30

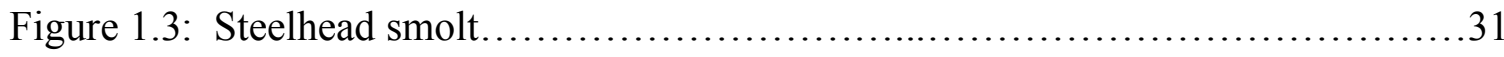

Figure 1.4: Alternative reproductive strategies of Chinook salmon...................32

Figure 1.5: Conceptual diagram of dissertation framework..........................33

\section{Chapter 2 Figures}

Figure 2.1: Map of the Lower Columbia River hydrosystem...........................61

Figure 2.2: Variable importance for the survival of Chinook salmon passing the Lower

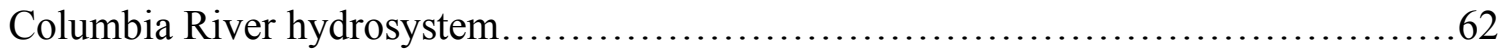

Figure 2.3: Variable importance for the survival of steelhead passing the Lower Columbia River hydrosystem

Figure 2.4: Partial dependence plots for Chinook salmon by variable and dam passage

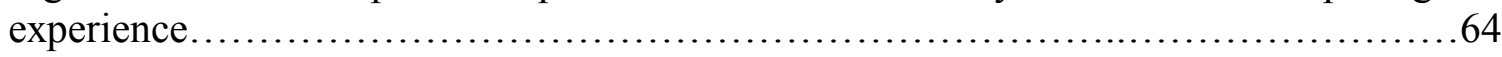

Figure 2.5: Partial dependence plots for steelhead by variable and dam passage

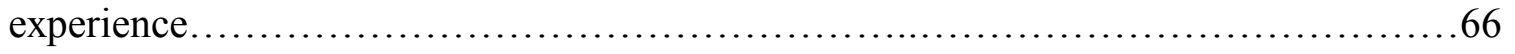

\section{Chapter 3 Figures}

Figure 3.1: Frequency and proportion of precocious wild and hatchery Chinook salmon. 102

Figure 3.2: Map of the Columbia River Basin with major tributaries....................103

Figure 3.3: Relative variable importance for wild Chinook salmon generated from random forest and artificial neural networks.

Figure 3.4: Partial dependence plots showing the probability of wild Chinook salmon returning precociously based on marginal effects of predictor variables 
Figure 3.5: Two-way partial dependence plot for wild Chinook salmon showing the interaction of the marginal effects of fish length $(\mathrm{mm})$ and other predictor variables...106

Figure 3.6: Relative variable importance for hatchery Chinook salmon generated from random forest and artificial neural networks....................................107

Figure 3.7: Partial dependence plots showing the probability of hatchery Chinook salmon returning precociously based on marginal effects of predictor variables

Figure 3.8: Two-way partial dependence plot for hatchery Chinook salmon showing the interaction of the marginal effects of fish length $(\mathrm{mm})$ and other predictor variables....109

\section{Chapter 4 Figures}

Figure 4.1: Landmark locations used in geometric morphometric analysis of juvenile Chinook salmon and steelhead.

Figure 4.2: Generalized Procrustes aligned shapes for wild and hatchery Chinook salmon and steelhead. 144

Figure 4.3: Allometric vectors for wild and hatchery Chinook salmon................145

Figure 4.4: Constrained ordination plot for wild and hatchery Chinook salmon.........146

Figure 4.5: Allometric vectors for wild and hatchery steelhead......................147

Figure 4.6: Constrained ordination plot for wild and hatchery steelhead...............148 


\section{Chapter 1 - Salmon Ecology and Population Dynamics in the Columbia River Basin}

Freshwater ecosystems have been identified as one of the most imperiled ecosystems in the world (Dudgeon et al. 2006, Light and Marchetti 2007). These ecosystems contain approximately $40 \%$ of global fish diversity while covering less than $1 \%$ of the Earth's surface (Dudgeon et al. 2006). High species richness and endemism are hallmarks of freshwater ecosystems worldwide (Malmqvist and Rundle 2002, Revenga et al. 2005). While given less attention than their terrestrial counterparts, projected mean extinction rates for freshwater species are roughly five times greater than the projected rates for terrestrial species loss (Benke 1990, Ricciardi and Rasmussen 1999, Light and Marchetti 2007). The vast majority of threats to freshwater systems, both globally and in North America, are anthropogenic disturbances arising within the last 150 years (Dudgeon et al. 2006). Threats to freshwater systems, and the species they support, come in a wide array but are largely due to direct physical alterations or indirect alterations to catchments surrounding these systems (Light and Marchetti 2007). For example, all rivers within the United States that are greater than $1000 \mathrm{~km}$ in length, with the exception of one (i.e. Yellowstone River), have been altered for hydroelectric generation and/or navigation (Benke 1990). Impoundments in the Northern Hemisphere have been so extensive that the cumulative effects of water storage by large dams have resulted in measurable changes in the Earth's rotation and gravitational field (Chao 1995).

For thousands of years humans have preferentially settled near waterbodies (Revenga et al, 2010). Freshwater systems provide humans with sustenance, water for domestic, 
industrial and agricultural needs, power production, waste disposal, navigation and transportation routes, and recreational activities (Malmqvist and Rundle 2002). The alterations to freshwater systems required to meet the growing human demands have been substantial, with future demands and alterations projected to increase (Dudgeon et al. 2006).

\section{The River Continuum}

The negative impacts of anthropogenic alterations within and adjacent to lotic systems are virtually ubiquitous, in part, because of the difficulties in understanding the large spatial and temporal processes occurring. Fausch et al. (2002) discussed the historical gap between scientific understanding of the natural processes occurring in lotic systems and human disturbances as a problem of scale. Natural processes and anthropogenic disturbances often operate over long temporal scales and over larger spatial scales (basin scale), while scientific understanding and management of these systems has historically occurred at small (reach scale) to intermediate scales (segment scale; Fausch et al. 2002). Vannote et al. (1980) published a landmark paper that synthesized research and concepts into a framework called the "River Continuum Concept". This concept was one of the first to examine the river system as a whole, considering the predictable biological changes that mirror a gradient of changing physical factors, from headwaters to river mouth (Vannote et al. 1980). This insight into the longitudinally connected nature of rivers furthered our understanding of lotic systems and was soon enhanced by the serial discontinuity concept that incorporated the effects of 
human alterations within this otherwise predictable continuum (Ward and Stanford 1983). The serial discontinuity concept highlights how the gradual and predictable changes observed in lotic systems are frequently interrupted by hydroelectric dams and their associated reservoirs, resulting in punctuated deviations away from the steady gradient of change in regards to biological assemblages, sediment loads and temperature regimes (Ward and Stanford 1983).

The distribution, high diversity, and localized endemism of river fishes are due, in part, to dispersal limitations within and among drainages embedded within the terrestrial landscape. The linear morphology of freshwater lotic systems within the terrestrial landscape makes these systems highly sensitive to land-use changes as well as terrestrial inputs into the river (Malmqvist and Rundle 2002). River systems as landscape features are influenced at multiple temporal and spatial scales, where long-term processes such as volcanic uplift, erosion, and climate patterns influence intermediate-term physical processes such as channel morphology, flow rates, and temperature, which in turn create habitat and niche space for organisms on a short time scale (Sherwood et al. 1990, Schlosser 1991, Allan 2004). This series of nested influencing factors, as well as the recognition that lotic systems include suites of complex habitat mosaics, predictable environmental patterns, disturbance regimes, and high connectivity within basins, has led to the introduction of the term "riverscape" (Allan 2004).

The Columbia Riverscape 
In North America, the Columbia River and its associated tributaries are a prime example of a large riverscape. The Columbia River Basin (CRB) is the second largest river system, by volume, in the United States and the largest river draining into the Pacific Ocean from North America. The catchment area of the CRB is over $660,000 \mathrm{~km}^{2}$, encompassing seven U.S. states and one Canadian province. The basin is divided by the Cascade Mountains into two major ecotypes: the wet, temperate western sub-basin and the arid, eastern sub-basin. While the western sub-basin makes up only roughly $8 \%$ of the total drainage area, it contributes $24 \%$ of the total flow volume due mostly to orographic precipitation in the Coast Range and Cascade Mountains (Simenstad et al. 1990).

There is a long history of anthropogenically-induced change within the Columbia River Basin. This change began tens of thousands of years ago with the arrival of the First Nations and persists throughout the basin today (Craig and Hacker 1938, Butler and O'Connor 2004). Anthropogenic changes have reshaped this riverscape on human time scales instead of the geologic time scales of the past. Nearly all aspects of the Columbia River Basin, including biotic and abiotic factors, have experienced anthropogenic changes within the last hundred and fifty years and researchers have been attempting to assess and quantify the consequences of these changes (Gresh et al. 2000).

Over the years, the Columbia River has served many different roles for humans living along its banks. Examples include thousands of years of settlement and salmon harvest by indigenous peoples, the introduction of Euro-American settlers who developed the commercial canning industry $(1850$ - 1938), large-scale hydro-development $(1938-$ 
1975), and the era of salmon (Oncorhynchus spp.) protection that began with the listing of Snake River salmon stocks under the Endangered Species Act in the 1990s (NOAA Fisheries 2008).

Prior to Euro-American arrival to the west coast of the United States, indigenous peoples lived along the Columbia River for roughly 10,000 years (Butler and O'Connor 2004). Some of the earliest archaeological sites in the Pacific Northwest come from an area called "The Dalles of the Columbia" (current location of The Dalles, Oregon) where the Columbia River dropped $25 \mathrm{~m}$ through a series of falls and chutes over a distance of $20 \mathrm{~km}$. This section of river provided a prime indigenous salmon fishing location until it was inundated by the reservoir of The Dalles Dam in 1956 (Butler and O’Connor 2004). Beginning in the mid-1800s, canneries were established along the Columbia River between the Snake River and Astoria, Oregon. At the peak of operation, 39 canneries processed approximately 43 million pounds of salmon annually. By 1890, fishermen and canneries began to notice decreasing abundances of the major salmon stocks and by 1935, only 1.5 million pounds of salmon were processed annually (Craig and Hacker 1938). In 1938, the Bonneville Dam was completed on the mainstem Columbia River, which marked the expansion of large-scale hydro-development culminating in 56 hydroelectric dams and 77 multi-purpose dams (irrigation, flood control, hydroelectric generation, navigation, recreation) throughout the basin. Today, fifty percent of the power in the Pacific Northwest is supplied from hydroelectric power production (Northwest Power and Conservation Council 2014). 


\section{Columbia River Salmonids}

There are five extant Pacific salmon species found within the Columbia River Basin: Chinook (O. tshawytsha), Coho (O. kisutch), Sockeye (O. nerka), Chum (O. keta) and steelhead (O. mykiss: ocean-going Rainbow Trout). All salmon species occurring in the Columbia River have complex, anadromous life cycles, including rearing in freshwater, migrating to the ocean for growth, and returning to freshwater for reproduction (Figure 1.1). With the exception of iteroparous steelhead (i.e. potential for multiple reproductive episodes), all Pacific salmon are semelparous (i.e. single reproductive episode). The details of speciation are uncertain but it is believed that Pacific and Atlantic salmon (Salmo spp.) diverged sometime during the Miocene (15 - 20 million years before present; Healey 1991, Waples et al. 2008). As a result of tectonic uplift along the Pacific coast, a heterogeneous and dynamic set of habitats promoted Pacific salmon speciation through isolation, resulting in the multitude of species observed today (Waples et al. 2008). Steelhead were previously classified in the genus Salmo, but recent phylogenetic work placed them among the genus Oncorhynchus. Fish in the Salmonidae family are tetraploid (having four copies of chromosomes) and as such, genes can rapidly evolve because duplicate, homologous genes provide evolutionary security in dynamic environments (Waples et al. 2008).

Because of their life histories and widespread distributions throughout the Columbia River Basin, my research focuses on Chinook salmon and steelhead populations (Figures 1.2, 1.3). Chinook salmon have two main forms, the stream-type and ocean-type that are differentiated by their life history patterns. The stream-type 
spends one year or more in freshwater (egg - parr stage) before initiating migration (smolt), utilize extensive offshore ocean habitats and returns to natal streams several months prior to spawning (adult). Stream-type Chinook are also called spring-run Chinook because this is the season that adults return to the freshwater habitat or yearling migrants (juvenile migrants). The ocean-type migrates to the ocean quickly after emergence from the gravel, typically within 3 months (i.e. sub-yearling migrants), spends most of their ocean residence in coastal waters and returns to natal streams days to weeks before spawning in the fall. This form is also called fall Chinook for the season of adult returns and generally spawns in tributaries closer to the ocean that the stream-type. Due to spatial and temporal isolation between closely related populations distributed throughout the Columbia River Basin, asynchronous populations (e.g. populations that undergo life history transitions at different times) have evolved localized adaptations and geographically specific life histories that have placed them on independent evolutionary trajectories (Waples et al. 2008, Moore et al. 2014). Variation in life histories can buffer the overall population from fluctuating and adverse environmental conditions through the portfolio effect (Schindler et al. 2010, Moore et al. 2014). These genetically distinct populations segments are recognized as Evolutionarily Significant Units (ESUs: Waples et al. 2008). One such variation in Chinook salmon life history is age of maturity, which is highly plastic and can display an alternative precocious reproductive strategy (Figure 1.4; Gross 1991). Fish that employ the precocious reproductive strategy mature at ages between 1-3 years post-fertilization, may or may not migrate to the ocean, display no secondary sexual characteristics and utilize a sneaking, rather than competitive strategy 
(Larsen et al. 2004, Berejikian et al. 2010). Steelhead are iteroparous (up to 4 reproductive episodes in a lifetime) and display a staggering amount of life history variation (Moore et al. 2014). Rainbow trout are the resident freshwater form that forgo migration, while steelhead refers to the anadromous form.

\section{Anthropogenic Disturbances}

Salmonids within the Columbia River have been highly affected by four major human activities, termed the $4 \mathrm{Hs}$, over the past 150 years: harvest (i.e. commercial adult fishery), hydroelectric power generation, hatchery supplementation, and habitat loss (Figure 1.5; Waples 1999, McHugh et al. 2004, Bottom et al. 2005). Prior to modern anthropogenic influences within the basin, adult returns were estimated to range between 7 - 30 million adult salmon annually. In the late 1990s, this number dropped to roughly 1 million annual adult returns, with approximately $80 \%$ of fish originating from hatcheries (Williams et al. 1999). The first Columbia River salmon species to be listed as endangered under the Endangered Species Act was the Snake River Sockeye salmon $(O$. nerka) in 1991 (NOAA Fisheries 2008). There are currently thirteen Columbia River salmon and steelhead ESUs that have been listed as threatened or endangered under the Endangered Species Act (NOAA Fisheries 2008). Each of these anthropogenic disturbances has singular and interactive effects throughout the basin. Additionally, there is a growing appreciation for how these freshwater disturbances carryover to later affect fish while in the marine phase (Beamish and Mahnken 2001, Tucker et al. 2012). The 
following is a brief summary of the effects of each type of anthropogenic alteration and how it influences salmon populations.

Harvest

Humans have settled and utilized the vast resources of the Columbia River for millennia (Craig and Hacker 1938, Butler and O’Connor 2004). The dip net fishery at Celilo Falls on the Columbia River (present day The Dalles, Oregon) is said to have been the largest native fishery in North America and has been inhabited by humans for $>9,000$ years (Butler and O'Connor 2004). An early estimate of the annual salmon take of the First Nations in the 1800s was around 1.8 million pounds (Schoning et al. 1951). In the late 1800 s, commercial harvests peaked at approximately 43 million pounds salmon (Craig and Hacker 1938). In 2000, there was an estimated 1.2 million pounds of salmon caught during commercial harvest (Gresh et al. 2000). In general, hatcheries within the CRB operate to supplement depleted wild populations with hatchery fish for commercial and recreational fisheries (Araki et al. 2008, Kostow 2009).

One growing concern for ecologists within the CRB is the decrease in marinederived nutrients returning to freshwater systems. A side effect of commercial salmon fishery has been downward size selection of adults, resulting in smaller adult fish (Bigler et al. 1996). Salmon take advantage of the relatively plentiful food supplies in the ocean environment, where the majority of their mass is derived, and return to nutrient-poor freshwater systems with large amounts of marine carbon, nitrogen and phosphorous (Wipfli and Baxter 2010). The marine-derived nutrients brought upstream by adults are 
increasingly recognized as an important part of nutrient cycling and directly influence the survival and growth of juvenile salmon in these systems (Gresh et al. 2000). The reduced size and abundance of salmon has resulted in a nutrient deficit in low order streams in the Pacific Northwest (Gresh et al. 2000).

\section{Hydropower Generation}

Large-scale hydropower development began in the U.S. in the early 1900s, with the broad goals of providing flood control, increased water supplies, increased navigation routes and energy production (Williams et al. 1999). Hydroelectric development has reduced critical habitat for fishes (spawning, rearing) and other aquatic organisms, altered natural disturbance regimes, altered flow patterns, reduced mass transport of sediment, created barriers to longitudinal migration, and created novel habitats that are often invaded by non-native species (Ligon et al. 1995, Poff et al. 1997, Bottom et al. 2005). Some ESA-listed salmon populations (upper Snake River Chinook salmon and steelhead) must pass as many as eight large-scale hydroelectric dams during their migration to the ocean. Hydroelectric dams currently restrict Chinook salmon and steelhead to $60 \%$ of their historical range and have extirpated wild populations from upstream areas above Hells Canyon on the Snake River and Grand Coulee Dam on the Columbia River (Sheer and Steel 2006).

Juveniles migrating towards the ocean may experience repeated delays, injury, stress, disorientation, and increased predation rates following passage through a dam and its associated reservoir (Abernethy et al. 2001, Čada 2001). These effects can manifest 
directly as mortality or indirectly through reduced vigor that increases susceptibility to predation or disease. Currently, most dams on the Columbia River provide three downstream passage routes for migrating juveniles: turbine passage, spillway passage, and juvenile bypass (Muir et al. 2001). When migrants pass directly through the turbines they are exposed to extreme pressures and suffer mechanical injuries and generally experience the highest rates of mortality (Bickford and Skalski 2000, Budy et al. 2002). Juvenile passage through the bypass structures involves direction by guidance screens into a series of pipes that lead around or through the dam. Fish taking this passage route experience high velocities $\left(9 \mathrm{~m} \cdot \mathrm{s}^{-1}\right)$, rapid pressure changes ( 1 to 3 and back to 1 atmospheres within 10 seconds), and are then returned to the river up to $0.5 \mathrm{~km}$ downstream (Budy et al. 2002). Fish entering the juvenile bypass have intermediate survival compared to the other passage routes and may also be collected/held for sampling or barge transport through the remaining hydrosystem.

Voluntarily spilling water over the top of dams (i.e. "spill”) began at some facilities in 1994, in an effort to reduce the direct salmon mortality associated with turbine and juvenile bypass routes (Muir et al. 2001). Dams on the Snake and Columbia Rivers now regularly voluntarily spill water during the juvenile migration season (April June). Spillway passage leads to the highest survival rates of any passage route but is not without dangers. During years of intermediate to high flow volumes, water spilling over the dams creates an environment of supersaturated dissolved gas concentrations that have been shown to negatively impact smolt (Beeman and Maule 2006). Most research to date has focused on assessing direct mortality of juveniles at each hydroelectric dam 
separately (reach to segment scale), and as a result of low survival of endangered stocks, regulations imposed by the 2008 Biological Opinion requires $96 \%$ survival of yearling Chinook salmon and steelhead at each dam (NOAA Fisheries 2008). Adult salmon returning from the ocean experience passage bottlenecks at the upstream fish ladders at each of the passable dams.

The holding capacity of freshwater reservoirs (globally) has been so extensive that it is estimated to have lowered sea level by $3 \mathrm{~cm}$ over the past 50 years (Chao 1995). Reservoirs formed behind dams have significantly altered river hydrology, water temperature and velocity, disrupted migration patterns and timing, inundated historical critical habitat and provided novel conditions for invasive species (McCullough 1999, Faulkner et al. 2012). Due to the abundance and spatial arrangement of hydroelectric dams and associated reservoirs, there are currently only $70 \mathrm{~km}$ of free-flowing river remaining in the Columbia River above the Bonneville dam (Becker 1985, Caudill et al. 2007). Ironically, this area is called the Hanford Reach and has remained unaltered only because of its proximity to the Hanford Nuclear Power site (Becker 1985).

\section{Hatcheries}

Hatchery supplementation and augmentation programs have steadily increased salmonid production over time to offset declining and extant wild populations (Unwin and Glova 1997, Larsen et al. 2004). In 2009, over 380 million hatchery raised salmon and steelhead were released by government agencies throughout the United States, with the majority of those fish released into the Columbia River Basin (Kostow 2009). Fish 
hatcheries were started in the Columbia Basin in the early 1900s to offset declining salmon stocks and bolster the commercial fishery.

Concerns over the impact of hatchery-reared salmonids on wild populations have spurred much research into the possible genetic and biological effects that domesticated hatchery fish may have on wild populations (Araki et al. 2008). One difficulty in assessing the risks that hatcheries pose to wild populations is the dramatic differences in management practices from one facility to the next. Federal, state, and tribal agencies operate under different missions and with different goals, making the assessment of program success extremely difficult (Bugert 1998, Reisenbichler and Rubin 1999, Brannon et al. 2004). Traditional hatchery practices raised fish for harvest by the commercial, recreational and tribal fisheries (Galbreath et al. 2008). Currently, hatcheries can be divided into segregated (uses only hatchery origin fish as broodstock) or integrated (uses a combination of wild and hatchery fish for broodstock) programs, which differ in their genetic management and broodstock selection strategies. These hatcheries can be further classified as harvest or conservation programs based on production goals. Fish from harvest programs are intended to become large, anadromous adults intended to supplement the salmon fishery and generally come from segregated broodstock. These fish are not intended to reproduce with wild populations. Conservation programs typically use some combination of wild and hatchery broodstock (integrated) and are intended to produce anadromous adults that spawn with specifically targeted, depleted wild populations (Galbreath et al. 2008, Harstad et al. 2014). 
The environment in which hatchery fish are reared is substantially different from the wild environment (Waples 1999). The hatchery settling has been described as a psychosensory-deprived environment (Olla et al. 1998). Holding pens, where fry, parr and smolt are held are generally long, linear concrete raceways with unvaried, shallow depth and no structural heterogeneity. Differences between wild and hatchery rearing environment include food (quantity, quality, delivery, frequency, type), substrate (cover, structure, water depth), fish densities, water (temperature, chemistry, turbidity), flow velocity, competition, and predators (Reisenbichler and Rubin 1999, Waples 1999). Hatchery salmon have increased agonistic behavior, increased rates of precocious maturation, reduced predator avoidance, decreased survival rates, altered life-stage mortality rates, decreased spawning success, and altered morphology compared to wild fish (Berejikian et al. 2000, Einum and Fleming 2001, Larsen et al. 2004, Brannon et al. 2004, Araki et al. 2008, Kostow 2009). Domestication selection has been shown to genetically alter hatchery populations within 1-2 generations (Reisenbichler and Rubin 1999, Waples 1999, Brannon et al. 2004).

\section{Habitat Loss}

Due to their complex life histories, salmonids require a wide variety of interconnected habitats throughout their ontogeny (Williams et al. 1999, Budy et al. 2002, Bottom et al. 2005). Habitat loss throughout the entire CRB has been the result of hydrodevelopment, urbanization, and terrestrial land-use practices (Budy et al. 2002). Entire upriver sections of the upper Columbia River (above Grand Coulee Dam circa 1938) and 
Snake River (above Hells Canyon Dam circa 1967) were extirpated of Chinook populations by impassable dams (Bottom et al. 2005). Roughly $87 \%$ of historical Chinook salmon spawning habitat on the mainstem Columbia River and $65 \%$ of estuarine rearing habitat have been lost (Bottom et al. 2005, Sheer and Steel 2006). The connectivity between these critical habitats has been highly diminished due to hydrodevelopment, with some salmon stocks passing through as many as eight large dams between spawning grounds and the estuary (Faulkner et al. 2012). For many populations of salmonids, habitat restoration (i.e. habitat improvements to existing/remain rearing, spawning, and migratory habitats) and recovery (i.e. reclamation of historical rearing, spawning, and migratory habitats) is the only long-term solution to the current reliance on hatchery-produced fish.

\section{Marine Environment}

A growing body of evidence suggests that the marine environment is of great importance to salmonid ecology and indicates reciprocal population dynamics between the freshwater and marine phases (Scheuerell et al. 2005). While the ocean phase has always been recognized as an important life stage, the ability to obtain data regarding salmonid distribution, behavior, mortality, and habitat use in the marine environment has been difficult (Miller et al. 2014). Recent advances in technology (e.g. acoustic tracking arrays along the continental shelf) and long-term data sets (e.g. annual trolling surveys, PIT Tag Information System) are providing crucial information about how freshwater and marine life-stages are connected and mutually influenced by environmental 
conditions experienced in both. Large- and intermediate-scale climate indices (e.g. Pacific Decadal Oscillation, El Nino/Southern Oscillation and coastal upwelling index) have been shown to affect salmon population dynamics (Mantua et al. 1997, Peterson et al. 2014). Productive marine conditions, influencing trophic conditions in a bottom-up fashion, affect adult salmon returns to freshwater (Peterson et al. 2014). The first few months at sea have been identified as a critical period affecting salmonid life history decisions and population dynamics, where fluctuating marine conditions operating at different scales exert strong influences (Tucker et al. 2012, Miller et al. 2014, Peterson et al. 2014). Additionally, the importance of marine-derived nutrient subsidies entering oligotrophic freshwater habitats, in the form of adult salmon, are increasingly understood to affect both aquatic and terrestrial ecosystems (Gresh et al. 2000, Scheuerell et al. 2005). Salmon attain $>95 \%$ of their biomass in their marine phase and post-spawning carcasses support a suite of aquatic and terrestrial organisms from macroinvertebrates to fishes (including other salmon; Scheuerell et al. 2005).

\section{Objectives}

In broad terms, the intent of my research is to make a significant contribution to the body of knowledge regarding the effects of large-scale anthropogenic change to salmon populations within the context of a riverscape. While there is great value in understanding how anthropogenic influences affect populations and processes at small scales (i.e. reach and segment scale), there is great need to better understand processes at larger spatial and temporal scales (i.e. watershed or ecosystem scale: Reeves et al. 1995, 
Scheuerell et al. 2005). One goal of my research is to integrate large-scale environmental processes to the scale of the individual fish. Each chapter of my research used an individual-based approach because physiological, morphological, and behavioral changes occurring in response to anthropogenic alterations transpire at this level (Reeves et al. 1995). To accomplish this individual-based approach, I matched relevant environmental variables experienced by each fish that depended on the spatial and temporal exposures to that fish. A substantial amount of salmon research in the Columbia basin relies on averages taken from groups of tagged fish experiencing conditions over small spatial and temporal scales, resulting in a loss of relevant population-level information.

Chapter 2 focuses on the biotic and abiotic factors that influence the survival of outmigrating Chinook salmon and steelhead smolt passing different numbers of hydroprojects. The goals were to determine if the spatial arrangement of dams in the lower Columbia River represented a pulse (acute) or press-type (chronic) ecological disturbance and to evaluate how ecological variables varied for fish passing 1,2 or 3 dams. This research added an ecological disturbance perspective to an ongoing debate over the effects of latent mortality cause by hydroelectric dam passage (Budy et al. 2002).

Chapter 3 investigates changes in the age of maturity life history pattern of wild and hatchery Chinook salmon over time. The goal was to assess how seasonal environmental variables, experienced by individuals across life stages and environments, influence precocious maturation. This research compared precociousness in hatchery and wild fish and added a significant contributed to our understanding of this alternative life history strategy in wild populations. 
Lastly, Chapter 4 uses geometric morphometrics to assess shape differences between wild and hatchery Chinook salmon and steelhead smolts. The objective was to determine the effects of different rearing environments on juvenile body shape. This chapter utilized new analytical techniques from contemporary morphometric studies and added to the body of literature regarding hatchery practices in the CRB.

While many of the implications of this research are specific to the Columbia River Basin and to the salmon populations found therein, the findings are transferable to other systems and other species (more so for species with complex life history patterns). While large-scale hydro-development of rivers has slowed in the United States, it has increased in developing countries such as China and India (Oud 2002). Overharvesting of fishes continues worldwide and habitat loss remains a leading contributor of global biodiversity loss (aquatic and terrestrial; Dudgeon et al. 2006). Thus, continued evaluation of anthropogenic stressors influencing salmonid populations, across spatial and temporal scales, is needed to better understand and manage the effects of human activities on freshwater resources and fishes. 


\section{References}

Abernethy, C. S., B. G. Amidan, and G. Cada. 2001. Laboratory studies of the effects of pressure and dissolved gas supersaturation on turbine-passed fish. Pacific Northwest National Laboratory, Richland, WA, PNNL-13470.

Allan, J. D. 2004. Landscapes and Riverscapes: The influence of land use on stream ecosystems. Annual Review of Ecology, Evolution, and Systematics 35:257-284.

Araki, H., B. A. Berejikian, M. J. Ford, and M. S. Blouin. 2008. Fitness of hatcheryreared salmonids in the wild. Evolutionary Applications 1:342-355.

Beamish, R. J., and C. Mahnken. 2001. A critical size and period hypothesis to explain natural regulation of salmon abundance and the linkage to climate and climate change. Progress in Oceanography 49:423-437.

Becker, C. D. 1985. Anadromous salmonids of the Hanford Reach, Columbia River: 1984 status. Pacific Northwest Laboratory, Richland, WA, PNL-5371.

Beeman, J. W., and A. G. Maule. 2006. Migration depths of juvenile Chinook salmon and steelhead relative to total dissolved gas supersaturation in a Columbia River reservoir. Transactions of the American Fisheries Society 135:584-594.

Benke, A. C. 1990. A perspective on America's vanishing streams. Journal of the North American Benthological Society 9:77-88.

Berejikian, B. A., E. P. Tezak, T. A. Flagg, A. L. LaRae, and E. R. Kummerow. 2000. Social dominance, growth, and habitat use of age- 0 steelhead grown in enriched and conventional hatchery rearing environments. Canadian Journal of Fisheries and Aquatic Sciences 57:628-636 
Berejikian, B. A., D. M. Van Doornik, R. C. Endicott, T. L. Hoffnagle, E. P. Tezak, M. E. Moore, and J. Atkins. 2010. Mating success of alternative male phenotypes and evidence for frequency-dependent selection in Chinook salmon, Oncorhynchus tshawytscha. Canadian Journal of Fisheries and Aquatic Sciences 67:1933-1941.

Bickford, S. A., and J. R. Skalski. 2000. Reanalysis and interpretation of 25 years of Snake-Columbia River juvenile salmonid survival studies. North American Journal of Fisheries Management 20:53-68.

Bigler, B. S., D. W. Welch, and J. H. Helle. 1996. A review of size trends among North Pacific salmon (Oncorhynchus spp.). Canadian Journal of Fisheries and Aquatic Sciences 53:455-465.

Bottom, D. L., C. A. Simenstad, J. Burke, A. M. Baptista, D. A. Jay, K. K. Jone, E. Casillas, and M. H. Schiewe. 2005. Salmon at river's end: the role of the estuary in the decline and recovery of Columbia River salmon. U.S. Dept. Commer., NOAA Tech. Memo. NMFS-NWFSC-68, 246 p.

Brannon, E. L., D. F. Amend, M. A. Cronin, J. E. Lannan, S. LaPatra, W. J. McNeil, R. E. Noble, C. E. Smith, A. J. Talbot, G. A. Wedemeyer, and H. Westers. 2004. The controversy about salmon hatcheries. Fisheries 29:12-31.

Budy, P., G. P. Thiede, N. Bouwes, C. E. Petrosky, and H. Schaller. 2002. Evidence linking delayed mortality of Snake River salmon to their earlier hydrosystem experience. North American Journal of Fisheries Management 22:35-51.

Bugert, R. M. 1998. Mechanics of supplementation in the Columbia River. Fisheries 23:11-20. 
Butler, V. L., and J. E. O’Connor. 2004. 9000 years of salmon fishing on the Columbia River, North America. Quaternary Research 62:1-8.

Čada, G. F. 2001. The development of advanced hydroelectric turbines to improve fish passage survival. Fisheries 26:14-23.

Caudill, C. C., W. R. Daigle, M. L. Keefer, C. T. Boggs, M. A. Jepson, B. J. Burke, R. W. Zabel, T. C. Bjornn, and C. A. Peery. 2007. Slow dam passage in adult Columbia River salmonids associated with unsuccessful migration: delayed negative effects of passage obstacles or condition-dependent mortality? Canadian Journal of Fisheries and Aquatic Sciences 64:979-995.

Chao, B. F. 1995. Anthropogenic impact on global geodynamics due to reservoir water impoundment. Geophysical Research Letters 22:3529-3532.

Craig, J. A., and R. L. Hacker. 1938. The history and development of the fisheries of the Columbia River. Fishery Bulletin 49:133-213.

Dudgeon, D., A. H. Arthington, M. O. Gessner, Z. Kawabata, D. J. Knowler, C. Lévêque, R. J. Naiman, A. Prieur-Richard, D. Soto, and M. L. Stiassny. 2006. Freshwater biodiversity: importance, threats, status and conservation challenges. Biological reviews $81: 163-182$.

Einum, S., and I. Fleming. 2001. Implications of stocking: Ecological interactions between wild and released Salmonids. Nordic Journal of Freshwater Research, $75,56-70$.

Faulkner, J. R., S. G. Smith, W. D. Muir, D. M. Marsh, and R. W. Zabel. 2011. Survival 
estimates for the passage of spring-migrating juvenile salmonids through Snake and Columbia River dams and reservoirs, 2011. Report of the National Marine Fisheries Service to the Bonneville Power Administration, Portland, Oregon.

Fausch, K. D., C. E. Torgersen, C. V. Baxter, and H. W. Li. 2002. Landscapes to riverscapes: Bridging the gap between research and conservation of stream fishes: A continuous view of the river is needed to understand how processes interacting among scales set the context for stream fishes and their habitat. BioScience $52: 483-498$.

Galbreath, P. F., C. A. Beasley, B. A. Berejikian, R. W. Carmichael, D. E. Fast, M. J. Ford, J. A. Hesse, L. L. McDonald, A. R. Murdoch, and C. M. Peven. 2008. Recommendations for broad scale monitoring to evaluate the effects of hatchery supplementation on the fitness of natural salmon and steelhead populations. Final Draft Report of the Ad Hoc Supplementation Monitoring and Evaluation Workgroup.

Gresh, T., J. Lichatowich, and P. Schoonmaker. 2000. An estimation of historic and current levels of salmon production in the Northeast Pacific ecosystem: Evidence of a nutrient deficit in the freshwater systems of the Pacific Northwest. Fisheries 25:15-21.

Gross, M. R. 1991. Salmon Breeding Behavior and Life History Evolution in Changing Environments. Ecology 72:1180-1186. 
Harstad, D. L., D. A. Larsen, and B. R. Beckman. 2014. Variation in minijack rate among hatchery populations of Columbia River Basin Chinook salmon. Transactions of the American Fisheries Society 143:768-778.

Healey, M. 1991. Life history of chinook salmon (Oncorhynchus tshawytscha). Pacific salmon life histories:313-393.

Kostow, K. 2009. Factors that contribute to the ecological risks of salmon and steelhead hatchery programs and some mitigating strategies. Reviews in Fish Biology and Fisheries 19:9-31.

Larsen, D. A., B. R. Beckman, K. A. Cooper, D. Barrett, M. Johnston, P. Swanson, and W. W. Dickhoff. 2004. Assessment of high rates of precocious male maturation in a spring Chinook salmon supplementation hatchery program. Transactions of the American Fisheries Society 133:98-120.

Larsen, D. A., D. L. Harstad, C. R. Strom, M. V. Johnston, C. M. Knudsen, D. E. Fast, T. N. Pearsons, and B. R. Beckman. 2013. Early life history variation in hatcheryand natural-origin spring Chinook Salmon in the Yakima River, Washington. Transactions of the American Fisheries Society 142:540-555.

Light, T., and M. P. Marchetti. 2007. Distinguishing between invasions and habitat changes as drivers of diversity loss among California's freshwater fishes. Conservation Biology 21:434-446.

Ligon, F. K., W. E. Dietrich, and W. J. Trush. 1995. Downstream ecological effects of dams. BioScience 45:183-192. 
Malmqvist, B., and S. Rundle. 2002. Threats to the running water ecosystems of the world. Environmental Conservation 29(2):134-153.

Mantua, N. J., S. R. Hare, Y. Zhang, J. M. Wallace, and R. C. Francis. 1997. A Pacific interdecadal climate oscillation with impacts on salmon production. Bulletin of the American Meteorological Society 78:1069-1079.

McCullough, D. A. 1999. A review and synthesis of effects of alterations to the water temperature regime on freshwater life stages of salmonids, with special reference to Chinook salmon. U.S. Environmental Protection Agency, Region 10, Seattle, WA EPA 910/R-99-010.

McHugh, P., P. Budy, and H. Schaller. 2004. A model-based assessment of the potential response of Snake River spring-summer Chinook salmon to habitat improvements. Transactions of the American Fisheries Society 133:622-638.

Miller, J., D. Teel, W. Peterson, A. Baptista, and S. M. Carlson. 2014. Assessing the relative importance of local and regional processes on the survival of a threatened salmon population. PLOS ONE 9(6): e99814.

Moore, J. W., J. D. Yeakel, D. Peard, J. Lough, and M. Beere. 2014. Life-history diversity and its importance to population stability and persistence of a migratory fish: steelhead in two large North American watersheds. Journal of Animal Ecology 83:1035-1046.

Muir, W. D., S. G. Smith, J. G. Williams, and B. P. Sandford. 2001. Survival of juvenile salmonids passing through bypass systems, turbines, and spillways with and 
without flow deflectors at Snake River dams. North American Journal of Fisheries Management 21:135-146.

NOAA Fisheries. 2008. Biological Opinion (BiOp) on the operation of the Federal Columbia River Power System (FCRPS). U.S. Department of Commerce, National Marine Fisheries Service, Northwest Regional Office, Seattle, Washington.

Northwest Power and Conservation Council. 2014. Columbia river basin fish and wildlife program 2014. Northwest Power and Conservation Council.

Olla, B. L., M. W. Davis, and C. H. Ryer. 1998. Understanding how the hatchery environment represses or promotes the development of behavioral survival skills. Bulletin of Marine Science 62:531-550.

Oud, E. 2002. The evolving context for hydropower development. Hydropower, Society, and the Environment in the 21st Century 30:1215-1223.

Peterson, W. T., J. L. Fisher, J. O. Peterson, C. A. Morgan, B. J. Burke, and K. L. Fresh. 2014. Applied fisheries oceanography: Ecosystem indicators of ocean conditions inform fisheries management in the California Current. Oceanography 27:80-89.

Poff, N. L., J. D. Allan, M. B. Bain, J. R. Karr, K. L. Prestegaard, B. D. Richter, R. E. Sparks, and J. C. Stromberg. 1997. The natural flow regime. BioScience 47:769784.

Reeves, G. H., L. E. Benda, K. M. Burnett, P. A. Bisson, and J. R. Sedell. 1995. A disturbance-based ecosystem approach to maintaining and restoring freshwater 
habitats of evolutionarily significant units of anadromous salmonids in the Pacific Northwest. American Fisheries Society Symposium 17:334-349.

Reisenbichler, R. R., and S. P. Rubin. 1999. Genetic changes from artificial propagation of Pacific salmon affect the productivity and viability of supplemented populations. ICES Journal of Marine Science: Journal du Conseil 56:459-466.

Revenga, C., I. Campbell, R. Abell, P. de Villiers, and M. Bryer. 2005. Prospects for monitoring freshwater ecosystems towards the 2010 targets. Philosophical Transactions of the Royal Society B: Biological Sciences 360:397-413.

Ricciardi, A., and J. B. Rasmussen. 1999. Extinction rates of North American freshwater fauna. Conservation Biology 13:1220-1222.

Scheuerell, M. D., P. S. Levin, R. W. Zabel, J. G. Williams, and B. L. Sanderson. 2005. A new perspective on the importance of marine-derived nutrients to threatened stocks of Pacific salmon (Oncorhynchus spp.). Canadian Journal of Fisheries and Aquatic Sciences 62:961-964.

Schindler, D. E., R. Hilborn, B. Chasco, C. P. Boatright, T. P. Quinn, L. A. Rogers, and M. S. Webster. 2010. Population diversity and the portfolio effect in an exploited species. Nature 465:609.

Schlosser, I. J. 1991. Stream fish ecology: A landscape perspective. BioScience 41:704712.

Schoning, R. W., T. R. Merrell, and D. R. Johnson. 1951. The Indian dip net fishery at Celilo Falls on the Columbia River. Portland, Or. Oregon Fish Commission. 
Sheer, M. B., and E. A. Steel. 2006. Lost watersheds: Barriers, aquatic habitat connectivity, and salmon persistence in the Willamette and Lower Columbia River Basins. Transactions of the American Fisheries Society 135:1654-1669.

Sherwood, C. R., D. A. Jay, R. Bradford Harvey, P. Hamilton, and C. A. Simenstad. 1990. Historical changes in the Columbia River Estuary. Progress in Oceanography 25:299-352.

Simenstad, C. A., L. F. Small, C. David McIntire, D. A. Jay, and C. Sherwood. 1990. Columbia River estuary studies: an introduction to the estuary, a brief history, and prior studies. Progress in Oceanography 25:1-13.

Tucker, S., M. Trudel, D. Welch, J. Candy, J. Morris, M. Thiess, C. Wallace, and T. Beacham. 2012. Annual coastal migration of juvenile Chinook salmon: Static stock-specific patterns in a highly dynamic ocean. Marine Ecology Progress Series 449:245-262.

Unwin, M. J., and G. J. Glova. 1997. Changes in life history parameters in a naturally spawning population of chinook salmon (Oncorhynchus tshawytscha) associated with releases of hatchery-reared fish. Canadian Journal of Fisheries and Aquatic Sciences 54:1235-1245.

Vannote, R. L., G. W. Minshall, K. W. Cummins, J. R. Sedell, and C. E. Cushing. 1980. The river continuum concept. Canadian journal of fisheries and aquatic sciences $37: 130-137$.

Waples, R. S. 1999. Dispelling some myths about hatcheries. Fisheries 24:12-21. 
Waples, R. S., G. R. Pess, and T. Beechie. 2008. Evolutionary history of Pacific salmon in dynamic environments. Evolutionary Applications 1:189-206.

Ward, J. V., and J. Stanford. 1983. The serial discontinuity concept of lotic ecosystems. Dynamics of lotic ecosystems 10:29-42.

Williams, R. N., P. A. Bisson, D. L. Bottom, L. D. Calvin, C. C. Coutant, M. W. Erho, C. A. Frissell, J. A. Lichatowich, W. J. Liss, W. E. McConnaha, P. R. Mundy, J. A. Stanford, and R. R. Whitney. 1999. Return to the river: Scientific issues in the restoration of salmonid fishes in the Columbia River. Fisheries 24:10-19.

Wipfli, M. S., and C. V. Baxter. 2010. Linking ecosystems, food webs, and fish production: subsidies in salmonid watersheds. Fisheries 35:373-387. 


\section{Figures}

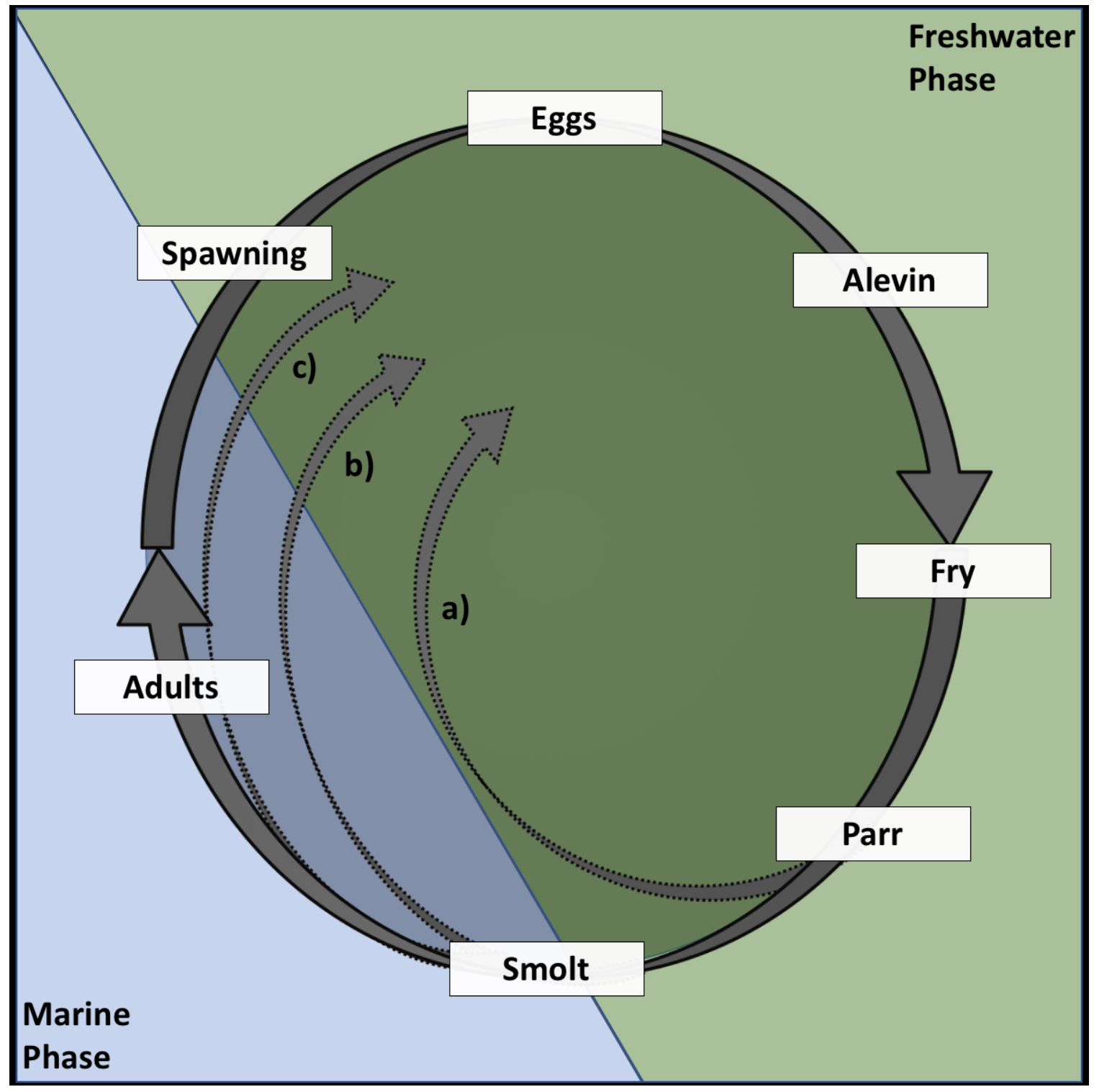

Figure 1.1 General conceptual diagram of Pacific salmon life cycle. Outer circle is the most common life history strategy for wild spring-run Chinook salmon (spends 2-3 years in marine phase). Dashed arrows represent three different variations of the precocious life history strategy where young fish reach sexual maturity before others of their cohort: a) precocious parr (freshwater residents, age 1); b) mini-jacks (migrate to estuary/ocean, age 2); and c) jacks (spend 1 year in ocean phase, age 3). Ages are given in whole year increments from fertilization to age of sexual maturation (see Larsen et al. 2013). 


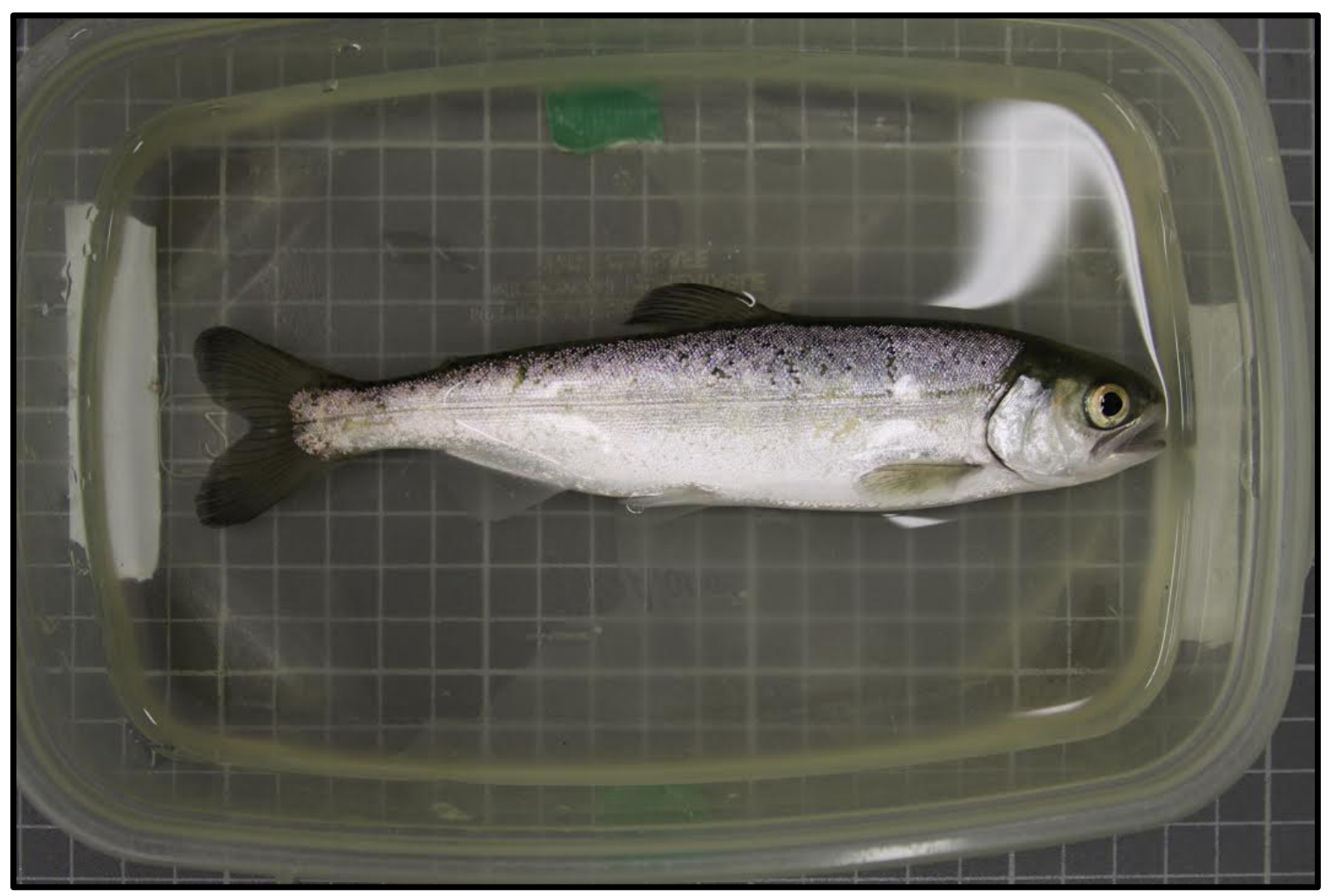

Figure 1.2 Chinook salmon smolt prior to tagging at John Day Dam smolt monitoring facility. 


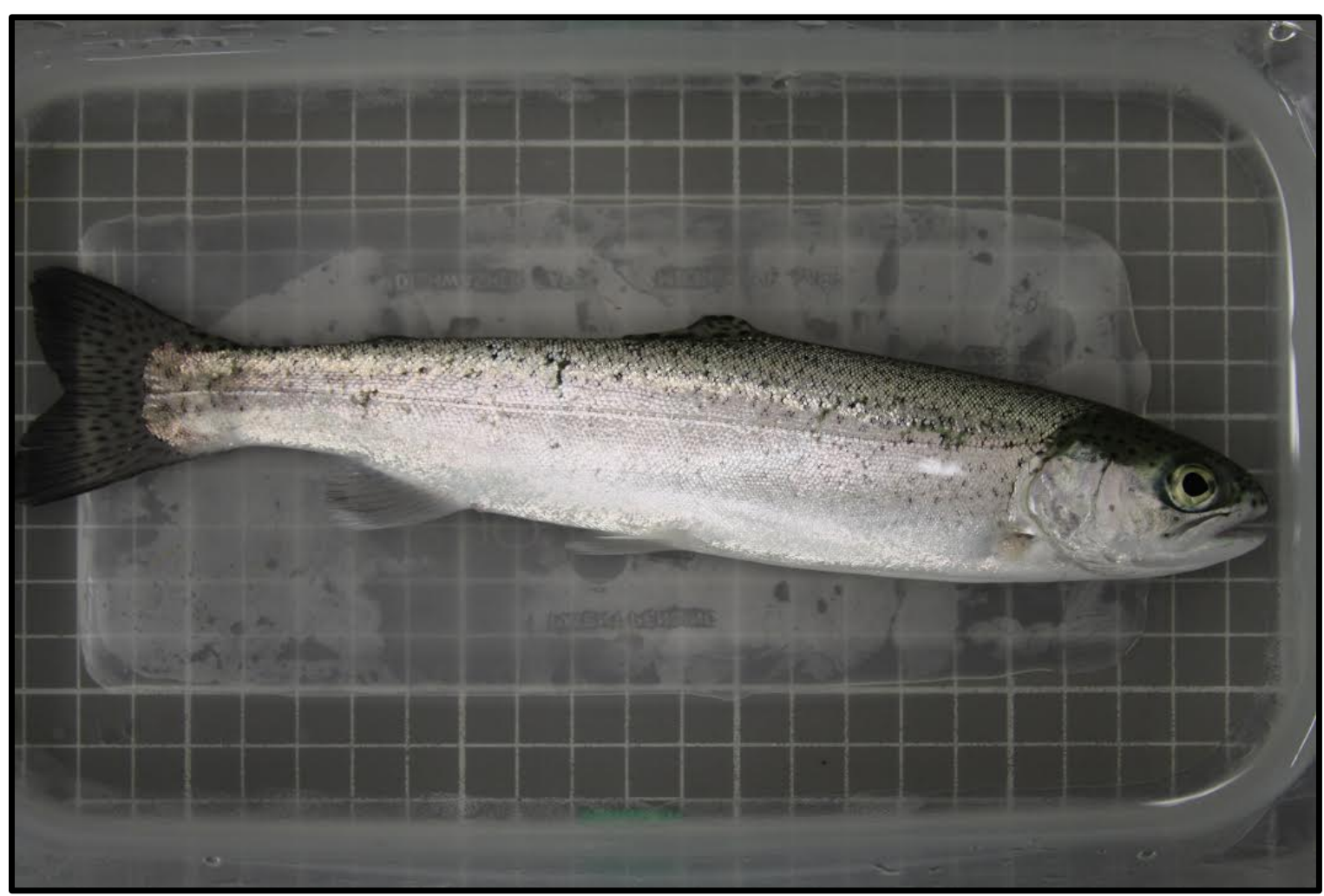

Figure 1.3 Steelhead smolt prior to tagging at John Day Dam smolt monitoring facility. 


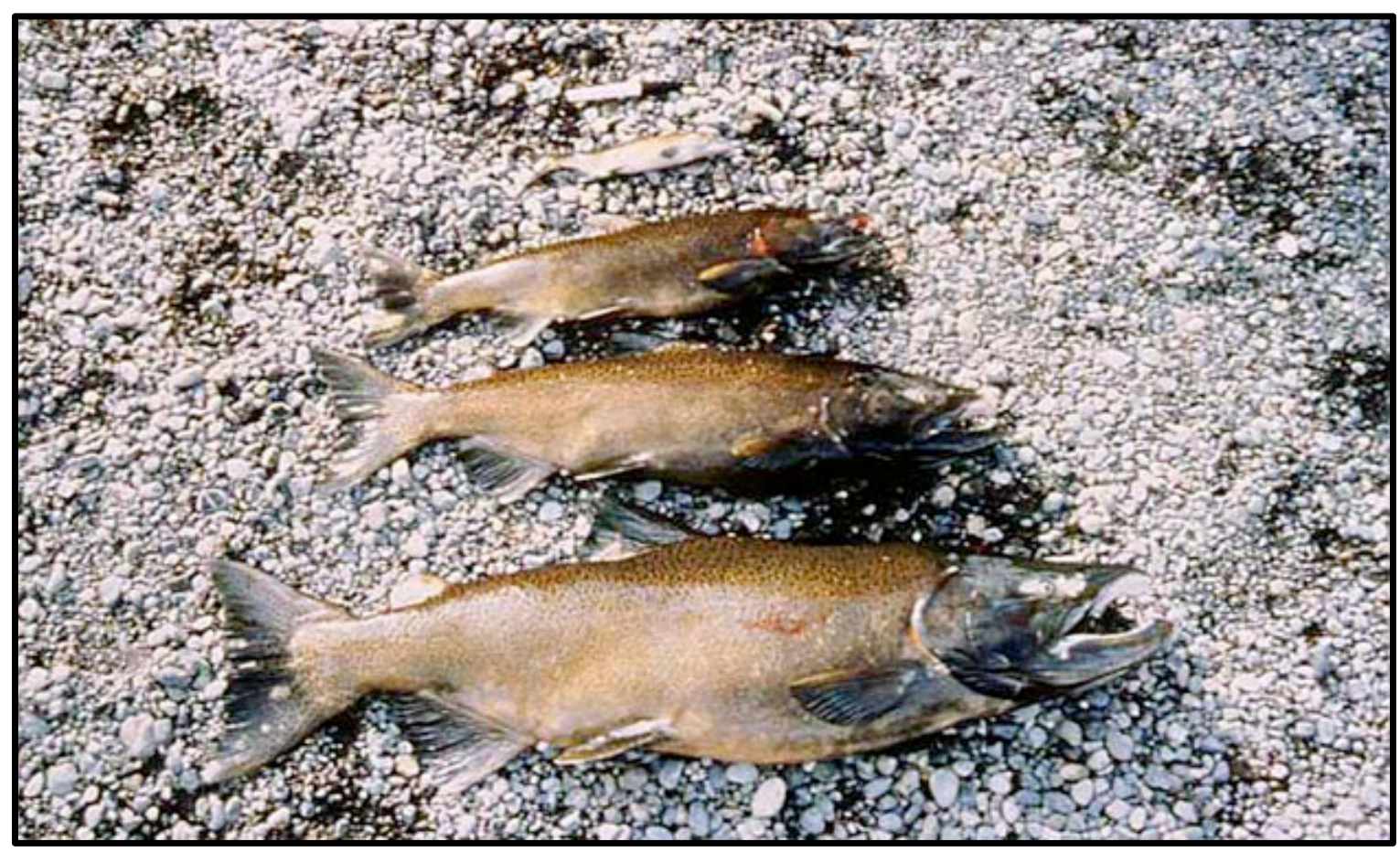

Figure 1.4 Alternative reproductive strategies of Chinook salmon. All fish are sexually mature males. From the top down: precocious parr (age 1), mini-Jack (age 2), Jack (age 3 ) and adult (age 4+). Photo by Oregon Department of Fish and Wildlife. 


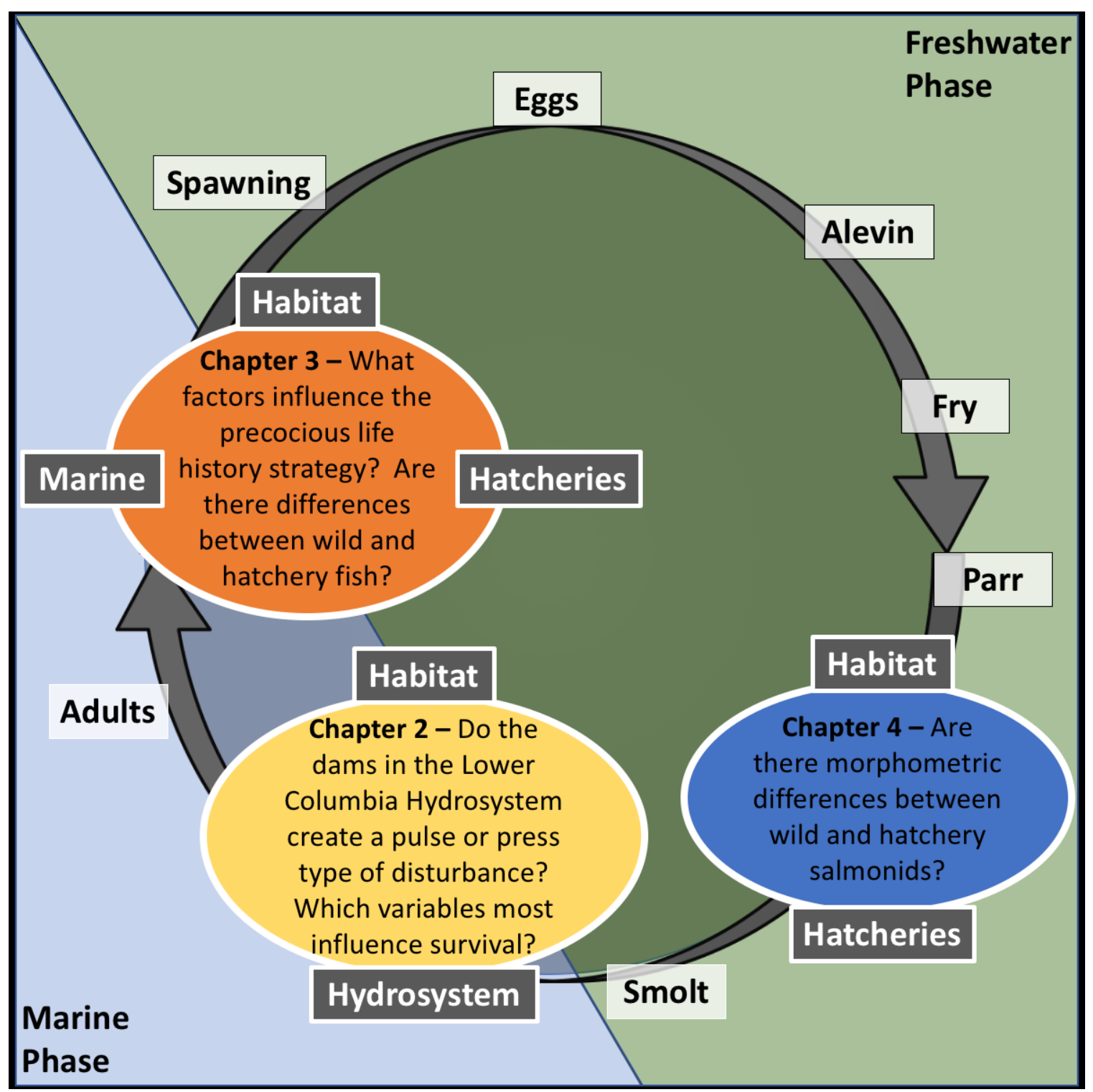

Figure 1.5. Conceptual diagram of chapters 2 - 4. Diagram shows the approximate life cycle stage, questions being asked and major anthropogenic and environmental influences being investigated. 


\section{Chapter 2 - Factors Influencing the Survival of Outmigrating Juvenile Salmonids through Multiple Dam Passages: An Individual-Based Approach}

Note: This chapter was published as an open-access journal article in Ecology and Evolution

Elder, T., C. M. Woodley, M. A. Weiland, and A. L. Strecker. 2016. Factors influencing the survival of outmigrating juvenile salmonids through multiple dam passages: an individual-based approach. Ecology and Evolution 6:5881-5892. 


\section{Introduction}

Anthropogenic alterations within and adjacent to freshwater ecosystems have caused habitat degradation and loss, resulting in the decline of many aquatic species (Poff et al. 1997, Dudgeon et al. 2006). Pacific salmon populations face serious humanmediated threats across multiple life-stages and throughout much of their distribution (Bigler et al. 1996, Budy et al. 2002). The Columbia River Basin in western North America is one of the most dammed river systems globally and has experienced extensive anthropogenic alterations that have affected many organisms, including the early life stages of salmonids (Gresh et al. 2000, Smith et al. 2003).

The creation of the Federal Columbia River Power System (hydroelectric dams and reservoirs) has significantly altered the physical, chemical, and biological structure of the Columbia River, including: increases in water temperature, total dissolved gas, and predation pressure; altered flow regimes; and disrupted salmonid migration (Raymond 1979, Giorgi et al. 1997, Bickford and Skalski 2000, Petersen 2001, Smith et al. 2003, Kuehne and Olden 2012). Repeated delays in smolt outmigration, injury, stress, and disorientation caused during passage through hydroelectric power facilities and their associated reservoirs can manifest directly as mortality or indirectly due to increased susceptibility to predation or disease (Abernethy et al. 2001, Čada 2001). Of particular importance are the cumulative effects that occur in situ as juvenile salmon migrate through multiple hydroelectric power projects (Schaller et al. 1999).

While Pacific salmon have evolved a suite of life history traits that provide resilience through unpredictable environmental variability, there is much to learn about 
how disturbances caused by hydroelectric dams within altered systems affect the ecology and survival of migrating smolts (Hicks et al. 1991). I was particularly interested in whether conditions created by the hydrosystem in the Lower Columbia River constitute a pulse disturbance (i.e., acute stress) or a press disturbance (i.e., chronic stress) for migrating smolts (Reeves et al. 1995). If hydroelectric dams create a pulse disturbance within the migration corridor, acute exposures to areas of deleterious environmental conditions should not result in cumulative effects for fish passing multiple dams. On the other hand, if conditions within the hydrosystem create a press disturbance, I would expect chronic exposures and cumulative negative effects for smolt passing multiple dams.

I identified biological and environmental variables that influenced yearling Chinook salmon and steelhead passing one, two and three dams in the Lower Columbia River and determined each variables' importance in terms of survival. Previous research has investigated the effect of environmental variables on groups of tagged fish, often passing a single dam and reservoir, but my study is the first to my knowledge to compare how the survival of individual fish, implanted with acoustic transmitters, is influenced by environmental factors for fish passing one, two or three dams. I was seeking a better understanding of how the importance of variables changes for fish passing different numbers of dams and associated reservoirs during outmigration in order to better appreciate the dynamic and altered ecological processes influencing salmonids in the Columbia River Basin and other impounded systems. 
I hypothesized that: 1) the survival of fish passing one, two and three dams will be influenced by different biological and environmental variables (Schaller and Petrosky 2007); 2) variables affecting fish survival through multiple dams will show cumulative effects (press disturbance) compared to fish passing a single dam (pulse disturbance) (Petrosky and Schaller 2010); and 3) based on the similar life-cycle stages, juvenile Chinook salmon and steelhead will respond similarly to altered environmental variables (Haeseker et al. 2012).

\section{Methods}

\section{Study area and experimental design}

The Columbia River Basin occupies an area of $660,480 \mathrm{~km}^{2}$ and is the second largest river system, by volume, in the United States. My study area covered the mainstem Lower Columbia River from river kilometer (rkm) 161 to 390, including three hydroelectric power projects: Bonneville Dam (BON, rkm 234), The Dalles Dam (TDA, rkm 309), and John Day Dam (JDA, rkm 347: Figure 2.1). Each dam has multiple fish passage routes that allow migrating smolt downstream. All dams are equipped with a powerhouse, a spillway, and either a juvenile by-pass structure (BON, JDA), sluiceway (BON, TDA) or surface-weir (JDA) (Plosky et al. 2012).

Yearling spring-run Chinook salmon and steelhead outmigrating between April 25 - May 28, 2011 were collected at the John Day Dam smolt monitoring facility. Chinook salmon $(n=5208)$ and steelhead $(n=5175)$ smolt included in the study ranged in size from $95-299 \mathrm{~mm}$ (fork length), were not moribund (i.e., not expected to die 
within $24 \mathrm{hrs}$ ), had no deformities or injuries that would prevent tag insertion and surgical closure (i.e., pronounced spinal deformation, large wounds on abdomen), and had not been previously tagged (i.e., PIT, acoustic or radio transmitter). Fish were surgically implanted with: 1) a passive integrated transponder (PIT) (HPT12, BioMark, Boise, ID); and 2) a Juvenile Salmon Acoustic Telemetry Systems (JSATS) acoustic micro-transmitter (Model SS130, Advanced Telemetry Systems, Isanti, MN). The JSATS transmitters actively broadcast a unique 156-db acoustic signal with a pulse interval of three seconds, but have a limited battery-powered lifespan (Appendix A.1). All fish were released into the mainstem Lower Columbia River at one of five release points after an 18-24 h recovery period (see Skalski et al. 2012a, 2012b, 2012c for details regarding permitting and fish handling). Fish handling, surgical procedures and transportation experience was standardized between all fish release groups and sites. As juveniles migrated downstream from release points, they were detected inriver passing up to six autonomous hydrophone arrays (Figure 2.1). Each detection array consisted of three to nine hydrophones capable of detecting and recording the unique acoustic signal transmitted from each implanted fish. Additionally, each hydroelectric power project was retrofitted with $83-98$ hydrophones on the forebay of each dam. Fish detections were considered confirmed if a unique acoustic signal was detected four times within a 48-second period at a single detection array. Fish that were detected at an array and then not detected at any subsequent arrays were considered mortalities of unknown cause (i.e., dam-passage related mortality, predation, dropped tags, or termination of migration). To ensure that all smolts migrating through the hydroelectric power system 
had adequate time to pass, the in-river and dam-mounted detection arrays were monitored through June 2011.

My research utilized a subset of data collected in 2011 by Pacific Northwest National Laboratories (PNNL) as part of the 2008 Federal Columbia River Power System Biological Opinion Compliance Monitoring. Details specific to the experimental designs, methodologies, and statistical assumptions for each hydroelectric power project can be found in Johnson et al. (2012), Ploskey et al. (2012), Weiland et al. (2013) and Skalski et al. (2012a-c). As a result of different subsampling, analysis and modeling techniques, survival estimates differ from previously published compliance reports.

\section{Environmental Data}

The Columbia Basin Research Data Acquisition in Real Time (DART) program collects hourly environmental data on total project outflow discharge $\left(\mathrm{m}^{3} \cdot \mathrm{s}^{-1}\right)$, spillway discharge $\left(\mathrm{m}^{3} \cdot \mathrm{s}^{-1}\right)$, water temperature $\left({ }^{\circ} \mathrm{C}\right)$, total dissolved gas $(\%)$ and atmospheric barometric pressure $(\mathrm{mmHg})$ at the forebay of each dam in the Lower Columbia River hydrosystem (http://www.cbr.washington.edu/dart). Ranges of environmental variables at each dam are reported in Appendix A.2. Correlations between environmental variables at each dam are reported in Appendix A.3. Correlations between environmental variables at The Dalles Dam are reported in Appendix A.4. For each individual fish, I created an averaged index representing the unique environmental conditions experienced by that fish based on the time between its release and last detection through a given array. This index of averaged hourly environmental variables was applied to each fish based on which 
dams were passed (e.g., fish passing BON were assigned the averaged hourly environmental variables from BON, while fish passing JDA, TDA and BON were assigned the averaged environmental variables from all dams over the time period between release and last detection).

\section{Data Analysis}

I used random sampling to assign fish into treatments that passed through different numbers of dams (i.e., passing one, two, or three dams), which were stratified by release date. Random sampling was conducted without replacement (i.e., all fish within each treatment group are independent of fish in other treatment groups), allowing for comparison between dam passages. The one dam treatment group was comprised of fish passing only Bonneville, The Dalles or John Day Dams (Table 2.1). The two dam treatment group included fish passing John Day and The Dalles Dam and fish passing The Dalles Dam and Bonneville. The three dam treatment group passed all dams in the system (Table 2.1). This experimental design controlled for differences in survival caused by environmental and structural differences between each dam and changes in environmental conditions throughout the season.

In order to confirm a basic assumption that fish passing different numbers of dams have different survival rates, a block design analysis of variance (ANOVA) was used to test the effect of number of dam passages (treatment; $n=3$ ) on survival estimates for each species, while controlling for seasonal changes associated with release date (blocks; $n=16$ ). A post-hoc Tukey's Honest Significant Difference (HSD) test was used 
to identify specific differences between treatment groups (Appendix A.5). Pearson's Chisquared Tests were used to determine if significant differences existed between the survival of yearling Chinook salmon and steelhead.

For each fish, the predictor variables included the aforementioned physical variables (water temperature, outflow discharge, spillway discharge, total dissolved gas, and atmospheric barometric pressure), as well as fish migration velocity $\left(\mathrm{km} \cdot \mathrm{h}^{-1}\right.$ : distance each fish traveled between release site and survival through a specific detection array, divided by the time between release and detection at that array; Table 2.1), fish length $(\mathrm{mm})$ and release date (day of year). In order to understand the relationships between predictor variables, a principal component analysis (PCA) was run on centered and scaled environmental data for Chinook passing one dam (Appendix A.6). This subset of data had the largest number of observations and contained environmental data from all three dams in the Lower Columbia River hydrosystem and thus I believe it was the most representative set of environmental conditions experienced by migrating smolt. The PCA indicated that the first four principal components explained $95.22 \%$ of the variance among the predictor variables (Appendix A.6). The first principal component (PC1) explained $65.02 \%$ of the variance and was driven by positive correlations between release date, outflow discharge, spillway discharge, water temperature and dissolved gas. The second and third principal components explained $12.97 \%$ and $11.95 \%$ of the variance, respectively, and were both driven by fish length and barometric pressure. Principal component 4 explained $5.25 \%$ of the variance and was dominated by fish velocity. Fish length, barometric pressure and fish velocity were orthogonal in the PCA (i.e., 
uncorrelated) and were therefore interpreted with more confidence in subsequent analyses.

Random forest analyses were performed using the randomForest package in $\mathrm{R}$ (Liaw and Wiener 2014). Random forests utilize an ensemble bootstrapping technique, which produces a forest of classification trees, created and validated with randomly selected subsets of data. After producing 5,000 trees for each species and each dam passage experience, variable importance was assessed based on the classification accuracy rates of all trees in that model (Cutler et al. 2007, Olden et al. 2008). The classification accuracy rate is the percent of fish that were correctly classified (PCC), where models with correct classifications $>50 \%$ are considered better than random (Cutler et al. 2007). Cohen's Kappa statistic was calculated for each fish species and each dam passage experience to compare predicted and expected model accuracy, while accounting for model agreements due to random chance (Cutler et al. 2007). Kappa values range from -1 to 1 , where values between $0.41-0.60$ indicate moderate agreement, $0.61-0.80$ indicate substantial agreement and $0.81-1.0$ indicate almost perfect agreement (Viera and Garrett 2005). Negative values occur when agreement between predicted and expected model accuracy occur less often by chance alone. I chose random forest analysis, instead of more familiar logistic regression, in order to retain biologically significant predictor variables. In past studies, biologically-important variables have been excluded from traditional regression analysis based on multicollinearity with other biologically significant variables (Giorgi et al. 1997, Smith et al. 2003, Petrosky and Schaller 2010; Appendix A.4). 
Random forest used two randomly selected predictor variables as candidates for each split during tree creation, thus substantially reducing the impact of correlated variables on the forest of 5000 trees. Variable importance was calculated using the Gini Index, a measure of node impurity calculated from the random forest, where large decreases in Gini Index indicate higher variable importance (De'ath and Fabricius 2000). Cross-validated partial dependence plots were generated with the interpret $R$ package in $\mathrm{R}$ (Ballings and Van den Poel 2015) and were used to evaluate the effect of each variable on survival while averaging out the effects of other variables. For each dam passage experience confidence intervals were created from 10 cross-validated random forest models and represent the interquartile range. All analyses were conducted using $\mathrm{R}$ version 3.0.1 (R Core Team 2013).

\section{Results}

There was a significant difference between the survival of yearling Chinook salmon passing one, two and three dams after controlling for release date (block design ANOVA: $\left.F_{2,16}=14.37, p<0.01\right)$. A post-hoc Tukey's HSD test showed a significant difference between Chinook passing one and two, and one and three dams $(p<0.05)$, but not between fish passing two and three dams $(p=0.32)$. There was also a significant difference between the survival of steelhead passing different numbers of dams while controlling for release date $\left(F_{2,16}=4.46, p=0.02\right)$, but this difference was only significant for steelhead passing one and three dams (Tukey's HSD: $p<0.05$ : Appendix A.5). 
The survival of yearling Chinook salmon passing one, two and three dams was $87.8,83.8$ and $81.7 \%$, respectively, while the survival of steelhead smolt passing one, two and three dams was $90.7,86.1$ and $84.3 \%$ respectively. There was not a significant difference between the survival of juvenile Chinook salmon and steelhead passing any number of dams (Pearson's Chi-squared test, $\chi^{2}=1.83, p=0.39$ ), despite differences in fish length between these species (Chinook salmon mean $=148.3 \mathrm{~mm}( \pm 20.8 \mathrm{SD})$, steelhead mean $203.7 \mathrm{~mm}( \pm 24.5 \mathrm{SD})$; Welch Two Sample t-test, $t=-151.84, p<0.01)$.

The survival of both species passing one or two dams was most influenced by water temperature, dissolved gas, outflow discharge and barometric pressure in random forest models, whereas fish passing three dams were most influenced by spillway discharge, fish velocity and barometric pressure (Figure 2.2, 2.3). Random forest models for Chinook salmon and steelhead resulted in Cohen's Kappa statistics that ranged between $0.52-0.69$, indicating moderate to substantial agreement between expected and predicted model accuracies (Table 2.2). For all Chinook and steelhead models, sensitivity (the models' ability to accurately predict survival) was greater than $98 \%$ and specificity (ability to predict mortality) ranged between $43-60 \%$ for Chinook and $39-50 \%$ for steelhead (Table 2.2).

Partial dependence plots generated from ten, cross-validated random forest models show the partial effect of each predictor variable on the probability of survival while averaging out the effects of other variables. For both Chinook and steelhead passing one dam, barometric pressure $<756 \mathrm{mmHg}$ had relatively little effect on survival, while pressure $>756 \mathrm{mmHg}$ decreased survival probabilities (Figure 2.4a, 2.5a). For fish 
passing multiple dams the range of barometric pressures that maintained survival rates above $80 \%$ grew smaller with greater dam passages indicating a cumulative effect of barometric pressure (Figure 2.4b,c, 2.5b,c). In general, steelhead that passed multiple dams were more resilient to the effects of higher barometric pressures $(>760 \mathrm{mmHg})$ than Chinook salmon (Figure 2.4, 2.5).

Survival of Chinook and steelhead passing one dam decreased as dissolved gas concentrations increased above $113 \%$ (Figure $2.4 \mathrm{~d}, 2.5 \mathrm{~d}$ ). For both species passing two dams there is a sharp decrease in survival at $113 \%$ and then again at concentrations $>120 \%$ (Figure 2.4e, 2.5e). There was a non-linear relationship with dissolved gas for both species passing three dams, with low concentrations having a similar negative effect on survival as high concentrations (Figure 2.4f, 2.5f). Though a similar pattern exists between these species, steelhead appear more tolerant of elevated dissolved gas concentrations between 113 - 120\% (Figure 2.4d-f, 2.5d-f).

Chinook passing one and two dams showed increased survival with increasing outflow discharge (Figure 2.4g,h). For steelhead passing one dam, outflow discharge between $7,000-10,000 \mathrm{~m}^{3} \cdot \mathrm{s}^{-1}$ showed the highest survival (Figure $2.5 \mathrm{~g}$ ). For both species passing three dams there is a large increase in survival at outflow discharges between $6000-7000 \mathrm{~m}^{3} \cdot \mathrm{s}^{-1}$ and then virtually no effect above $7,000 \mathrm{~m}^{3} \cdot \mathrm{s}^{-1}$ (Figure $2.4 \mathrm{i}$, 2.5i).

There was a slight decrease in survival with increasing spill discharge for both species passing a single dam (Figure $2.4 \mathrm{j}, 2.5 \mathrm{j}$ ). Fish passing three dams showed a sharp increase in survival at spill discharges $\sim 3000 \mathrm{~m}^{3} \cdot \mathrm{s}^{-1}$ (Figure $2.41,2.51$ ). Interestingly, 
after averaging out the effects of other variables, survival probabilities based on spill volume alone were asymptotic around $70 \%$ and did not increase as spill discharges increased above $3000 \mathrm{~m}^{3} \cdot \mathrm{s}^{-1}$ (Figures $2.4 \mathrm{j}-1,2.5 \mathrm{j}-1$ ).

In general, for both species and all dam passages, survival increased as water temperatures increased up to $12^{\circ} \mathrm{C}$; however, for temperatures above $12^{\circ} \mathrm{C}$ survival drops quickly (Figure 2.4m-o, 2.5m-o). Steelhead survival, in general, appeared more resilient to the effects of water temperatures than Chinook salmon survival (Figure 2.4m-o, 2.5mo).

For both species passing a single dam, fish velocities around $2 \mathrm{~km} \cdot \mathrm{h}^{-1}$ showed the highest survival (Figure 2.4p, 2.5p). For Chinook passing two dams survival was highest around $4.5 \mathrm{~km} \cdot \mathrm{h}^{-1}$, while for steelhead there was sharp increase in survival between $0.5-$ $2 \mathrm{~km} \cdot \mathrm{h}^{-1}$ and little effect of increasing velocity past $2 \mathrm{~km} \cdot \mathrm{h}^{-1}$ (Figure $2.4 \mathrm{q}, 2.5 \mathrm{q}$ ). For both species passing three dams survival increased substantially as fish velocity increased, though interestingly, survival declined slightly for Chinook salmon at velocities $>3 \mathrm{~km} \cdot \mathrm{h}^{-1}$, while steelhead survival remained high for all velocities (Figure $2.4 \mathrm{r}, 2.5 \mathrm{r})$

\section{Discussion}

The influence of biological and environmental variables on smolt survival changed depending on dam passage experience and I observed cumulative, negative effects for fish passing multiple dams. My analysis indicates that the ecological effects of hydropower facilities are not confined to isolated areas of deleterious environment 
conditions (i.e., pulse disturbance), but rather, exert a cumulative influence on migrating smolt, affecting survival throughout my study system (i.e., press disturbance). For both Chinook salmon and steelhead, atmospheric barometric pressure, dissolved gas concentrations, outflow discharge, spillway discharge, water temperature and fish velocity were identified as most influential in terms of survival; however the importance of these variables changed based on how many dams were experienced. For example, fish velocity had little effect on the survival of Chinook salmon passing a single dam, while survival of Chinook passing three dams was strongly negatively affected when fish traveled at low velocities.

In general, Chinook salmon and steelhead responded similarly to altered ecological conditions. I believe that the strength and influence of the altered river conditions acting on salmonids during this life-stage overcomes physiological and biological differences between these species. Both species had statistically similar survival rates for each dam passage and had similar overall responses to environmental conditions. Steelhead appeared to handle the effects of dissolved gas slightly better than Chinook salmon, but this trend was not reflected in overall survival rates. These findings suggest that strategies that create more favorable ecological conditions, that improve survival for one species, will benefit other salmonid species as well. The influence of environmental variables and their implications are discussed below.

Outflow discharge has been shown to affect survival indirectly, by slowing migration and leading to increased predation and longer exposures to deleterious environmental variables (Raymond 1979, Weitkamp and Katz 1980, Giorgi et al. 1997). 
In my study, increasing outflow discharge did not increase survival of smolt passing one or two dams but there was a substantial benefit to smolt passing three dams (Figure 2.4, 2.5). The effect of flow volume on smolt survival is likely more important during low flow years when delayed migration and predation risks are higher (Connor et al. 2003, Smith et al. 2003), compared to years of high flow volumes where secondary processes such as involuntary spill dominate survival patterns (this study, Raymond 1979).

Beginning in 1991 the US Army Corps of Engineers began implementing measures at Snake and Columbia river dams to increase the survival of fish populations listed under the Endangered Species Act (USACE 2011). One successful management strategy is a program of voluntary water release through spillways during juvenile outmigration periods. Smolt passage through spillways have been repeatedly shown to have the highest survival rates of any in-river passage route (Muir et al. 2001, Budy et al. 2002). During years of high spring run-off when water flows exceed hydroelectric capacity, dams are forced into periods of involuntary spill, which result in dissolved gas concentrations that exceed the State of Oregon's water quality standard for concentrations $<110 \%$ saturation (USACE 2011; Appendix A.7). In my study, migrating Chinook salmon and steelhead were strongly influenced by high flow volumes and cascading effects resulting from involuntary spill through the Lower Columbia River hydrosystem.

As seen over the course of my study period, high flow volumes and involuntary spill elevate dissolved gas concentrations resulting from entrained atmospheric gasses held in solution (Johnson et al. 2005; Appendix A.7). Gas concentrations $>100 \%$ 
saturation have been shown to have both acute and chronic effects on salmonids that manifests as gas bubble trauma, which is most affected by the concentration of dissolved gas and the length of exposure (Mesa et al. 2000). While acute exposure to gas concentrations $<120 \%$ are unlikely to cause direct mortality, chronic exposure and behavioral changes to compensate for high levels of gas may indirectly increase both species' susceptibility to predation and disease (e.g., Ebel \& Raymond 1976, Mesa \& Warren 1997). Over the course of my study, the median dissolved gas concentrations were 116.6, 113.3 and $112.7 \%$ at the forebay of BON, TDA and JDA respectively, with maximum concentrations of 124.7, 126.2 and 131\% (Appendix A.2). These concentrations are well within the ranges found to cause gas bubble trauma in salmonids (Colt 1986, Mesa and Warren 1997, Mesa et al. 2000).

Multiple factors acting in concert may influence how dissolved gas concentrations will affect migrating smolt, including barometric pressure, water temperature and fish velocity (Colt 1986, Mesa et al. 2000). The influence of atmospheric barometric pressure on dissolved gas concentrations has received little attention in recent years. The difference between atmospheric barometric pressure and total gas pressure of water is called the differential pressure $(\Delta \mathrm{P})$, where $\Delta \mathrm{P}$ values $<0$ inhibit bubble formation and values $>0$ can lead to gas bubble formation in aquatic organisms (Colt 1986). Salmonids experience chronic gas bubble trauma when $\Delta \mathrm{P}$ is between $38-76 \mathrm{~mm} \mathrm{Hg}$ and acute gas bubble trauma at levels $>76 \mathrm{~mm} \mathrm{Hg}$ (Colt 1986). Salmonids can behaviorally adjust swimming depths to avoid $\Delta \mathrm{P}>38 \mathrm{mmHg}$. Though $\Delta \mathrm{P}$ changes throughout the season, with changing spillway discharge and barometric pressure, migration depths $>2 \mathrm{~m}$ would 
compensate for all $\Delta \mathrm{P}$ values calculated over my study period (Appendix A.8). Despite no difference in survival estimates, my partial dependence plots indicate that steelhead are slightly better adapted to an environment of elevated barometric pressures and dissolved gas concentrations compared to Chinook salmon (Figure 2.4, 2.5).

In addition to depth compensation, migrating smolt can reduce the effect of gas bubble trauma by increasing swimming velocity, which reduces exposure times to elevated gas levels. For both species passing a single dam, all measured velocities maintained survival probabilities above $80 \%$. For fish passing two and three dams, fish velocities less than $2.5 \mathrm{~km} \cdot \mathrm{h}^{-1}$ resulted in survival well below $80 \%$ (Figure $2.4 \mathrm{q}-\mathrm{r}, 2.5 \mathrm{q}-\mathrm{r}$ ). This finding suggests that faster fish limit exposure time to sub-lethal levels of dissolved gas or other sources of mortality and supports my cumulative effect hypothesis.

For both species I observed a positive relationship between survival and water temperatures between $9-12^{\circ} \mathrm{C}$ (Figure $\left.2.4,2.5\right)$. At temperatures $>12^{\circ} \mathrm{C}$, survival decreased for both species but this effect was stronger for Chinook salmon. Water temperatures observed between April and June were well below acute lethal levels for both species $\left(<24^{\circ} \mathrm{C}\right.$; Sullivan et al. 2000), thus I hypothesize that the pattern of increasing survival with increasing temperature is related to the inverse relationship between water temperature and dissolved gas concentrations. Weitkamp and Katz (1980) report that as water temperatures rise its capacity to hold dissolved gas in solution decreases, thus reducing the risk of gas bubble trauma for fish.

\section{Conclusions}


Fish passing one, two and three dams experience varying environmental conditions that differentially affect survival rates. Separating the mortality of fish based on dam passage experience from other forces of mortality remains an ongoing challenge. The majority of Chinook salmon and steelhead smolt in the Lower Columbia River are outmigrating from upriver sites and therefore likely pass through multiple dams. While salmonids are physiologically and behaviorally adapted to wide ranges of environmental conditions, the altered state of the Lower Columbia River hydrosystem represents novel conditions for which smolts have little evolutionary context (Hicks et al. 1991). Despite being spatially isolated in the system, the temporal frequency that smolts encounter these dams equates to a press disturbance, limiting smolts' ability to recover from one set of deleterious conditions before experiencing another significant disturbance. I found tempered encouragement in the convergent responses of Chinook salmon and steelhead survival to the altered environmental conditions in the Lower Columbia River. I believe this finding indicates that management actions intended to improve smolt survival for one species will be beneficial to other salmonids.

Anthropogenic alterations within freshwater ecosystems have caused substantial impacts to aquatic organisms throughout the world. Continued monitoring and evaluation of the ecological impacts of hydroelectric development is needed to conserve current threatened and endangered species and to prevent further species loss globally. 


\section{References}

Abernethy, C.S.; Amidan, B.G. \& Cada, G. (2001) Laboratory Studies of the Effects of Pressure and Dissolved Gas Supersaturation on Turbine-passed Fish. Pacific Northwest National Laboratory, Richland, WA, PNNL-13470.

Ballings, M \& Van den Poel, D. (2016) interpretR: Binary Classifier and Regression Model Interpretation Function

Beeman, J.W. \& Maule, A.G. (2006) Migration Depths of Juvenile Chinook Salmon and Steelhead Relative to Total Dissolved Gas Supersaturation in a Columbia River Reservoir. Transactions of the American Fisheries Society, 135, 584-594.

Bickford, S.A. \& Skalski, J.R. (2000) Reanalysis and Interpretation of 25 Years of Snake-Columbia River Juvenile Salmonid Survival Studies. North American Journal of Fisheries Management, 20, 53-68.

Bigler, B.S.; Welch, D.W. \& Helle, J.H. (1996) A Review of Size Trends Among North Pacific Salmon (Oncorhynchus spp.). Canadian Journal of Fisheries and Aquatic Sciences, 53, 455-465.

Budy, P.; Thiede, G.P.; Bouwes, N.; Petrosky, C.E. \& Schaller, H. (2002) Evidence Linking Delayed Mortality of Snake River Salmon to Their Earlier Hydrosystem Experience. North American Journal of Fisheries Management, 22, 35-51.

Connor, W.P.; Burge, H.L.; Yearsley, J.R. \& Bjornn, T.C. (2003) Influence of Flow and Temperature on Survival of Wild Subyearling Fall Chinook Salmon in the Snake River. North American Journal of Fisheries Management, 23, 362-375. 
Cutler, D.R.; Edwards Jr, T.C.; Beard, K.H.; Cutler, A.; Hess, K.T.; Gibson, J. \& Lawler, J.J. (2007) Random Forests for Classification in Ecology. Ecology, 88, 27832792.

De'ath, G. \& Fabricius, K.E. (2000) Classification and Regression Trees: A Powerful Yet Simple Technique for Ecological Data Analysis. Ecology, 81, 3178-3192.

Dudgeon, D.; Arthington, A.H.; Gessner, M.O.; Kawabata, Z.; Knowler, D.J.; Lévêque, C.; Naiman, R.J.; Prieur-Richard, A.; Soto, D. \& Stiassny, M.L. (2006) Freshwater Biodiversity: Importance, Threats, Status and Conservation Challenges. Biological Reviews, 81, 163-182.

Ebel, W.J. \& Raymond, H.L. (1976) Effect of Atmospheric Gas Supersaturation on Salmon and Steelhead Trout of the Snake and Columbia Rivers. Marine Fisheries Review, 38, 1-14.

Giorgi, A.E.; Hillman, T.W.; Stevenson, J.R.; Hays, S.G. \& Peven, C.M. (1997) Factors That Influence the Downstream Migration Rates of Juvenile Salmon and Steelhead through the Hydroelectric System in the Mid-Columbia River Basin. North American Journal of Fisheries Management, 17, 268-282.

Gresh, T.; Lichatowich, J. \& Schoonmaker, P. (2000) An Estimation of Historic and Current Levels of Salmon Production in the Northeast Pacific Ecosystem: Evidence of a Nutrient Deficit in the Freshwater Systems of the Pacific Northwest. Fisheries, 25, 15-21.

Haeseker, S.L.; McCann, J.A.; Tuomikoski, J. \& Chockley, B. (2012) Assessing Freshwater and Marine Environmental Influences on Life-Stage-Specific Survival 
Rates of Snake River Spring-Summer Chinook Salmon and Steelhead. Transactions of the American Fisheries Society, 141, 121-138.

Hicks, B.J.; Hall, J.D.; Bisson, P. \& Sedell, J. (1991) Responses of salmonids to habitat changes. American Fisheries Society Special Publication, 19, 483-518.

Johnson, G.E.; Hennen, M.J.; Zimmerman, S.A.; Batten, G.; Carpenter, S.M.; Deng, Z.; Fu, T.; Hughes, J.S.; Martinez, J.J. \& Ploskey, G.R. (2012) Survival and Passage of Yearling Chinook Salmon and Steelhead at The Dalles Dam, Spring 2011. Pacific Northwest National Laboratory, Richland, WA. PNNL-21826

Kuehne, L.M. \& Olden, J.D. (2012) Prey Naivety in the Behavioural Responses of Juvenile Chinook Salmon (Oncorhynchus tshawytscha) to an Invasive Predator. Freshwater Biology, 57, 1126-1137.

Lady, J.M.; Westhagen, P. \& Skalski, J.R. (2010) Program ATLAS 1: Active Tag Life Adjusted Survival. http://www.cbr.washington.edu/analysis/apps/atlas Liaw, A. \& Wiener, M. (2014) Classification and Regression by randomForest.

Mesa, M.G. \& Warren, J.J. (1997) Predator Avoidance Ability of Juvenile Chinook Salmon (Oncorhynchus tshawytscha) Subjected to Sub-lethal Exposures of Gassupersaturated Water. Canadian Journal of Fisheries and Aquatic Sciences, 54, $757-764$.

Mesa, M.G.; Weiland, L.K. \& Maule, A.G. (2000) Progression and Severity of Gas Bubble Trauma in Juvenile Salmonids. Transactions of the American Fisheries Society, 129, 174-185. 
Muir, W.D.; Smith, S.G.; Williams, J.G. \& Sandford, B.P. (2001) Survival of Juvenile Salmonids Passing through Bypass Systems, Turbines, and Spillways with and without Flow Deflectors at Snake River Dams. North American Journal of Fisheries Management, 21, 135-146.

NOAA Fisheries. (2008) Biological Opinion (BiOp) on the Operation of the Federal Columbia River Power System (FCRPS). U.S. Department of Commerce, National Marine Fisheries Service, Northwest Regional Office, Seattle, Washington.

Olden, J.D.; Lawler, J.J. \& Poff, N.L. (2008) Machine Learning Methods Without Tears: A Primer for Ecologists. The Quarterly Review of Biology, 83, 171-193.

Petersen, J.H. (2001) Density, Aggregation, and Body Size of Northern Pikeminnow Preying on Juvenile Salmonids in a Large River. Journal of Fish Biology, 58, $1137-1148$.

Ploskey, G.; Weiland, M. \& Carlson, T. (2012) Route-Specific Passage Proportions and Survival Rates for Fish Passing through John Day Dam, The Dalles Dam, and Bonneville Dam in 2010 and 2011. Pacific Northwest National Laboratory, Richland, WA, PNNL-21442.

Poff, N.L.; Allan, J.D.; Bain, M.B.; Karr, J.R.; Prestegaard, K.L.; Richter, B.D.; Sparks, R.E. \& Stromberg, J.C. (1997) The Natural Flow Regime. BioScience, 47, 769784. 
Raymond, H.L. (1979) Effects of Dams and Impoundments on Migrations of Juvenile Chinook Salmon and Steelhead from the Snake River, 1966 to 1975. Transactions of the American Fisheries Society, 108, 505-529.

R Core Team. (2013) R: A Language and Environment for Statistical Computing. R Foundation for Statistical Computing, Vienna, Austria.

Reeves, G.H.; Benda, L.E.; Burnett, K.M.; Bisson, P.A. \& Sedell, J.R. (1995) A disturbancebased ecosystem approach to maintaining and restoring freshwater habitats of evolutionarily significant units of anadromous salmonids in the Pacific Northwest. American Fisheries Society Symposium, 17, 334-349.

Shrimpton, J.M.; Randall, D.J. \& Fidler, L.E. (1990) Factors affecting swim bladder volume in rainbow trout (Oncorhynchus mykiss) held in gas supersaturated water. Canadian Journal of Zoology, 68, 962-968.

Skalski, J.R.; Townsend, R.L.; Seaburg, A.G.; Johnson, G.E.; Ploskey, G.R. \& Carlson, T.J. (2012a) Compliance Monitoring of Juvenile Yearling Chinook Salmon and Steelhead Survival and Passage at The Dalles Dam, Spring 2011. Pacific Northwest National Laboratory, Richland, WA. PNNL- 21124

Skalski, J.R.; Townsend, R.L.; Seaburg, A.G.; Ploskey, G.R. \& Carlson, T.J. (2012b) Compliance Monitoring of Yearling Chinook Salmon and Juvenile Steelhead Survival and Passage at Bonneville Dam, Spring 2011. Pacific Northwest National Laboratory, Richland, WA. PNNL- 21175

Skalski, J.R.; Townsend, R.L.; Seaburg, A.G.; Weiland, M.A.; Woodley, C.M.; Hughes, J.S. \& Carlson, T.J. (2012c) Compliance Monitoring of Yearling Chinook Salmon 
and Juvenile Steelhead Survival and Passage at John Day Dam, Spring 2011. Pacific Northwest National Laboratory, Richland, WA. PNNL-21176.

Smith, S.G.; Muir, W.D.; Hockersmith, E.E.; Zabel, R.W.; Graves, R.J.; Ross, C.V.; Connor, W.P. \& Arnsberg, B.D. (2003) Influence of River Conditions on Survival and Travel Time of Snake River Subyearling Fall Chinook Salmon. North American Journal of Fisheries Management, 23, 939-961.

Sullivan, K.; Martin, D.; Cardwell, R.; Toll, J.E. \& Duke, S. (2000) An Analysis of The Effects of Temperature on Salmonids of The Pacific Northwest With Implications for Selecting Temperature Criteria. Sustainable Ecosystems Institute, Portland, Oregon.

Townsend, R.; Skalski, J.; Dillingham, P. \& Steig, T. (2006) Correcting Bias in Survival Estimation Resulting from Tag Failure in Acoustic and Radio-telemetry Studies. Journal of Agricultural, Biological, and Environmental Statistics, 11, 183-196.

USACE. (2011) 2011 Dissolved Gas and Water Temperature Report - Columbia River Basin. Water Quality Unit Reservoir Control Center Columbia Basin Water Management Division U.S. Army Corps of Engineers Northwest Division, Portland, Oregon.

Viera, A.J. \& Garrett, J.M. (2005) Understanding Inter-observer Agreement: The Kappa Statistic. Fam Med, 37, 360-363.

Weiland, M.A.; Woodley, C.M.; Ploskey, G.R.; Hughes, J.S.; Kim, J.A.; Deng, Z.; Fu, T.; Fischer, E.S.; Skalski, J. \& Townsend, R.L. (2013) Acoustic Telemetry 
Evaluation of Juvenile Salmonid Passage and Survival at John Day Dam, 2010. Pacific Northwest National Laboratory, Richland, WA. PNNL 22177. 


\section{Tables}

Table 2.1. Description of dam passage experience for fish, including which dams were passed, release sites and detection arrays, the source of environmental data that was applied to each fish, the number of smolt, and survival estimates. Smolt passing one and two dams were combined for analysis from fish passing different dams (e.g., one dam passage included fish passing BON, TDA, and JDA and two dam fish passed JDA - TDA and TDA $-\mathrm{BON})$. Pearson's Chi Squared Tests were performed within treatment groups to test whether fish passing a single dam (either BON, TDA or JDA) or two dams (JDA TDA, TDA - BON) had statistically different survival estimates (shared italic letters indicate no significance, while different letters indicate significant differences within each dam passage experience). Analysis of variance was performed between combined passages (i.e. one, two or three dams) and controlled for release date. Post-hoc Tukey's Honest Significant Difference Test was used to identify differences between survival based on passage experience (bold letters).

\begin{tabular}{|c|c|c|c|c|c|c|c|}
\hline & $\begin{array}{l}\text { Dams } \\
\text { Passed }\end{array}$ & $\begin{array}{c}\text { Release } \\
\text { and } \\
\text { Detection } \\
\text { Arrays } \\
\text { (rkm) } \\
\end{array}$ & $\begin{array}{c}\text { Source of } \\
\text { Environmental } \\
\text { Data }\end{array}$ & $\begin{array}{c}\text { Chinook } \\
\text { (n) }\end{array}$ & $\begin{array}{c}\text { Chinook } \\
\text { Survival } \\
(\%)\end{array}$ & $\begin{array}{l}\text { Steelhead } \\
\text { (n) }\end{array}$ & $\begin{array}{c}\text { Steelhead } \\
\text { Survival } \\
(\%)\end{array}$ \\
\hline 1 Dam & BON & $275-161$ & $\mathrm{BON}$ & 800 & $83.3^{b}$ & 794 & $92.8^{b}$ \\
\hline Passage & TDA & $325-275$ & TDA & 976 & $85.8^{b}$ & 955 & $86.0^{a}$ \\
\hline & JDA & $390-325$ & JDA & 728 & $93.3^{a}$ & 737 & $94.6^{b}$ \\
\hline Total & & & & 2504 & $87.8^{a}$ & 2486 & $90.7^{\mathrm{a}}$ \\
\hline $\begin{array}{l}2 \text { Dam } \\
\text { Passage }\end{array}$ & $\begin{array}{l}\text { TDA + } \\
\text { BON }\end{array}$ & $325-161$ & $\begin{array}{c}\text { Average of } \\
\text { TDA + BON }\end{array}$ & 978 & $85.0^{a}$ & 985 & $88.1^{b}$ \\
\hline & $\begin{array}{l}\text { JDA + } \\
\text { TDA }\end{array}$ & $390-275$ & $\begin{array}{r}\text { Average of } \\
\text { JDA + TDA }\end{array}$ & 724 & $84.0^{a}$ & 734 & $83.9^{a}$ \\
\hline Total & & & & 1702 & $83.8^{b}$ & 1719 & $86.1^{\mathrm{ab}}$ \\
\hline $\begin{array}{l}3 \text { Dam } \\
\text { Passage }\end{array}$ & $\begin{array}{l}\text { JDA + } \\
\text { TDA + } \\
\text { BON }\end{array}$ & $390-161$ & $\begin{array}{c}\text { Average of } \\
\text { JDA + TDA + } \\
\text { BON }\end{array}$ & 1002 & & 970 & \\
\hline Total & & & & 1002 & $81.7^{b}$ & 970 & $84.3^{\mathrm{b}}$ \\
\hline
\end{tabular}


Table 2.2. Performance of random forest models for yearling Chinook salmon and steelhead passing 1, 2 and 3 dams. Percent correctly classified (PCC) is the overall number of correctly classified model observations. Sensitivity is the percentage of times survival was correctly classified. Specificity is the percentage of times mortality was correctly classified. Cohen's Kappa statistic compares predicted model accuracy and expected model accuracy while accounting for agreement between models due to random chance.

\begin{tabular}{lcccccc}
\hline & \multicolumn{3}{c}{ Chinook Salmon } & \multicolumn{3}{c}{ Steelhead } \\
& 1 Dam & 2 Dams & 3 Dams & 1 Dam & 2 Dams & 3 Dams \\
\hline PCC (\%) & 94.4 & 89.8 & 91.8 & 94.3 & 91.8 & 91.8 \\
Sensitivity (\%) & 99.2 & 98.8 & 98.8 & 99.9 & 98.6 & 99.5 \\
Specificity (\%) & 60.0 & 43.4 & 60.7 & 39.1 & 42.5 & 50.0 \\
Cohen's Kappa & 0.69 & 0.53 & 0.68 & 0.53 & 0.52 & 0.61 \\
\hline
\end{tabular}


Figures

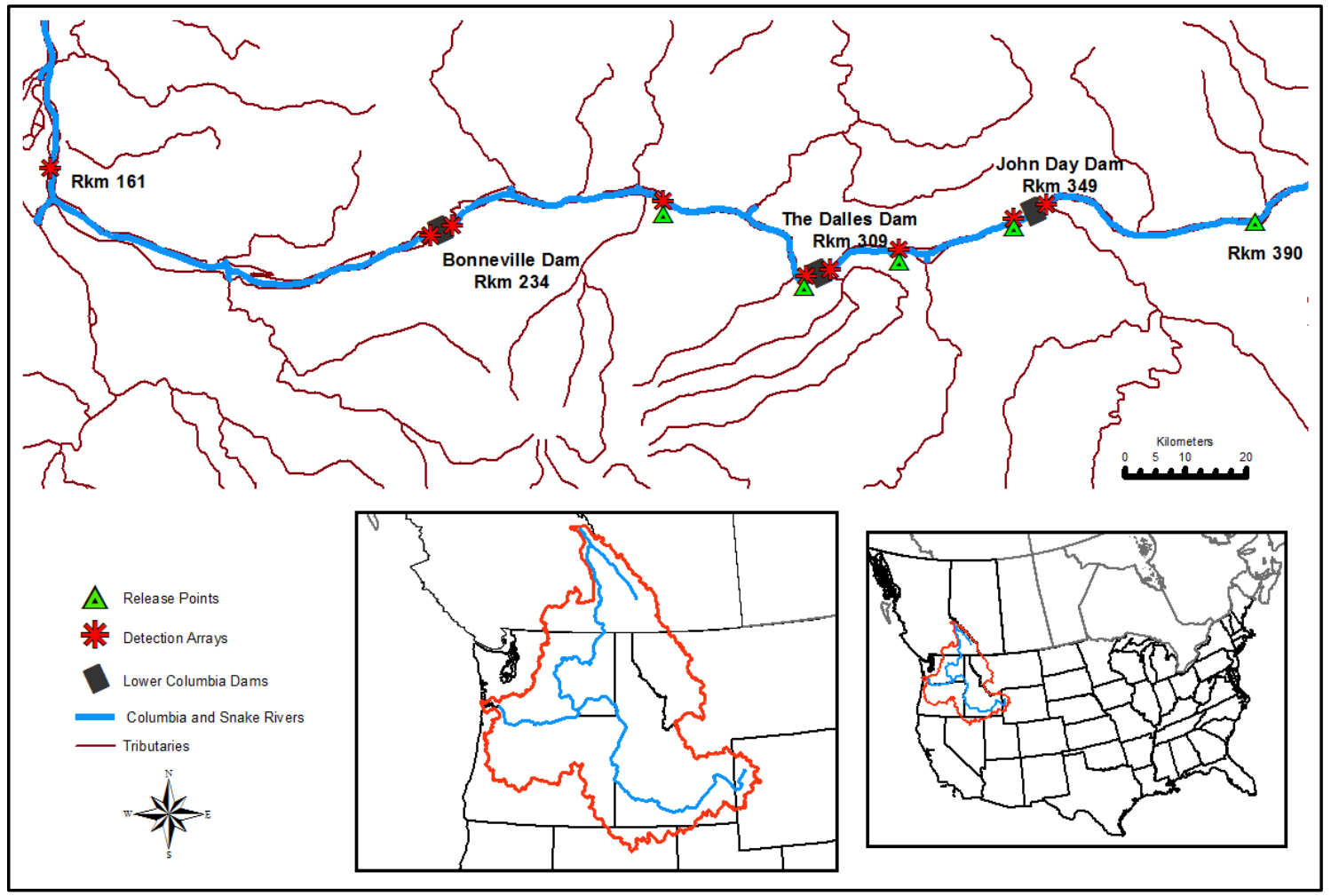

Figure 2.1. Map of the Lower Columbia River hydrosystem, including John Day Dam, The Dalles Dam and Bonneville Dam, autonomous detection arrays and release points for both Chinook salmon and steelhead passing one, two and three dams. Insets show the location of the Columbia River Basin within North America and major tributaries. 


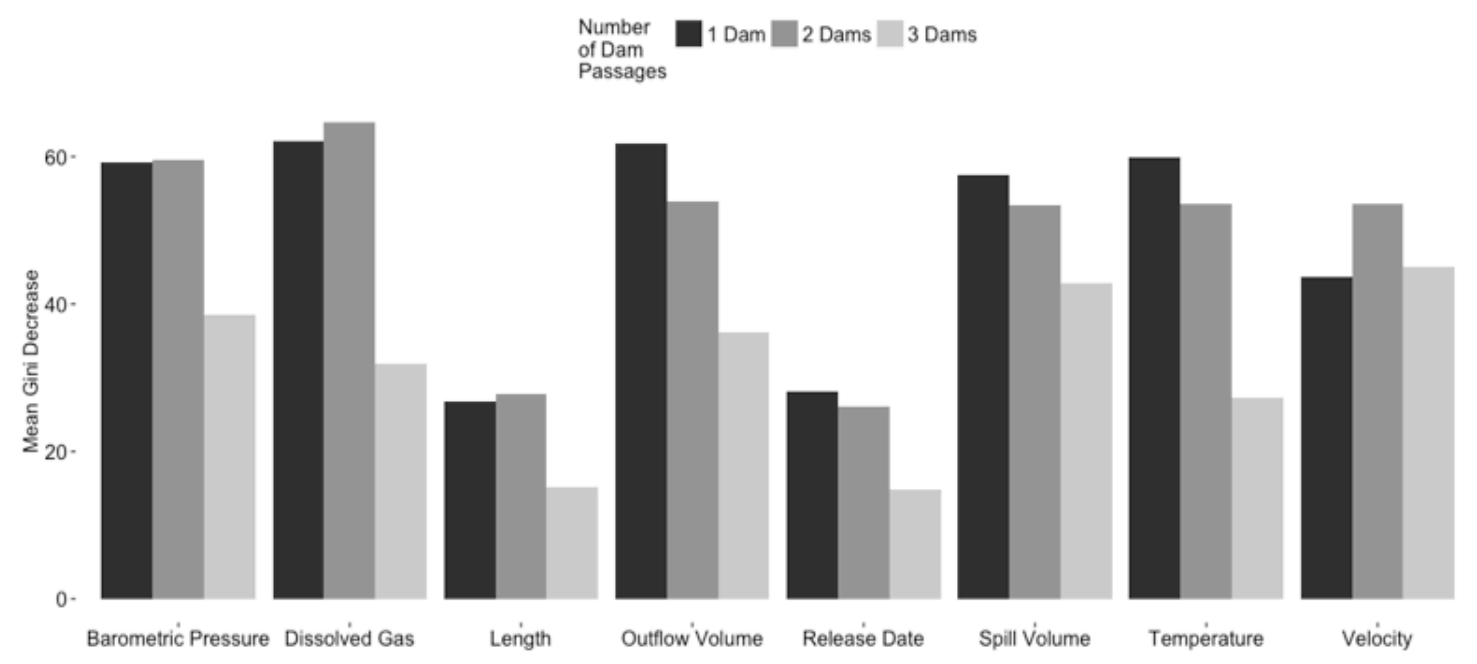

Figure 2.2. Variable importance for the survival of Chinook salmon passing through the Lower Columbia River hydroelectric power system for each individual random forest model (i.e., one, two, or three dams). Larger Gini values represent the most important variables regarding the survival of migrating smolts. 


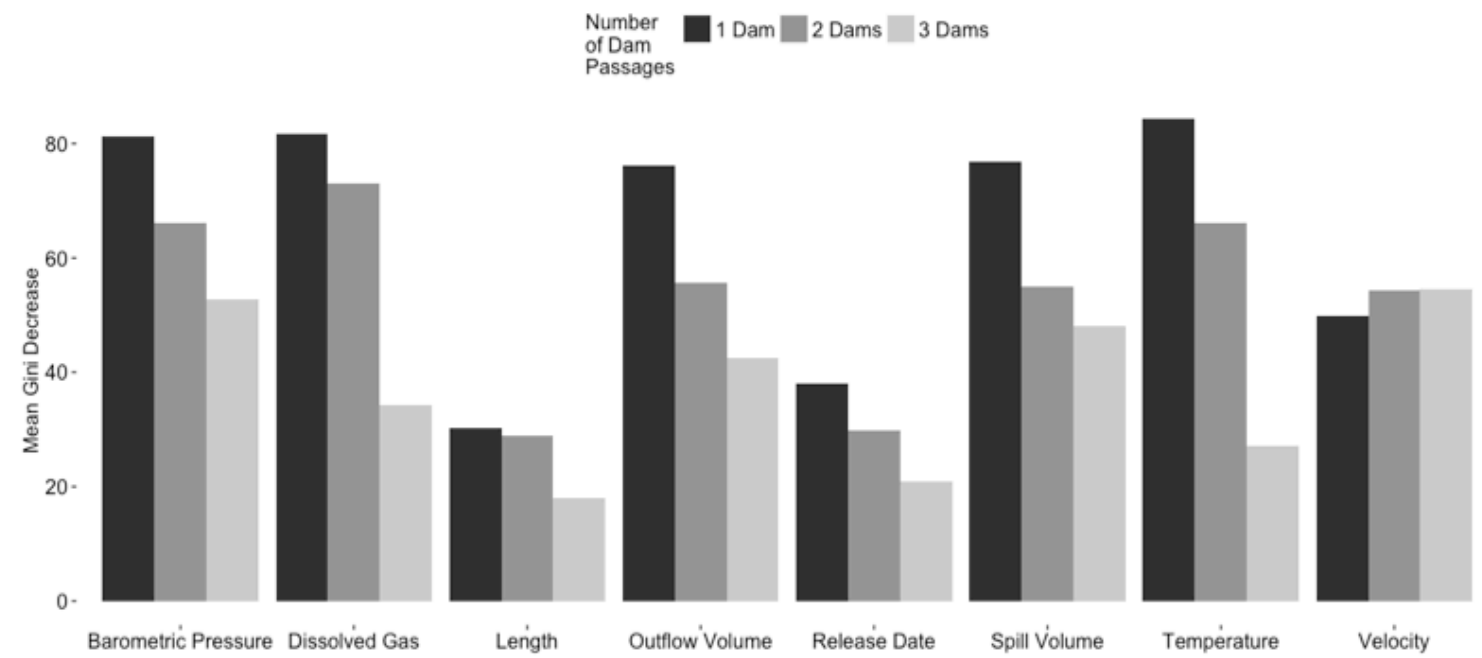

Figure 2.3. Variable importance for the survival of steelhead passing through the Lower Columbia River hydroelectric power system. Axis values as in Figure 2.2. 

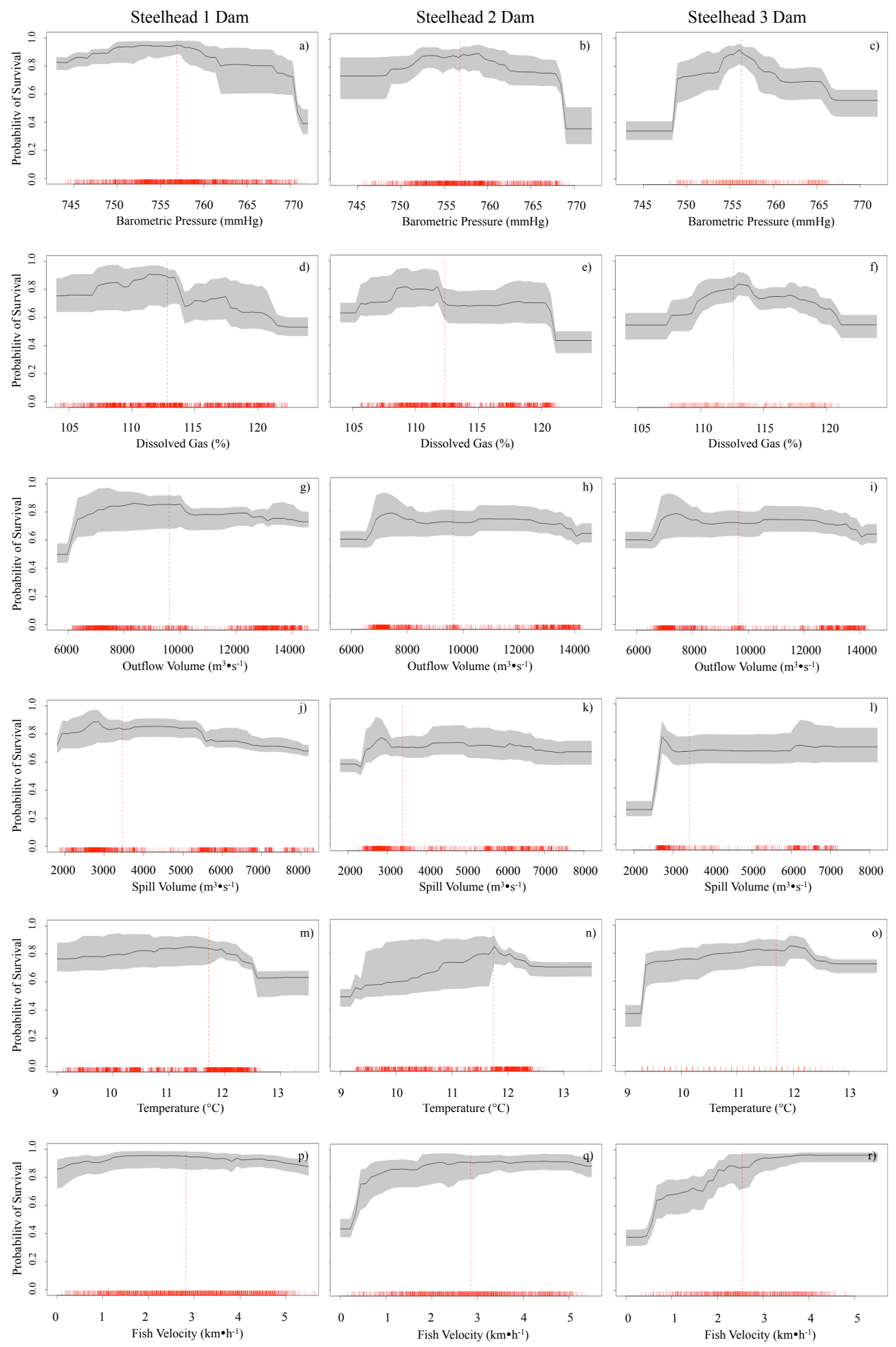

Figure 2.4. Partial dependence plots for Chinook salmon by variable and dam passage experience, generated from 10 cross-validated random forest models. Partial dependence plots show the probability of survival for a given predictor variable, while averaging out 
the effects of the other predictor variables. Confidence intervals represent the interquartile range (grey) and vertical dashed line represents the median for each variable (red). Rug marks along the x-axis indicate the number of fish experiencing those conditions. Plot areas at the extreme ends of the x-axis, with few observations, should be interpreted cautiously. 

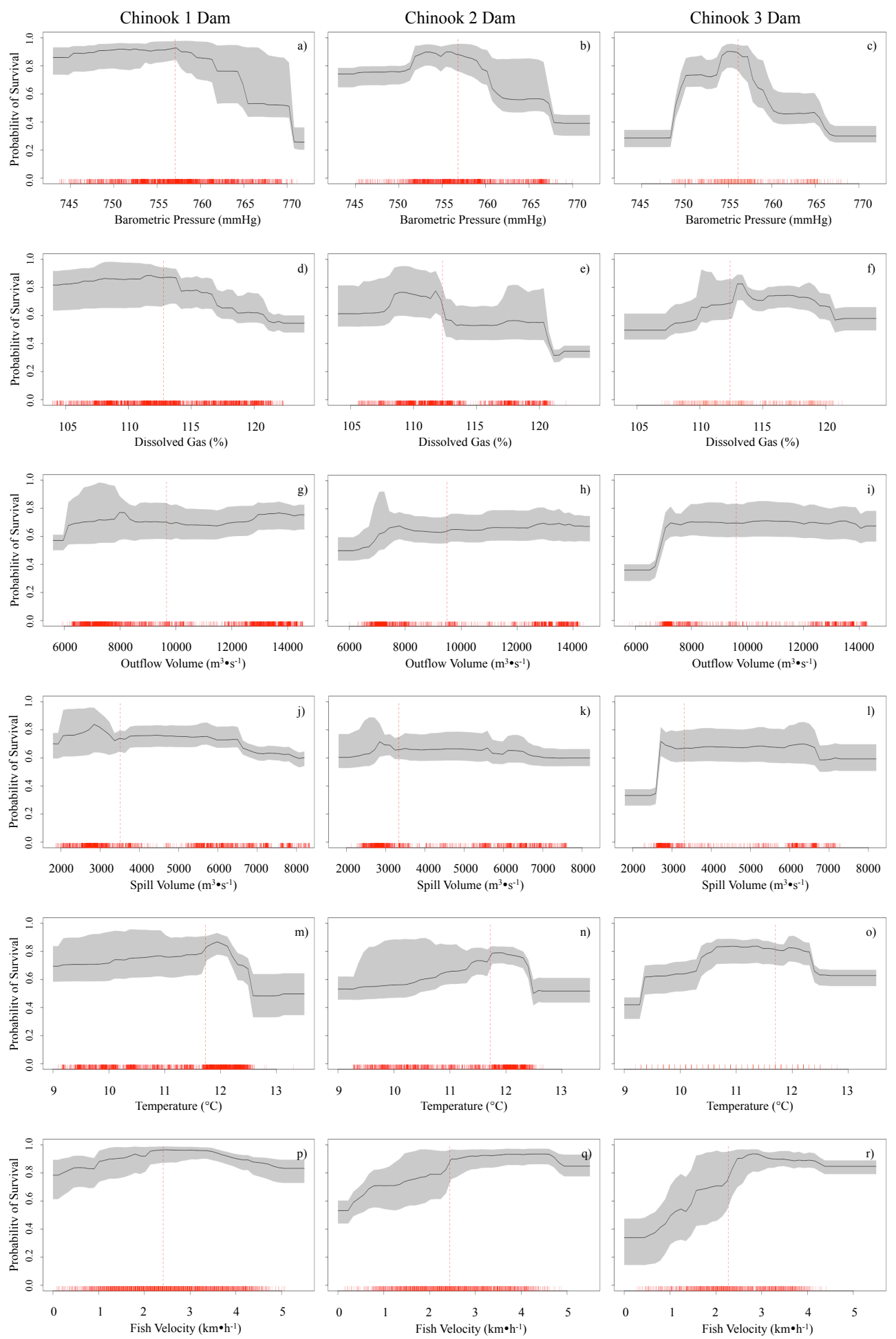

Figure 2.5. Partial dependence plots for steelhead by variable and dam passage. Symbols and axis values as in Figure 2.4. 


\section{Chapter 3 - Productive marine phases and density dependence influence early maturation in Chinook salmon}

Note: This chapter is in review as an open-access journal article in

$$
\text { Ecosphere }
$$

Elder, T. and A. L. Strecker. Submitted 2018. Productive marine phases and density dependence influence early maturation in Chinook salmon. Ecosphere (in review). 


\section{Introduction}

Life history strategies are combinations of biological characteristics that imbue increased fitness to individuals living within specific environments, and are major factors associated with population dynamics (Stearns 1976, Winemiller and Rose 1992). Life history strategies are wide ranging combinations of traits, which produce locally adapted phenotypes suited to unique environmental gradients and include tradeoffs between variables such as fecundity, age-specific survivorship, parental investment, and age of maturity (Winemiller and Rose 1992). Salmonids, including semelparous Chinook (Oncorhynchus tshawytscha) salmon, have evolved a complex life cycle that is adapted to a seasonally dynamic, low productivity freshwater environment, as well as high productivity marine environments. Chinook salmon life history is characterized by traits such as relatively high fecundity, longer life spans, parental care, and older ages at maturity (Vollestad et al. 2004, Mims et al. 2010).

Age of maturity among male Chinook salmon is increasingly understood to be highly plastic and can employ a precocious, alternative reproductive strategy, whereby males reach sexual maturity at young ages (age $1-3$ post fertilization) compared to females of the same brood year (Shearer et al. 2006, Morita and Fukuwaka 2007, Harstad et al. 2014). Genotype-by-environment interactions affect age of maturity in salmon (Power 1986, Sloat et al. 2014) and precociousness is thought to be a threshold trait influenced by some combination of juvenile body size, growth rates, and lipid content (Thorpe 1987, Gross 1991, Clarke and Blackburn 1994, Hopkins and Unwin 1997, Silverstein et al. 1998). 'Critical' periods $8-12$ months prior to maturation have been 
suggested, when individual fish assess their developmental potential based on size, growth rate, stored lipids or a combination of these factors, which will influence the maturation 'decision' of each fish (Silverstein et al. 1998, Shearer and Swanson 2000, Larsen et al. 2004, 2013). Precociousness appears to be, at least partially, sex-linked to the Y-chromosome, heritable from one generation to the next, irreversible, and is influenced by environmental factors (i.e. photoperiod, temperature, food availability and density dependent factors; Gross 1991, Hankin et al. 1993, Heath et al. 2002, Sloat et al. 2014). Precocious salmon differ from other sexually mature adults in that they have significantly smaller body sizes at maturity, may or may not display secondary sexual characteristics, and utilize a 'sneaking', rather than a competitive behavioral strategy during reproduction (Larsen et al. 2004, Berejikian et al. 2010).

As a result of overlapping anthropogenic and climatic stressors, distinct populations of Columbia River Chinook salmon have been listed under the Endangered Species Act (NOAA Fisheries 2008). Hatcheries have arisen throughout the basin to support and bolster declining salmon populations. In recent years, there have been high proportions of precocious Chinook salmon originating from hatcheries throughout the Columbia River basin (Larsen et al. 2004, Harstad et al. 2014). Several studies have identified specific hatchery practices (e.g. feeding regimes, temperature, fish density, food quality and origin of broodstock) that promote the precocious life history strategy (Larsen et al. 2013, Harstad et al. 2014). However, little is known about the occurrence of precociousness in wild populations and the factors that influence precociousness outside of the hatchery setting. While the majority of spring Chinook salmon in the 
Columbia River are of hatchery origin ( $~ 80 \%$; NOAA Fisheries 2008; Figure 3.1), I believe that a better understanding of the environmental mechanisms underlying precociousness in wild populations will help guide fisheries managers charged with protecting threatened and endangered populations.

I analyzed return data of individually tagged wild and hatchery origin spring Chinook salmon from throughout the Columbia River basin from 1998 - 2014 to compare the effects of biological and environmental variables on age at maturity. My approach used multiple statistical models in order to predict the occurrence of precocious (return age $<4$ years; see Larsen et al. 2013 for definitions of nomenclature and terms regarding age class distinctions) and adult (return age $\geq 4$ ) Chinook salmon. Based on past research, I hypothesized that precocious maturation in wild and hatchery Chinook would be influenced by factors that affect growth rates in both freshwater and marine environments (Table 3.1; Wilbur and Collins 1973, Clarke and Blackburn 1994, Day and Rowe 2002, Thorpe 2007, Jonsson et al. 2013). I hypothesized that precociousness in wild fish would be influenced by different environmental variables than hatchery-origin fish based on artificial hatchery rearing practices and physiological conditions achieved during early life stages in the hatchery setting (Table 3.1; Larsen et al. 2013).

\section{Methods}

Study Area

The Columbia River is a large and dynamic riverscape, covering an approximate area of $660,000 \mathrm{~km}^{2}$. This system was historically dominated by high spring runoff from 
snowmelt followed by decreasing flows throughout the summer months. Anthropogenic influences over the past 150 years have altered many of the historical physical and chemical processes in the Columbia basin such as flow volumes, temperatures, dissolved gas concentrations, sediment flow, and other processes (Smith et al. 2003, Williams et al. 2008).

\section{Chinook Salmon Return Data and Age Estimates}

Data on wild and hatchery spring-run (i.e. stream-type) Chinook salmon returning through the Bonneville Dam between 1998-2014 were gathered from the PIT Tag Information System (PTAGIS; Pacific States Marine Fisheries Commission 2014). Each fish was marked with a unique passive integrated transponder (PIT tag) and released into the Columbia River basin above Bonneville Dam (Prentice et al. 1990). Marked smolt migrated downstream through Bonneville Dam (east to west), spent some amount of time downstream, and then returned upstream through the dam's fish ladder and associated PIT tag interrogators (west to east; Figure 3.2). Between 1998-2014, 54,320 tagged fish were identified returning using this method. Data filtering and quality assessment resulted in 28,808 spring-run Chinook salmon (wild $n=6,793$; hatchery $n=22,015$ ) that spent a minimum of 20 days between release date and the last upstream detection at Bonneville Dam fish ladders. The 20-day threshold between release and detection was chosen to offset the large numbers of fish released from lower Columbia River hatcheries that were detected heading upstream from Bonneville Dam within days of release. These fish were potentially precocious parr (age 0 ) or mini-jacks (age 1) and were 
underrepresented in my data based on minimal migration distances from hatcheries farther upriver from Bonneville (see discussion in Beckman and Larsen 2005, Johnson et al. 2012). I observed repeated detections of individual fish at the Bonneville Dam fish ladders indicating either multiple dam passages (i.e. downstream through spillway/juvenile bypass, upstream through fish ladder, downstream again through spillway/juvenile bypass, back upstream through fish ladder) or multiple PIT detection records for fish maintaining position proximate to PIT detectors in the ladder. To ameliorate the problem of multiple detections of the same individual fish, I selected the last upstream record for each fish at the Bonneville Dam fish ladder. For all fish, I assumed that upstream migration through Bonneville Dam was indicative of sexual maturity (Tattam et al. 2015).

Wild fish were caught, tagged, and released from 91 different locations and hatchery fish originated from 27 different hatcheries with 83 hatchery release locations throughout Idaho, Oregon, and Washington (Figure 3.2). Metadata associated with each fish in the PTAGIS database identified fish run-type (spring-run), origin (wild or hatchery), release location and date, hatchery origin, fork length at the time of tagging and date of last detection at Bonneville Dam (Scheuerell 2005).

For each fish, age at return (i.e. age at maturity; Age $_{\text {return }}$ ) was calculated by adding the estimated age at the time of marking (Age mark$_{\text {; }}$ estimated) and time between release and last detection (Age detection; measured) at Bonneville Dam:

Eq 3.1. $\quad$ Age $_{\text {return }}=$ Age $_{\text {mark }}+$ Age $_{\text {detection }}$ 
Age $\mathrm{mark}_{\text {was }}$ determined by subtracting two years from the release year for fish that were tagged before July and subtracting one year from the release year for fish tagged after July. This procedure, based on fork lengths at the time of marking, appeared to reliably distinguish fish tagged as sub-yearlings from fish tagged as yearlings (Appendix B.1). Following the nomenclature of Larsen et al (2013), Age return $_{\text {was }}$ used to identify each individual fish as precocious (returning through the Bonneville Dam fish ladder $<4$ years from fertilization) or adult fish (returning through the Bonneville Dam fish ladder $\geq 4$ years from fertilization; Larsen et al 2013). The binary classification of precocious and adult returns afforded higher confidence in age estimates than classification into smaller bins such as yearly age classes (i.e. age 1, age 2).

\section{Environmental Variables}

I utilized the Columbia River Data Access in Real Time (University of Washington 2014) database to retrieve adult return counts and various freshwater, near-shore, and offshore marine indices known to influence salmon population dynamics in the northeastern Pacific Ocean. Summary details regarding variables can be found in Appendix B.2 and 3. My approach generated a unique seasonal index of environmental variables for each fish that was dependent on release site and year. I describe these variables below.

The Coastal Upwelling Index (CUI) is a volumetric measurement of the amount of water that is upwelled along the coast as a result of wind stress and affects near-shore plankton productivity (Schwing et al. 1996). The CUI values used in my models covered the spatial area between the $45^{\circ} \mathrm{N} 125^{\circ} \mathrm{W}$ and $48^{\circ} \mathrm{N} 125^{\circ} \mathrm{W}$ by averaging CUI values 
from these two locations. Positive coastal upwelling indicates cold, high salinity, nutrient-rich water being upwelled from depth and has been associated with increased smolt to adult survival for Snake River Chinook salmon (Scheuerell and Williams 2005). The Multivariate El Niño - Southern Oscillation Index (MEI) is comprised of six marine variables from the tropical Pacific Ocean and represents short-term variation on interannual time scales (Wolter and Timlin 1998). Positive values indicate warmer sea surface temperatures and less productive El Niño conditions, while negative values indicate cooler sea surface temperatures and more productive La Niña conditions along Oregon, Washington, and British Columbia coastlines. The Pacific Decadal Oscillation $(\mathrm{PDO})$ is an index of long-term variation in North Pacific sea surface temperatures on the scale of decades (Mantua et al. 1997). Positive values generally indicate warm, less productive periods along Oregon, Washington, and British Columbia coastlines, while negative values indicate cooler, more productive periods. Because of the variation in ocean entry times for different populations of Chinook salmon, I averaged the CUI, MEI, and PDO into two seasons: January - June and July - December. Because Chinook salmon can spend prolonged periods in the ocean environment, marine indices were applied to each fish twice: (1) during the year of release, capturing conditions experienced during ocean entry (smolt life stage); and (2) during the year of return, representing conditions experienced during ocean exit (reproductive life stage).

The Pacific Northwest Index (PNI) is an annual terrestrial climate index for the Columbia River basin that is produced from normalized air temperatures, precipitation, and snowpack data from three different locations in the Pacific Northwest (Ebbesmeyer 
and Strickland 1995). Positive values indicate years that are warmer and dryer, while negative values indicate years that are cooler and wetter than average. Density dependent effects on early life stages were modeled for wild fish using coarse-scale adult return counts by subbasin and brood year (e.g. adult returns to the Snake River subbasin in 2001; University of Washington 2014). See Appendix B.4 for details on adult return count calculations. Air temperature and precipitation data were retrieved from the PRISM database (Oregon State University 2016; 4-km grid cell resolution). Although stream temperatures may be a better indicator of freshwater conditions than air temperature, there are no datasets that have the temporal and spatial resolution that were required for my study. Air temperature is often used as a proxy for water temperature in situations where direct measurement is not feasible (Taylor 1990, Wenger et al. 2011). Daily precipitation $(\mathrm{mm})$ and maximum air temperature $\left({ }^{\circ} \mathrm{C}\right)$ were collected for each release site (wild $n=98$; hatchery $n=83$ ) between 1998 and 2014. For each fish, at each release site, the daily maximum temperatures and precipitation were averaged over each three-month season $($ winter $=\mathrm{JFM}$, spring $=$ AMJ, summer $=\mathrm{JAS}$, fall $=\mathrm{OND})$ between October 1 of the brood year and tagging date. Additionally, river distance from release site to ocean $(\mathrm{Rkm})$, latitude, and longitude were retrieved for each release site (Pacific States Marine Fisheries Commission 2015). I was unable to obtain data from hatcheries on rearing conditions.

Statistical Approaches for Modeling Precociousness 
Parallel comparisons of different modeling approaches may provide more insight than single models for complex, non-linear, datasets (Olden and Jackson 2002, Sharma and Jackson 2008). To understand the relationship between age of return (binary response variable: adult $=0$ and precocious $=1$ ) and my suite of predictor variables (categorical and numeric), I modeled these relationships using random forest and artificial neural networks. Random forests are an extension of classification and regression trees and employ an ensemble bootstrapping technique, which produces a forest of trees that are created and validated with randomly selected subsets of data (Cutler et al. 2007). Random forest analyses have no assumptions about the distribution of predictor or response variables and can accommodate correlated predictors (Cutler et al. 2007). I also used an artificial neural network because it is able to model non-linear associations and has no distributional assumptions about predictor or response variables (Olden et al. 2008). My artificial neural network models employed a feed-forward, multi-layer perceptron trained through back-propagation. I chose not to use a logistic regression approach because of high multicollinearity between biologically relevant predictor variables and non-linear relationships between predictors and response variables (Cutler et al. 2007).

Multiple parameters were optimized to fine tune the random forest and artificial neural network models and the combination of parameters that maximized model performance was selected. I used Cohen's Kappa statistic to maximize model performance for both random forests and artificial neural networks, because it is a measure of correctly classified observations that accounts for agreement between 
predicted and observed classifications that arise due to random chance (Viera and Garrett 2005, Cutler et al. 2007). The tuning parameters for the random forest model were the number of variables randomly sampled as candidates at each split and the number of trees grown. Hyper-parameters tested in the random forest analysis were: (1) number of variables set to $2,3,4,6,8$ and 10 randomly sampled at each split, and (2) a constant number of trees set to 1000 (Kuhn 2008). Artificial neural networks have three tuning parameters: number of hidden layers, size, and decay. The size parameter refers to the number of hidden neurons within each hidden layer, while the decay parameter reduces over-fitting. I compared neural network performance of single hidden layer models with size set to $2,4,6,8$ or 10 hidden neurons and decay set to 0.1 or 0.5 (Kuhn 2008).

Wild and hatchery fish were modeled separately using the caret package (Kuhn 2008) in R version 3.3.3 (R Core Team 2016). Each statistical model was run using three repetitions of a 10-fold cross-validation and was compared based on the predictive capacity of a randomly selected, centered and scaled, training data set $(80 \%$; wild $n=$ 5429 , hatchery $n=17614)$ on a testing data set $(20 \%$; wild $n=1357$, hatchery $n=4403)$. Following cross-validation and tuning with the training data, each statistical model was evaluated based on its predictive capacity of the independent testing set. Predictive capacity was assessed by the total percent of correctly classified observations (PCC), sensitivity (ability to accurately predict precocious fish), specificity (ability to accurately predict adult fish), and Cohen's Kappa statistic (accounts for prediction agreement due to random chance). To determine the effect of environment on precocious maturation, I ran random forest and artificial neural network models with: 1) freshwater variables only; 2) 
freshwater and marine variables during the year of outmigration; and 3) freshwater and marine variables during the year of outmigration and marine variables during the year of return. Relative variable importance measures (random forest $=$ Gini Index; artificial neural networks $=$ Garson Weights) were assessed within each model and used to visually compare the results of statistical approaches.

Partial dependence plots (with confidence intervals representing the interquartile range) were generated from a separate 10 -fold cross-validated random forest model using the interpretR package (Ballings and Van den Poel 2016). Two-way partial dependence plots produced by the $p d p$ package (Greenwell 2017) were created in order to better understand the relationship between age at return and influential predictor variables.

\section{Results}

\section{Model Performance}

For both wild and hatchery fish, full models that contained freshwater and marine variables during year of outmigration and marine variables during year of return had the highest prediction accuracy for precocious fish (Table 3.2). For wild fish, reduced models containing only freshwater variables showed considerably lower sensitivity in correctly predicting precociousness compared to full models (random forest: $7.2 \%$ decrease in sensitivity; artificial neural network: $18.4 \%$ decrease in sensitivity). For hatchery fish, reduced models showed slightly less sensitivity in correctly predicting precociousness compared to full models (random forest: $0.3 \%$ decrease in sensitivity; artificial neural network: $10.1 \%$ decrease in sensitivity). 
The full random forest models correctly classified $99 \%$ of observations in the testing data for wild and hatchery fish (Table 3.2). In both wild and hatchery models, specificity was $100 \%$. Sensitivity (correctly predict precocious fish) was $94 \%$ for wild fish (9 of 153 precocious fish misclassified as adults) and 99\% hatchery fish (6 of 1596 precocious fish misclassified as adults). Cohen's Kappa statistic was $>0.95$ for wild and hatchery models, indicating very high agreement between predicted and observed classes (Table 3.2). The tuning parameters for the best-fit random forest models of wild and hatchery fish were ten and four variables tried at each split, respectively, with the number of trees grown fixed at 1000 .

The artificial neural networks had good agreement with random forest models, correctly classifying $>99 \%$ of hatchery fish (Table 3.2 ). Specificity was $100 \%$ for wild and hatchery models and sensitivity was $96 \%$ for wild precocious fish (model misclassified 5 of 153 fish) and 99\% for hatchery precocious fish (model misclassified 5 of 1596 fish). Cohen's Kappa was $>0.95$ for wild and hatchery fish models (Table 3.2). The tuning parameters for the best fit neural network models for wild fish were a 30-10-1 network (30 input variables, 10 hidden neurons and 1 output) and for hatchery fish were a 31-10-1 network (31 input variables, 10 hidden neurons and 1 output) and decay set to 0.1 for both models.

\section{Influences on Precocious Maturation in Wild Fish}

My models identified a combination of freshwater, near-shore, and offshore marine variables that influenced precocious maturation in wild origin fish. The majority of 
freshwater variables ranked low in the variable importance measures, with the exception of adult return counts, Pacific Northwest Index during outmigration, and the maximum temperature during the first spring (Figure 3.3). There was a non-linear, positive relationship between adult return counts and the probability of maturing precociously, with fish experiencing adult returns $>100,000$ during their broodyear twice as likely to become precocious compared to fish experiencing returns counts $<40,000$ (Figure 3.4a). There was no discernable pattern of the Pacific Northwest Index during outmigration and the maximum temperature during spring with precociousness in partial dependence plots (Figure 3.4b,c). Because the Pacific Northwest Index and the maximum temperature ranked high in variable importance, but showed no pattern using one-way partial dependence plots (i.e. the marginal effect of a single variable after averaging out the effects of other variables), I hypothesized that there were interactive relationships between one or more other variables. Given that others have demonstrated the importance of body size and precociousness (Heath et al. 1997, Silverstein et al. 1998, Scheuerell 2005), I explored this relationship further by plotting two-way partial dependence plots between fish length at the time of marking and each of the high-ranking predictor variables (Figure 3.5). These plots revealed that large-bodied wild Chinook salmon $(>160 \mathrm{~mm})$ were more likely to become precocious when adult abundance was high $(>100,000)$, when freshwater environments were warmer and dryer (i.e. positive Pacific Northwest Index), and when maximum spring temperatures exceeded $15^{\circ} \mathrm{C}$ (Figure 3.5a-c). 
In general, near-shore marine variables had the largest influence on precocious maturation in wild spring Chinook. The multivariate El Niño - Southern Oscillation between January - June of return year, mean coastal upwelling during July - December of outmigration year, and mean coastal upwelling during January - June of return year had the highest relative importance in my models (Figure 3.3). There were non-linear relationships between coastal upwelling during July - December of outmigration year and coastal upwelling between January - June of return year with precociousness, but no discernable effect of El Niño - Southern Oscillation between January - June of return year on precociousness (Figure 3.4d, f). Fish experiencing positive coastal upwelling, regardless of timing, were more likely to become precocious than fish experiencing coastal downwelling (Figure 3.4e-f). Large fish $(>150 \mathrm{~mm}$ ) were more likely to become precocious when marine water temperatures were cooler (i.e. negative El Niño Southern Oscillation) and during periods of coastal upwelling between January - June of return year, while fish experiencing strong coastal upwelling between July - December of outmigration year were more likely to become precocious regardless of size (Figure 3.5df).

Offshore marine variables were intermediate between freshwater and near-shore marine variables in importance (Figure 3.3). Pacific Decadal Oscillation during the return year, regardless of season, ranked highest among the offshore variables, and the probability of maturing as a precocious fish increased during periods of cool sea surface temperatures and increased productivity (i.e. negative Pacific Decadal Oscillation (Figure 3.3, 4g-i). When fish were large $(>160 \mathrm{~mm})$, they were more likely to become 
precocious when Pacific Decadal Oscillations were negative, regardless of whether fish were emigrating, immigrating, or time of year (Figure 3.5g-i).

\section{Influences on Precocious Maturation in Hatchery Fish}

Precocious maturation in hatchery origin Chinook salmon was influenced by a combination of freshwater, near-shore and offshore variables. As with wild fish, freshwater variables generally ranked lowest in importance measures (Figure 3.6). The Pacific Northwest Index and the maximum spring temperature were the most influential freshwater variables. There was no discernable effect of the top three freshwater variables on precociousness in partial dependence plots (Figure 3.7a-c). Two-way partial dependence plots between fish length at the time of marking and each of the highestranking freshwater variables showed only slight interaction effects, with larger hatchery fish $(>150 \mathrm{~mm})$ having a nominally higher probability of maturing precociously when maximum spring temperatures were below $<16^{\circ} \mathrm{C}$ (Figure $3.8 \mathrm{c}$ ).

Near-shore marine variables, in general, ranked intermediate in variable importance measures for precocious hatchery fish. The multivariate El Niño - Southern Oscillation between January - June of outmigration year and July - December of return year, as well as the coastal upwelling index for January - June of return year ranked the highest of the near-shore variables (Figure 3.6). For hatchery fish, there was a very slight increase in the probability of becoming precocious when sea surface temperatures were warmer (i.e. positive El Niño - Southern Oscillation) between January - June of outmigration year (Figure 3.7d). There was a slight decrease in the probability of 
becoming precocious during coastal downwelling between January - June of return year and with warmer sea surface temperatures during July - December of return year (Figures 7e,f). Two-way partial dependence plots between fish length and each of the highest-ranking near-shore variables show little interaction effects (Figure 3.8d-f).

Offshore marine variables generally ranked the highest in importance measures from random forest and artificial neural network models. The Pacific Decadal Oscillation for all seasons during return and outmigration years were among the highest ranked offshore variables. No pattern emerged in partial dependence plots for the Pacific Decadal Oscillation during return year (Figure $3.7 \mathrm{~g}, \mathrm{~h}$ ) and only a slight increase in the probability of returning as a precocious fish when the Pacific Decadal Oscillation during January - June of outmigration year was positive (Figure 3.7i).

\section{Discussion}

I found that the precocious maturation in Chinook salmon has varied over time and appears to be influenced by freshwater and marine variables regardless of wild or hatchery origin. My results generally support my hypothesis that maturation in wild fish is influenced by factors that affect growth rates, specifically marine conditions known to increase trophic productivity from the bottom up (i.e. cold, high salinity, nutrient rich waters) (Table 3.1). I found that, in general, larger wild fish were more likely to mature early when experiencing conditions that provide growth opportunities. Size did not interact with environmental variables in hatchery fish, suggesting that these fish achieve the sizes required for precocious maturation prior to encountering the resource-rich 
marine environment. Precocious maturation in hatchery fish was broadly influenced by a combination of freshwater and marine variables that support growth but was highly variable. Lastly, wild Chinook also displayed a density-dependent response that was contrary to my predictions: I observed an increased probability of precocious maturation among larger fish when adult returns were high. Overall, my findings suggest that the first few months of ocean residence play a critical role in determining the life-history trajectory of wild Chinook salmon and to a lesser degree hatchery Chinook.

Over the 17 years of my study, the proportion of precocious Chinook salmon in the Columbia River basin has varied but is substantially higher in hatchery origin fish (Figure 3.1). Hatchery rearing practices have been shown to produce high proportions of precocious fish by altering dietary lipid levels, feeding rates, water temperatures, and criteria for how broodstock is selected (Larsen et al. 2004, Harstad et al. 2014). Past research found precocious spring Chinook salmon originating from all surveyed hatcheries in the Columbia basin, with annual rates ranging from $7-72 \%$ (Harstad et al. 2014). Much less is known about historical or current proportions of precocious maturation in wild origin fish. Precociousness in wild populations is likely affected by uncontained domestication selection occurring in the hatchery environment and introgression with hatchery fish on the spawning grounds (Reisenbichler and Rubin 1999, Sloat et al. 2014).

My results indicate that precocious maturation can be influenced by conditions experienced within both the freshwater and marine environments. I tested the importance of marine conditions by first eliminating marine variables during the year of return from 
my full models, and then removing all marine variables (Table 3.2). For wild fish, the ability to predict precocious maturation decreased following the removal of marine variables during return year and all marine variables in both models. Hatchery fish were invariant to removing marine variables during return year and moderately affected by removing all marine variables. I interpreted these findings three ways: 1) environmental conditions can advance or delay precocious maturation for fish entering the marine environment; 2) hatchery fish are less affected by marine conditions than wild fish, likely as a result of different physiological condition of the fish reaching the ocean; and 3) wild fish returning to freshwater in the spring are affected by marine conditions experienced between January - June of return year. Two critical periods, in the spring and fall (8-12 months prior to final maturation), have been proposed where Chinook salmon assess their developmental potential based on size, growth rate, and/or stored lipids that influence the maturation timing of each fish individually (Silverstein et al. 1998, Shearer and Swanson 2000, Day and Rowe 2002, Larsen et al. 2004, 2013). My results support the 'critical period' hypothesis for wild fish and suggest that favorable marine conditions experienced in summer and fall may initiate maturation (especially in larger fish) and conditions experienced in winter and spring influence whether maturation continues or is delayed (Silverstein et al. 1998). This finding may help inform fisheries managers responsible for modeling and predicting adult return counts to the Columbia Basin.

The results are consistent with my hypothesis and the findings of others: smolt length is associated with precocious maturation in wild and hatchery fish (Silverstein et al. 1998, Scheuerell 2005, Larsen et al. 2006, Shearer et al. 2006). However, fish length 
ranked low in relative importance in all my models (Figures 3, 6). My interpretation of this finding is that length is a proxy for size, growth rate, and/or stored lipids and can be generally used to identify fish that have surpassed a maturation size threshold. For fish that have exceeded this threshold, experiencing environmental conditions conducive to further growth advances them on the maturation pathway (Hankin et al. 1993, Silverstein et al. 1998). For fish that have not surpassed the size threshold, maturation is delayed until the next critical assessment period.

I found that larger wild fish had a higher probability of precocious maturation than smaller fish when encountering environmental conditions conducive to high growth rates. Consistent with my predictions I found that periods of positive coastal upwelling and cooler sea surface temperatures increased the probability of precociousness in wild Chinook (Figure 3.5d-i). Positive coastal upwelling represents cold, high-salinity, nutrient rich water being transported to the surface, resulting in increased trophic productivity in a bottom-up fashion. Negative values for both multivariate El Niño Southern Oscillation Index and the Pacific Decadal Oscillation are related to sea surface temperatures, nutrient upwelling, which partially determines prey availability, ocean growth, predation rates, and salmon abundance in the northeastern Pacific Ocean (Greene et al. 2005, Peterson et al. 2006). Trophic conditions (i.e. abundance and composition of secondary producers) during the early stages of salmon ocean residence have been found to affect growth (Tomaro et al. 2012). Following saltwater transition, high growth rates of precocious fish have been inferred from hatchery fish and collections on spawning grounds (Johnson et al. 2012). I found that when marine conditions are favorable for 
growth (i.e. positive CUI, negative MEI and PDO), wild fish larger than $150 \mathrm{~mm}$ are more likely to precociously mature (Figure $3.5 \mathrm{~d}-\mathrm{i}$ ).

My hatchery models achieved high prediction accuracies (Table 3.2); however, wide confidence intervals indicate broad variability in hatchery fish responses to environmental variables (Figure 3.7). I therefore interpret my hatchery models cautiously and refer the readers to the extensive work of Larsen et al. (2004, 2006, 2010 and 2013) regarding precociousness in hatchery origin Chinook salmon. One explanation for the variability observed in hatchery fish is that hatcheries range greatly in their goals and management strategies (Kostow 2009). Differences in the management strategies and desired outcomes of federal, state, and tribal hatcheries that raise fish for supplementation or conservation ends, appear to produce fish that interact in a wide variety of ways with their environment compared to wild fish. My results indicate that segregated hatcheries (those using only hatchery origin fish as broodstock) and harvest programs (goal of producing anadromous adults for harvest) have a larger effect on precocious maturation than integrated hatcheries (those using both hatchery and wild fish as broodstock) and conservation programs (stated goal of conserving genetic lineages; Figure 3.6b). Harstad et al. (2014) found fewer age 2 precocious fish in segregated hatchery programs in the Columbia River basin and hypothesized that domestication selection may result in an increase in the maturation size threshold of age 2 precocious fish. In contrast to wild fish, I found no clear interaction between size and high ranking environmental variables (Figure 3.8). 
Interestingly, precociousness in wild Chinook salmon appeared to have a densitydependent response in the freshwater environment (Table 3.1). I found that the probability of precocious maturation increased among large fish in years with high adult return counts (i.e. $>60,000$ returning adults; Figure 3.4a,5a). A plausible explanation is that adult return counts affect resource acquisition of smolts in resource-limited freshwater environments (Weitkamp et al. 2015). Past research has shown that juvenile growth can be affected by density-dependent competition for limited resources by intracohort conspecifics (Cowan et al. 2000) and an increase in population size of Pacific salmon could lead to a decrease in per-capita food availability (Morita and Fukuwaka 2007). My results indicate that in years with high adult returns, larger wild fish (>150 $\mathrm{mm}$ ) are more likely to become precocious than any fish (regardless of size) during years with low or intermediate adult return counts. Consistent with my predictions but in contrast to my findings, low adult abundance in the John Day River led to fewer, larger smolt and younger ages at maturation (Tattam et al. 2015). A second plausible explanation for the effect of adult returns on precociousness is that marine-derived nutrient deficiencies in freshwater may influence growth rates of rearing juveniles. Scheuerell et al (2005) found that in 1999 Chinook smolts in the Snake River exported more phosphorus than adults imported. In years with high adult returns, nutrient subsidies may increase freshwater productivity, allowing fish more growth opportunities.

\section{Conclusion}


There appears to be a temporally dynamic trade-off between the adult and precocious reproductive strategies, which can be facilitated by a combination of biological and environmental conditions experienced across environments. I found that precocious maturation, as observed in wild Chinook salmon, is likely affected by densitydependence in freshwater environments and resource abundance in the marine environment. Most previous work has been conducted on the occurrence of precocious fish produced from hatcheries and the long-term effects of altered rearing practices and domestication selection are still largely unknown (Larsen et al. 2004, Kostow 2009). Studies have shown that altering ration size and/or water temperature during critical developmental periods may reduce the occurrence of precocious maturation in hatcheries (Shearer and Swanson 2000, Larsen et al. 2004), but to my knowledge the majority of hatcheries practices have remained unchanged.

There are possible ecological and economic consequences that may result from the increasing occurrence of precocious fish (Larsen et al. 2004). Ecologically, there is strong evidence that anthropogenic alterations within the river environment are resulting in the high proportions of precocious fish (Larsen et al. 2005, Larsen et al. 2006, 2013, Harstad et al. 2014). As a result of their smaller body size, precocious fish transport fewer marine-derived nutrients from the ocean to freshwater habitats, further depressing nutrient subsidies in freshwater ecosystems. Marine-derived nutrients support diverse food webs and can increase the survival and growth of salmon during freshwater rearing (Scheuerell et al. 2005). A reduction in these nutrients may result in increased densitydependent processes in freshwater ecosystems by lowering overall productivity and 
carrying capacity (Scheuerell et al. 2005). Additionally, precocious fish spend more time in freshwater and may compete with or displace other freshwater species vying for limited resources (Larsen et al. 2004). Economically, high rates of hatchery produced precocious fish represents a tremendous loss of investment because these fish do not contribute to the adult salmon fishery (Larsen et al. 2004). Between $1997-2000$, a single hatchery supplementation program in the Columbia River basin released approximately 570,000 precocious fish that were intended for the adult fishery (Larsen et al. 2004). Further studies, specifically those investigating wild fish, are needed to better understand the mechanisms and long-term changes in life history strategies of Chinook salmon (Weitkamp et al. 2015). Considering my findings of the importance of the ocean environment on this alternative reproductive strategy, the implications of climate change and other anthropogenic stressors in the marine environment should be a topic of further study. 


\section{References}

Ballings, M., and D. Van den Poel. 2016. interpretR: Binary Classifier and Regression Model Interpretation Function.

Beckman, B. R., and D. A. Larsen. 2005. Upstream migration of minijack (age-2) Chinook Salmon in the Columbia River: behavior, abundance, distribution, and origin. Transactions of the American Fisheries Society 134:1520-1541.

Berejikian, B. A., D. M. Van Doornik, R. C. Endicott, T. L. Hoffnagle, E. P. Tezak, M. E. Moore, and J. Atkins. 2010. Mating success of alternative male phenotypes and evidence for frequency-dependent selection in Chinook salmon, Oncorhynchus tshawytscha. Canadian Journal of Fisheries and Aquatic Sciences 67:1933-1941.

Clarke, W. C., and J. Blackburn. 1994. Effect of growth on early sexual maturation in stream-type chinook salmon (Oncorhynchus tshawytscha). Aquaculture 121:95103.

Cowan, J. H., K. A. Rose, and D. R. DeVries. 2000. Is density-dependent growth in young-of-the-year fishes a question of critical weight? Reviews in Fish Biology and Fisheries 10:61-89.

Cutler, D. R., T. C. Edwards Jr, K. H. Beard, A. Cutler, K. T. Hess, J. Gibson, and J. J. Lawler. 2007. Random forests for classification in ecology. Ecology 88:27832792.

Day, T., and L. Rowe. 2002. Developmental thresholds and the evolution of reaction norms for age and size at life-history transitions. The American Naturalist $159: 338-350$. 
Ebbesmeyer, C. C., and R. M. Strickland. 1995. Oyster condition and climate: evidence from Willapa Bay. Washington Sea Grant Program.

Greene, C. M., D. W. Jensen, G. R. Pess, E. A. Steel, and E. Beamer. 2005. Effects of environmental conditions during stream, estuary, and ocean residency on Chinook Salmon return rates in the Skagit River, Washington. Transactions of the American Fisheries Society 134:1562-1581.

Greenwell, B. M. 2017. pdp: An R Package for Constructing Partial Dependence Plots. $R$ Journal 9:421-436.

Gross, M. R. 1991. Salmon breeding behavior and life history evolution in changing environments. Ecology 72:1180-1186.

Hankin, D. G., J. W. Nicholas, and T. W. Downey. 1993. Evidence for inheritance of age of maturity in chinook salmon (Oncorhynchus tshawytscha). Canadian Journal of Fisheries and Aquatic Sciences 50:347-358.

Harstad, D. L., D. A. Larsen, and B. R. Beckman. 2014. Variation in minijack rate among hatchery populations of Columbia River Basin Chinook Salmon. Transactions of the American Fisheries Society 143:768-778.

Heath, D. D., R. H. Devlin, J. W. Heath, R. M. Sweeting, B. A. McKeown, and G. K. Iwama. 1997. Growth and hormonal changes associated with precocious sexual maturation in male chinook salmon (Oncorhynchus tshawytscha (Walbaum)). Journal of Experimental Marine Biology and Ecology 208:239-250. 
Heath, D. D., L. Rankin, C. A. Bryden, J. W. Heath, and J. M. Shrimpton. 2002. Heritability and Y-chromosome influence in the jack male life history of chinook salmon (Oncorhynchus tshawytscha). Heredity 89:311-317.

Hopkins, C., and M. Unwin. 1997. The effect of restricted springtime feeding on growth and maturation of freshwater-reared Chinook salmon, Oncorhynchus tshawytscha (Walbaum). Aquaculture Research 28:545-549.

Johnson, J., T. Johnson, and T. Copeland. 2012. Defining life histories of precocious male parr, minijack, and jack Chinook salmon using scale patterns. Transactions of the American Fisheries Society 141:1545-1556.

Jonsson, B., N. Jonsson, and A. G. Finstad. 2013. Effects of temperature and food quality on age and size at maturity in ectotherms: an experimental test with Atlantic salmon. Journal of Animal Ecology 82:201-210.

Kostow, K. 2009. Factors that contribute to the ecological risks of salmon and steelhead hatchery programs and some mitigating strategies. Reviews in Fish Biology and Fisheries 19:9-31.

Kuhn, M. 2008. Caret package. Journal of Statistical Software 28:1-26.

Larsen, D. A., B. R. Beckman, K. A. Cooper, D. Barrett, M. Johnston, P. Swanson, and W. W. Dickhoff. 2004. Assessment of high rates of precocious male maturation in a spring Chinook salmon supplementation hatchery program. Transactions of the American Fisheries Society 133:98-120.

Larsen, D. A., B. R. Beckman, C. R. Strom, P. J. Parkins, K. A. Cooper, D. E. Fast, and W. W. Dickhoff. 2006. Growth modulation alters the incidence of early male 
maturation and physiological development of hatchery-reared spring Chinook salmon: a comparison with wild fish. Transactions of the American Fisheries Society 135:1017-1032.

Larsen, D. A., D. L. Harstad, C. R. Strom, M. V. Johnston, C. M. Knudsen, D. E. Fast, T. N. Pearsons, and B. R. Beckman. 2013. Early life history variation in hatcheryand natural-origin spring Chinook salmon in the Yakima River, Washington. Transactions of the American Fisheries Society 142:540-555.

Larsen, D., Beckman, B., Strom, C., Parkins, P., Cooper, K., Johnston, M., Fast, D., and Dickhoff, W. 2005. Growth rate modulation in spring Chinook salmon supplementation. Page 73. 2004-2005 Annual Report.

Mantua, N. J., S. R. Hare, Y. Zhang, J. M. Wallace, and R. C. Francis. 1997. A Pacific interdecadal climate oscillation with impacts on salmon production. Bulletin of the American Meteorological Society 78:1069-1079.

Mims, M., J. Olden, Z. Shattuck, and N. Poff. 2010. Life history trait diversity of native freshwater fishes in North America. Ecology of Freshwater Fish 19:390-400.

Morita, K., and M. Fukuwaka. 2007. Why age and size at maturity have changed in Pacific salmon. Marine Ecology Progress Series 335:289-294.

NOAA Fisheries. 2008. Biological Opinion (BiOp) on the operation of the Federal Columbia River Power System (FCRPS). U.S. Department of Commerce, National Marine Fisheries Service, Northwest Regional Office, Seattle, Washington. 
Olden, J. D., and D. A. Jackson. 2002. A comparison of statistical approaches for modelling fish species distributions. Freshwater Biology 47:1976-1995.

Olden, J. D., J. J. Lawler, and N. L. Poff. 2008. Machine learning methods without tears: A primer for ecologists. The Quarterly Review of Biology 83:171-193.

Oregon State University. 2016 Prism Climate Group. http://prism.oregonstate.edu/ Accessed: March 2016.

Peterson, W. T., R. C. Hooff, C. A. Morgan, K. L. Hunter, E. Casillas, and J. W. Ferguson. 2006. Ocean conditions and salmon survival in the northern California Current. www.nwfsc.noaa. gov/research/divisions/fed/ecosysrep.pdf [accessed 5 June 2009].

Power, G. 1986. Physical influences on age at maturity of Atlantic salmon (Salmo salar): a synthesis of ideas and questions. Salmonid age at maturity. Canadian Special Publication of Fisheries and Aquatic Sciences 89:91-101.

Prentice, E. F., T. A. Flagg, C. S. McCutcheon, D.F. Brastow. 1990. PIT-tag monitoring systems for hydroelectric dams and fish hatcheries. American Fisheries Society Symposium 7:323-334.

R Core Team. 2016. R: A Language and Environment for Statistical Computing. R Foundation for Statistical Computing, Vienna, Austria.

Reisenbichler, R. R., and S. P. Rubin. 1999. Genetic changes from artificial propagation of Pacific salmon affect the productivity and viability of supplemented populations. ICES Journal of Marine Science 56:459-466. 
Scheuerell, M. D. 2005. Influence of juvenile size on the age at maturity of individually marked wild Chinook salmon. Transactions of the American Fisheries Society 134:999-1004.

Scheuerell, M. D., P. S. Levin, R. W. Zabel, J. G. Williams, and B. L. Sanderson. 2005. A new perspective on the importance of marine-derived nutrients to threatened stocks of Pacific salmon (Oncorhynchus spp.). Canadian Journal of Fisheries and Aquatic Sciences 62:961-964.

Scheuerell, M. D., and J. G. Williams. 2005. Forecasting climate-induced changes in the survival of Snake River spring/summer Chinook salmon (Oncorhynchus tshawytscha). Fisheries Oceanography 14:448-457.

Schwing, F. B., M. O’Farrell, J. M. Steger, and K. Baltz. 1996. Coastal Upwelling indices west coast of North America. NOAA Tech. Rep., National Marine Fisheries Service Southwest Fisheries Science Center 231:144p.

Sharma, S., and D. A. Jackson. 2008. Predicting smallmouth bass (Micropterus dolomieu) occurrence across North America under climate change: a comparison of statistical approaches. Canadian Journal of Fisheries and Aquatic Sciences $65: 471-481$.

Shearer, K. D., and P. Swanson. 2000. The effect of whole body lipid on early sexual maturation of $1+$ age male chinook salmon (Oncorhynchus tshawytscha). Aquaculture 190:343-367.

Shearer, K., P. Parkins, B. Gadberry, B. Beckman, and P. Swanson. 2006. Effects of growth rate/body size and a low lipid diet on the incidence of early sexual 
maturation in juvenile male spring Chinook salmon (Oncorhynchus tshawytscha). Aquaculture 252:545-556.

Silverstein, J. T., K. D. Shearer, W. W. Dickhoff, and E. M. Plisetskaya. 1998. Effects of growth and fatness on sexual development of chinook salmon (Oncorhynchus tshawytscha) parr. Canadian Journal of Fisheries and Aquatic Sciences 55:23762382.

Sloat, M. R., D. J. Fraser, J. B. Dunham, J. A. Falke, C. E. Jordan, J. R. McMillan, and H. A. Ohms. 2014. Ecological and evolutionary patterns of freshwater maturation in Pacific and Atlantic salmonines. Reviews in Fish Biology and Fisheries 24:689707.

Smith, S. G., W. D. Muir, E. E. Hockersmith, R. W. Zabel, R. J. Graves, C. V. Ross, W. P. Connor, and B. D. Arnsberg. 2003. Influence of river conditions on survival and travel time of Snake River sub-yearling fall Chinook salmon. North American Journal of Fisheries Management 23:939-961.

Stearns, S. C. 1976. Life-history tactics: A review of the ideas. Quarterly Review of Biology: 3-47.

Tattam, I. A., J. R. Ruzycki, J. L. McCormick, and R. W. Carmichael. 2015. Length and condition of wild Chinook salmon smolts influence age at maturity. Transactions of the American Fisheries Society 144:1237-1248.

Taylor, E. 1990. Environmental correlates of life-history variation in juvenile chinook salmon, Oncorhynchus tshawytscha (Walbaum). Journal of Fish Biology 37:1-17. 
Thorpe, J. 1987. Smolting versus residency: developmental conflict in salmonids. American Fisheries Society Symposium 1:244-252.

Thorpe, J. E. 2007. Maturation responses of salmonids to changing developmental opportunities. Marine Ecology Progress Series 335:285-288.

Tomaro, L. M., D. J. Teel, W. T. Peterson, and J. A. Miller. 2012. When is bigger better? Early marine residence of middle and upper Columbia River spring Chinook salmon. Marine Ecology Progress Series, 452:237-252.

University of Washington. 2014. Columbia River data access in real time. http://www.cbr.washington.edu/dart. Accessed: December 2014

Viera, A. J., and J. M. Garrett. 2005. Understanding interobserver agreement: the kappa statistic. Family Medicine 37:360-363.

Vollestad, L. A., J. Peterson, and T. P. Quinn. 2004. Effects of freshwater and marine growth rates on early maturity in male coho and Chinook salmon. Transactions of the American Fisheries Society 133:495-503.

Weitkamp, L. A., D. J. Teel, M. Liermann, S. A. Hinton, D. M. Van Doornik, and P. J. Bentley. 2015. Stock-specific size and timing at ocean entry of Columbia River juvenile Chinook salmon and steelhead: Implications for early ocean growth. Marine and Coastal Fisheries 7:370-392.

Wenger, S. J., D. J. Isaak, C. H. Luce, H. M. Neville, K. D. Fausch, J. B. Dunham, D. C. Dauwalter, M. K. Young, M. M. Elsner, B. E. Rieman, A. F. Hamlet, and J. E. Williams. 2011. Flow regime, temperature, and biotic interactions drive 
differential declines of trout species under climate change. Proceedings of the National Academy of Sciences.

Wilbur, H. M., and J. P. Collins. 1973. Ecological aspects of amphibian metamorphosis. Science 182:1305.

Williams, J. G., R. W. Zabel, R. S. Waples, J. A. Hutchings, and W. P. Connor. 2008. Potential for anthropogenic disturbances to influence evolutionary change in the life history of a threatened salmonid. Evolutionary Applications 1:271-285.

Winemiller, K. O., and K. A. Rose. 1992. Patterns of life-history diversification in North American fishes: implications for population regulation. Canadian Journal of Fisheries and Aquatic Sciences 49:2196-2218.

Wolter, K., and M. S. Timlin. 1998. Measuring the strength of ENSO events: how does 1997/98 rank? Weather 53:315-324. 
Table 3.1. A priori predictions of the influence of freshwater, nearshore marine, and offshore marine variables on precocious maturation in Chinook salmon. Predicted influence indicates how an increase in each variable will affect precociousness.

\begin{tabular}{|c|c|c|c|}
\hline Environment & Variable & Description & $\begin{array}{l}\text { Predicted } \\
\text { Influence } \\
\quad \text { on } \\
\text { Precocious } \\
\text { Maturation } \\
\end{array}$ \\
\hline $\begin{array}{l}\text { Near-Shore } \\
\text { Marine }\end{array}$ & $\begin{array}{l}\text { Coastal Upwelling Index } \\
\text { (CUI) } \\
\text { Multivariate El Niño - } \\
\text { Southern Oscillation } \\
\text { (MEI) }\end{array}$ & $\begin{array}{l}(+) \text { cold, nutrient-rich water upwelling } \\
(-) \text { warm surface water downwelling } \\
(+) \text { warmer sea surface temperatures, El } \\
\text { Niño conditions (OR, WA, BC) } \\
(-) \text { cooler sea surface temperatures, } \\
\text { La Niña conditions (OR, WA, BC) }\end{array}$ & $\begin{array}{l}\uparrow \\
\downarrow\end{array}$ \\
\hline $\begin{array}{l}\text { Off-Shore } \\
\text { Marine }\end{array}$ & $\begin{array}{l}\text { Pacific Decadal } \\
\text { Oscillation (PDO) }\end{array}$ & $\begin{array}{l}(+) \text { warm sea surface temperatures, less } \\
\text { productive periods }(\mathrm{OR}, \mathrm{WA}, \mathrm{BC}) \\
(-) \text { cool sea surface temperatures, } \\
\text { productive periods }(\mathrm{OR}, \mathrm{WA}, \mathrm{BC})\end{array}$ & $\downarrow$ \\
\hline \multirow[t]{12}{*}{ Freshwater } & Pacific Northwest Index & $\begin{array}{l}(+) \text { warmer and dryer terrestrial } \\
\text { environment } \\
(-) \text { cooler and wetter terrestrial } \\
\text { environment }\end{array}$ & $\downarrow$ \\
\hline & Adult Return Count & $\begin{array}{l}\text { Coarse scale adult returns to Snake River, } \\
\text { Upper and Lower Columbia River }\end{array}$ & $\downarrow$ \\
\hline & Temperature & Estimated air temperature at release sites & $\uparrow$ \\
\hline & Precipitation & Estimated precipitation at release sites & $\uparrow$ \\
\hline & Distance to Ocean & $\begin{array}{l}\text { River distance from release sites to ocean } \\
(\mathrm{Rkm})\end{array}$ & 个 \\
\hline & Latitude & Latitude of release site & $\downarrow$ \\
\hline & Longitude & Longitude of release site & $\uparrow$ \\
\hline & Length & Length $(\mathrm{mm})$ of smolt at time of tagging & $\uparrow$ \\
\hline & Program Type ${ }^{1}$ & $\begin{array}{l}\text { Integrated: Uses both hatchery and wild } \\
\text { origin broodstock }\end{array}$ & $\downarrow$ \\
\hline & & $\begin{array}{l}\text { Segregated: Uses only hatchery origin } \\
\text { broodstock }\end{array}$ & $\uparrow$ \\
\hline & Intended Fish Use ${ }^{1}$ & $\begin{array}{l}\text { Harvest: Intended for salmon fisheries } \\
\text { harvest }\end{array}$ & $\uparrow$ \\
\hline & & $\begin{array}{l}\text { Conservation: Intended to augment } \\
\text { depleted wild populations }\end{array}$ & $\downarrow$ \\
\hline
\end{tabular}

${ }^{1}$ (Harstad et al. 2014) 
Table 3.2. Results from 10 -fold cross-validated random forest and artificial neural network models for wild and hatchery fish. Metrics for evaluating statistical models were overall percent of fish correctly classified (PCC), specificity (correct classification of adults), sensitivity (correct classification of precocious fish) and Cohen's Kappa statistic ( \pm Kappa SD from cross-validation). Variables included in the models were $F=$ freshwater $(n=16), M=$ marine during outmigration year $(n=6)$ and $M R=$ marine during return year $(n=7)$. Bold indicates models with the highest prediction accuracies.

\begin{tabular}{|c|c|c|c|c|c|c|}
\hline $\begin{array}{l}\text { Fish } \\
\text { Origin }\end{array}$ & Model & $\begin{array}{l}\text { Variables } \\
\text { Included } \\
\text { in the } \\
\text { Model } \\
\end{array}$ & $\begin{array}{c}\text { Percent } \\
\text { Correctly } \\
\text { Classified } \\
(\text { PCC }) \\
\end{array}$ & $\begin{array}{c}\text { Correct } \\
\text { Classification } \\
\text { of Adults } \\
\text { (Specificity) }\end{array}$ & $\begin{array}{c}\text { Correct } \\
\text { Classification } \\
\text { of Precocious } \\
\text { (Sensitivity) }\end{array}$ & $\begin{array}{c}\text { Cohen's } \\
\text { Kappa } \\
\text { Statistic }\end{array}$ \\
\hline \multirow[t]{6}{*}{ Wild } & Random & $\mathrm{F}, \mathrm{M}, \mathrm{MR}$ & $99.3 \%$ & $100 \%$ & $94.1 \%$ & $0.96( \pm 0.02)$ \\
\hline & Forest & $\mathrm{F}, \mathrm{M}$ & $98.1 \%$ & $99.9 \%$ & $84.3 \%$ & $0.90( \pm 0.02)$ \\
\hline & & $\mathrm{F}$ & $98.4 \%$ & $99.9 \%$ & $86.9 \%$ & $0.91(+0.02)$ \\
\hline & Artificial & $\mathrm{F}, \mathrm{M}, \mathrm{MR}$ & $99.6 \%$ & $100 \%$ & $96.7 \%$ & $0.98( \pm 0.01)$ \\
\hline & Neural & $\mathrm{F}, \mathrm{M}$ & $99.3 \%$ & $100 \%$ & $93.5 \%$ & $0.96( \pm 0.03)$ \\
\hline & Network & $\mathrm{F}$ & $96.9 \%$ & $99.3 \%$ & $78.3 \%$ & $0.83(+0.07)$ \\
\hline \multirow{6}{*}{ Hatchery } & Random & $\mathrm{F}, \mathrm{M}, \mathrm{MR}$ & $99.9 \%$ & $100 \%$ & $99.7 \%$ & $0.99( \pm 0.02)$ \\
\hline & Forest & $\mathrm{F}, \mathrm{M}$ & $99.9 \%$ & $99.9 \%$ & $99.7 \%$ & $0.99( \pm 0.01)$ \\
\hline & & $\mathrm{F}$ & $99.7 \%$ & $99.9 \%$ & $99.4 \%$ & $0.99( \pm 0.01)$ \\
\hline & Artificial & $\mathrm{F}, \mathrm{M}, \mathrm{MR}$ & $99.8 \%$ & $100 \%$ & $99.6 \%$ & $0.99( \pm 0.02)$ \\
\hline & Neural & $\mathrm{F}, \mathrm{M}$ & $99.9 \%$ & $100 \%$ & $99.6 \%$ & $0.96(+0.03)$ \\
\hline & Network & $\mathrm{F}$ & $94.7 \%$ & $97.7 \%$ & $89.5 \%$ & $0.88( \pm 0.04)$ \\
\hline
\end{tabular}



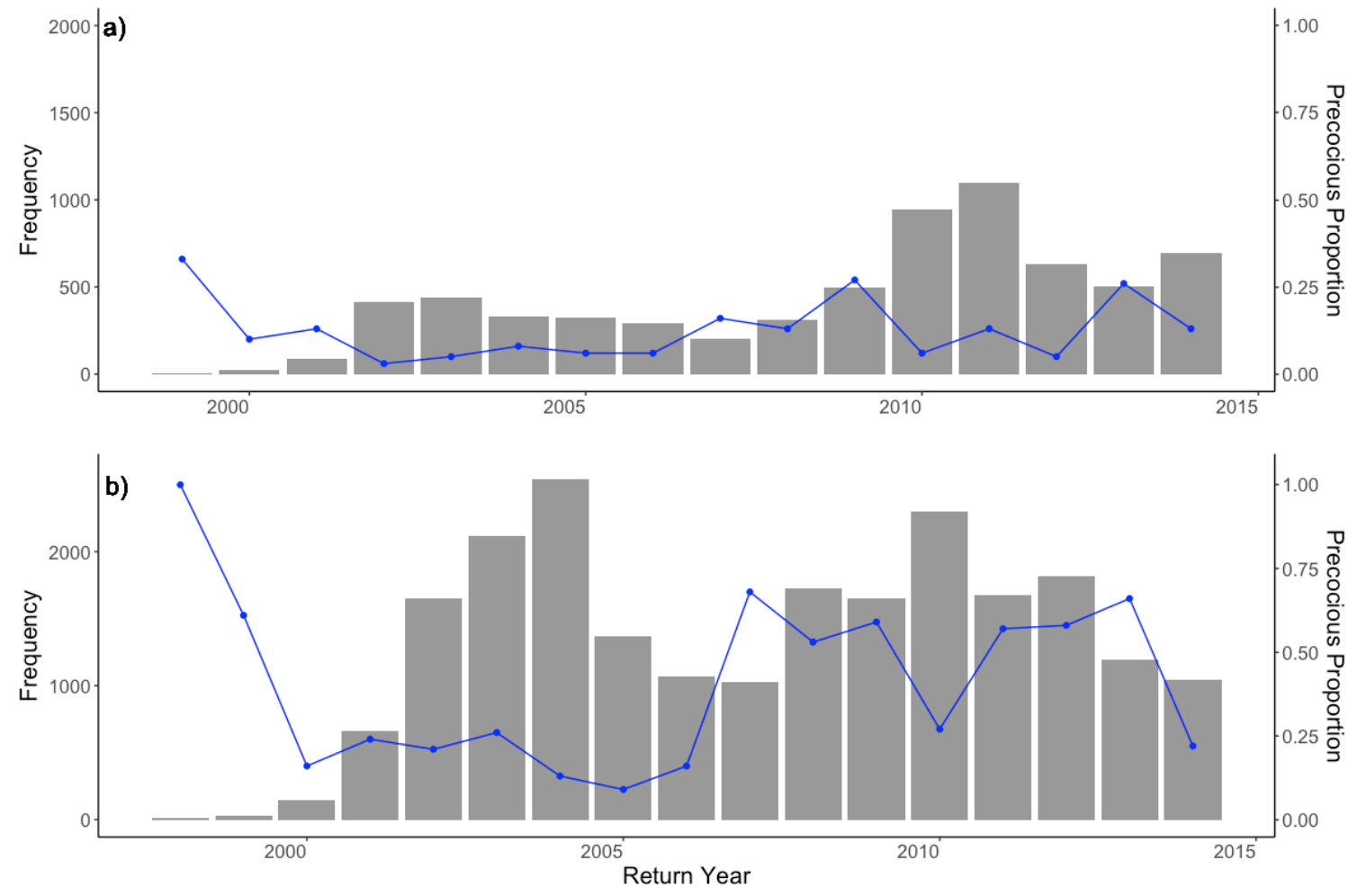

Figure 3.1. Frequency (left; grey bars) and proportion of precocious (right; blue circles) PIT tagged a) wild and b) hatchery fish returning through the Bonneville Dam between 1998 - 2014. Note: in 199813 out of 13 hatchery fish returning were precocious thus equaling $100 \%$. 


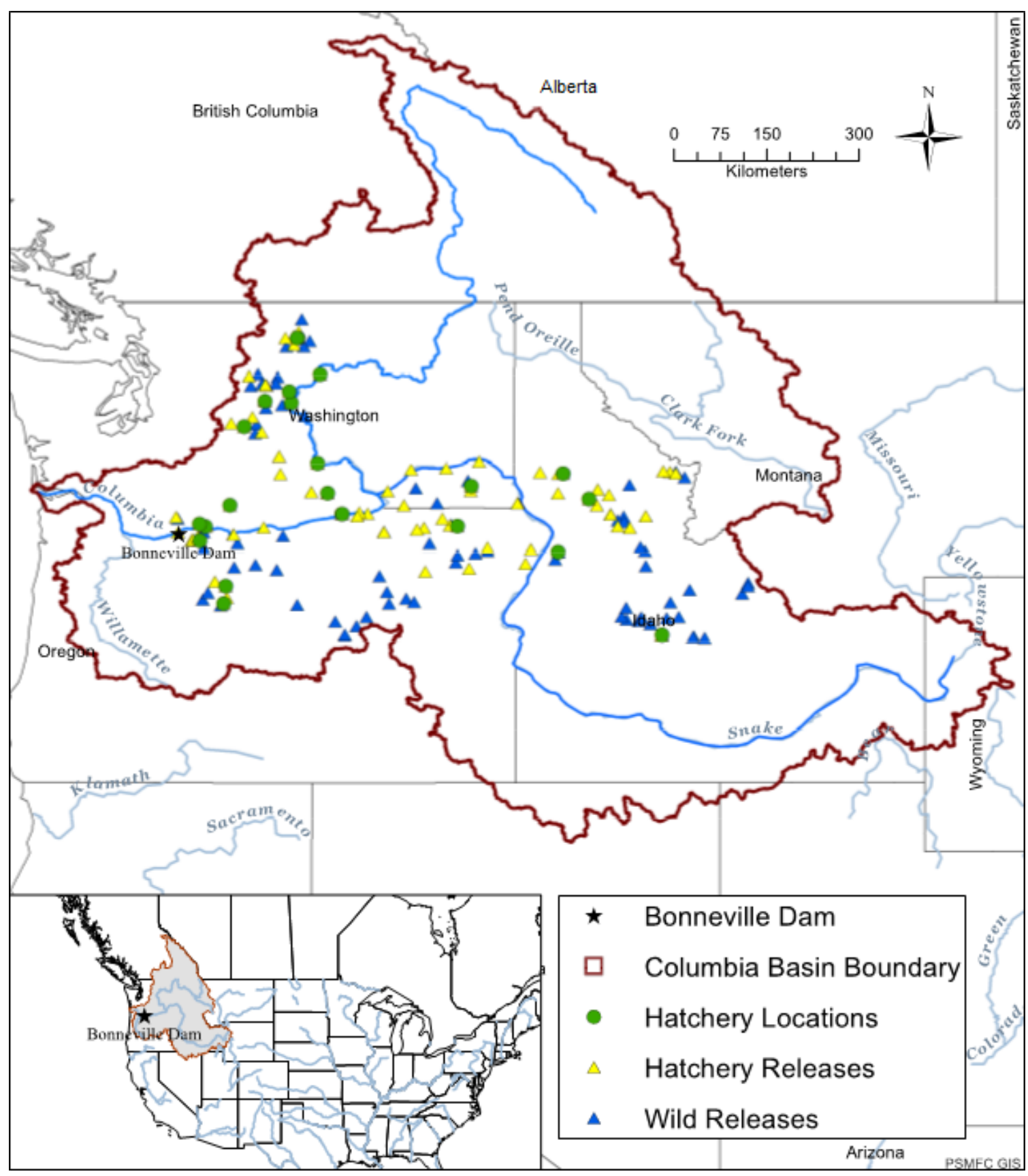

Figure 3.2. Columbia River basin with major tributaries. 

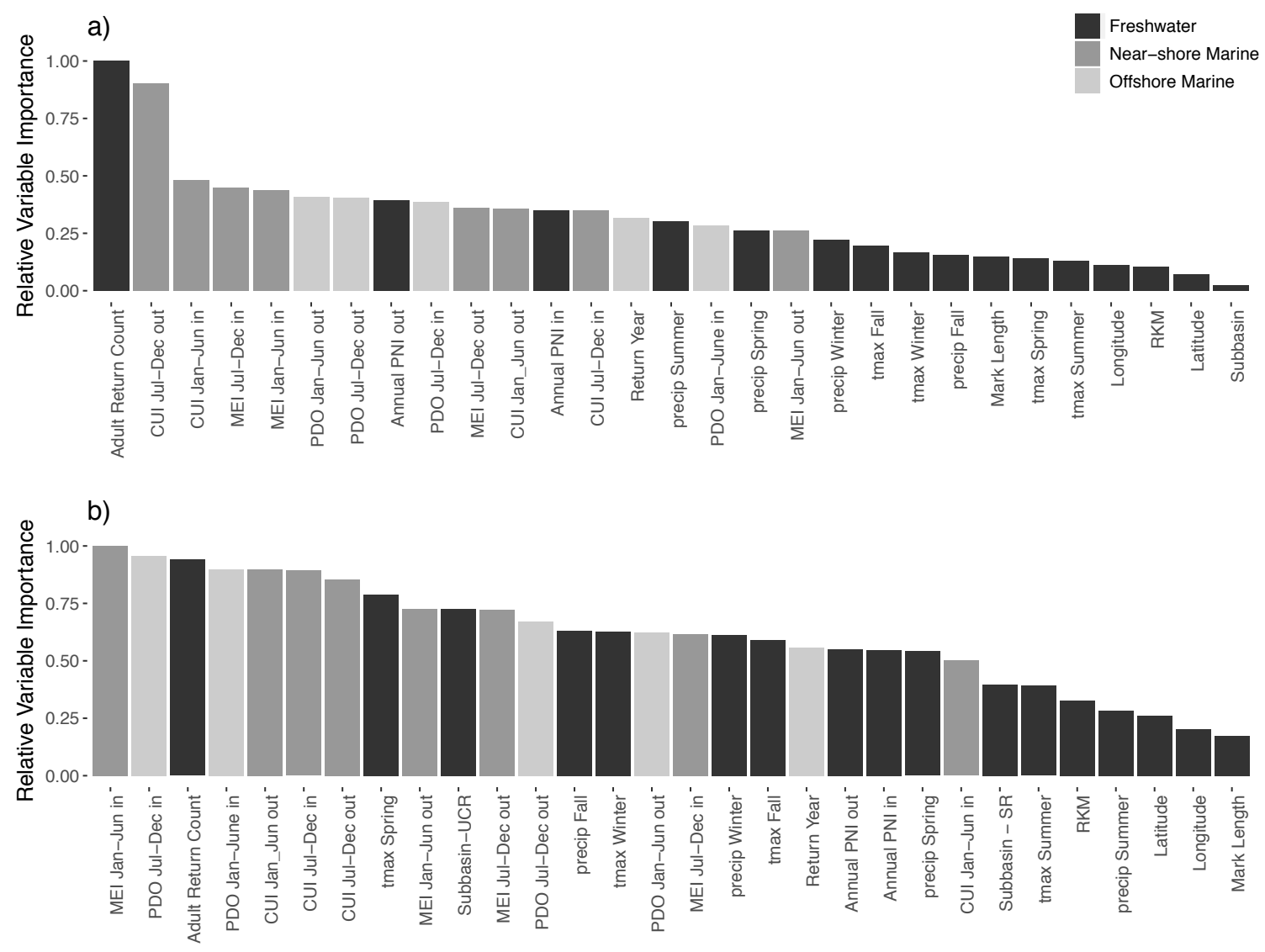

Figure 3.3. Relative variable importance plots for wild spring Chinook salmon generated from a) random forest model using the Gini Index and b) artificial neural networks using Garson Weights, grouped by environment. MEI = Multivariate El Niño - Southern Oscillation Index, CUI = Coastal Upwelling Index, PDO = Pacific Decadal Oscillation, $\operatorname{tmax}=$ mean maximum temperature, precip $=$ mean precipitation, Subbasin: $\mathrm{UCR}=$ upper Columbia River, SR = Snake River, RKM = river kilometers. "In" and "out" denote whether fish are immigrating or emigrating from the Columbia River. 

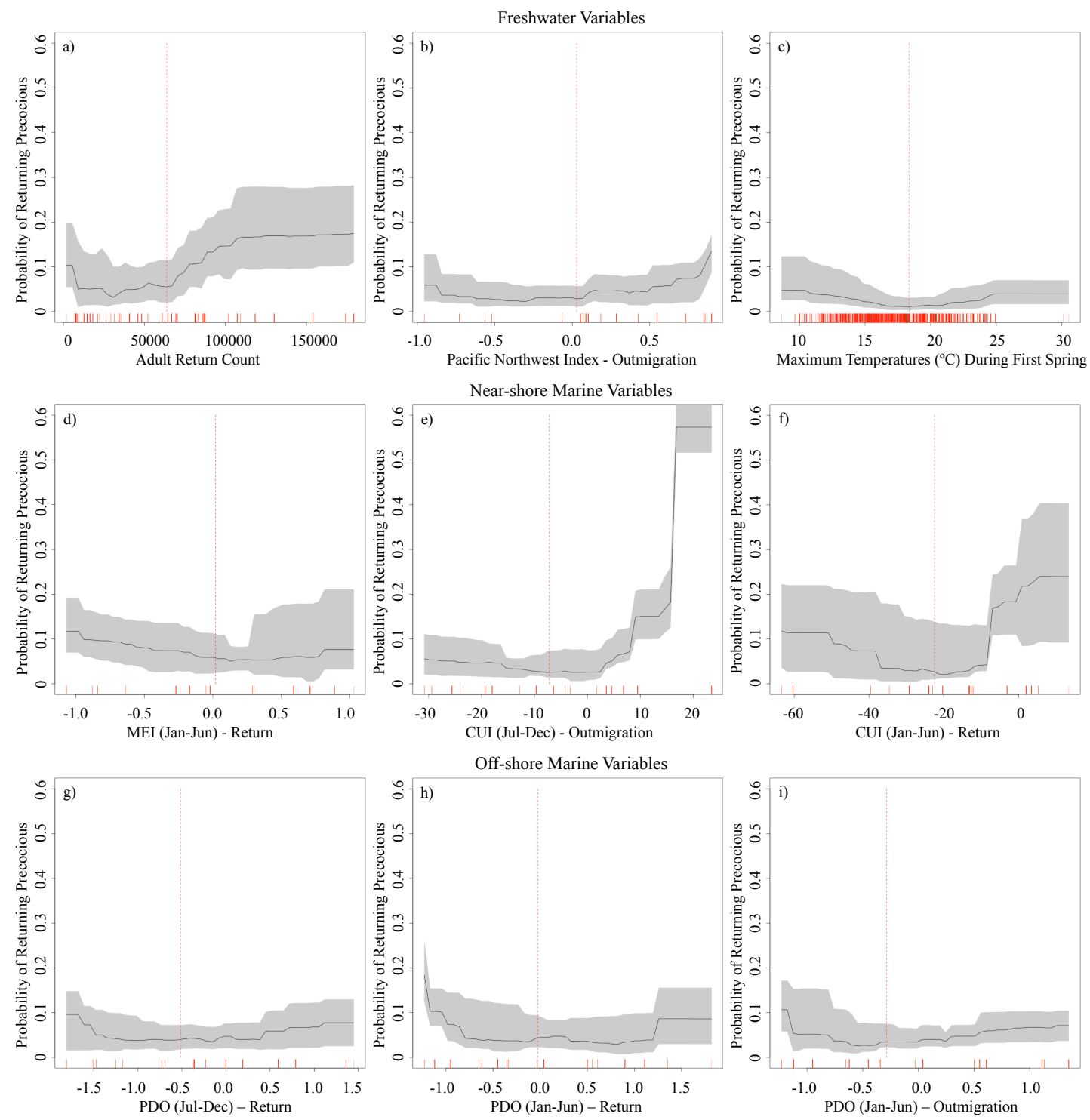

Figure 3.4. Partial dependence plots showing the probability of wild origin Chinook salmon returning precociously based on the marginal effect of each variable after averaging out the effects of all other variables. Highest-ranking (a-c) freshwater, (d-f) near-shore, and (g-i) offshore marine variables from random forest and artificial neural network model variable importance measures. Vertical, red dashed lines indicate the mean for each variable and grey represents the interquartile range. 

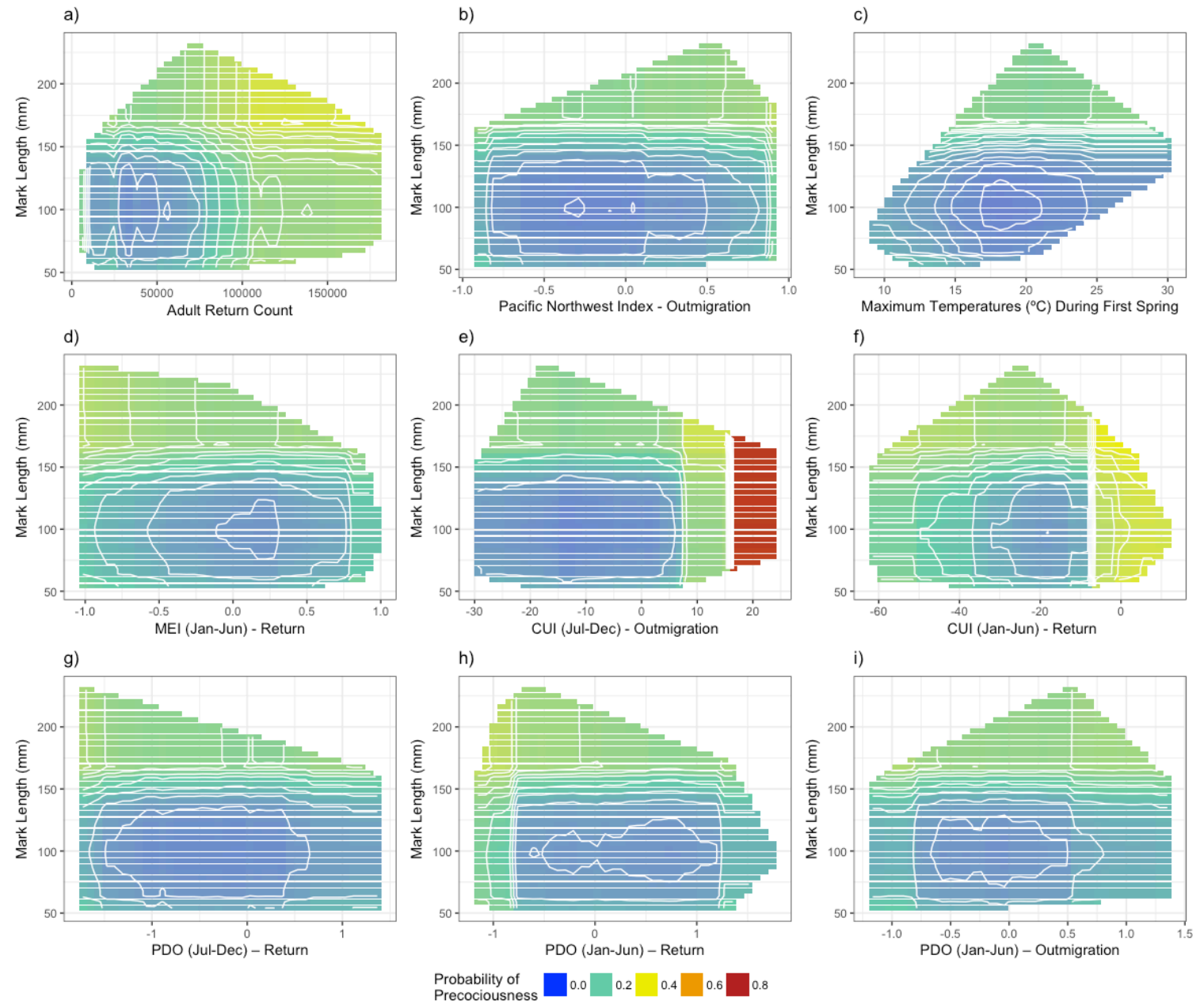

Figure 3.5. Two-way partial dependence plots for wild origin fish, showing the interaction of the marginal effect of fish length at the time of marking ( $\mathrm{mm})$ and (a-c) freshwater, (d-f) near-shore, and (g-i) offshore marine predictor variables that ranked high in random forest and artificial neural network variable importance. Color represents the probability of precocious maturation. 
a)
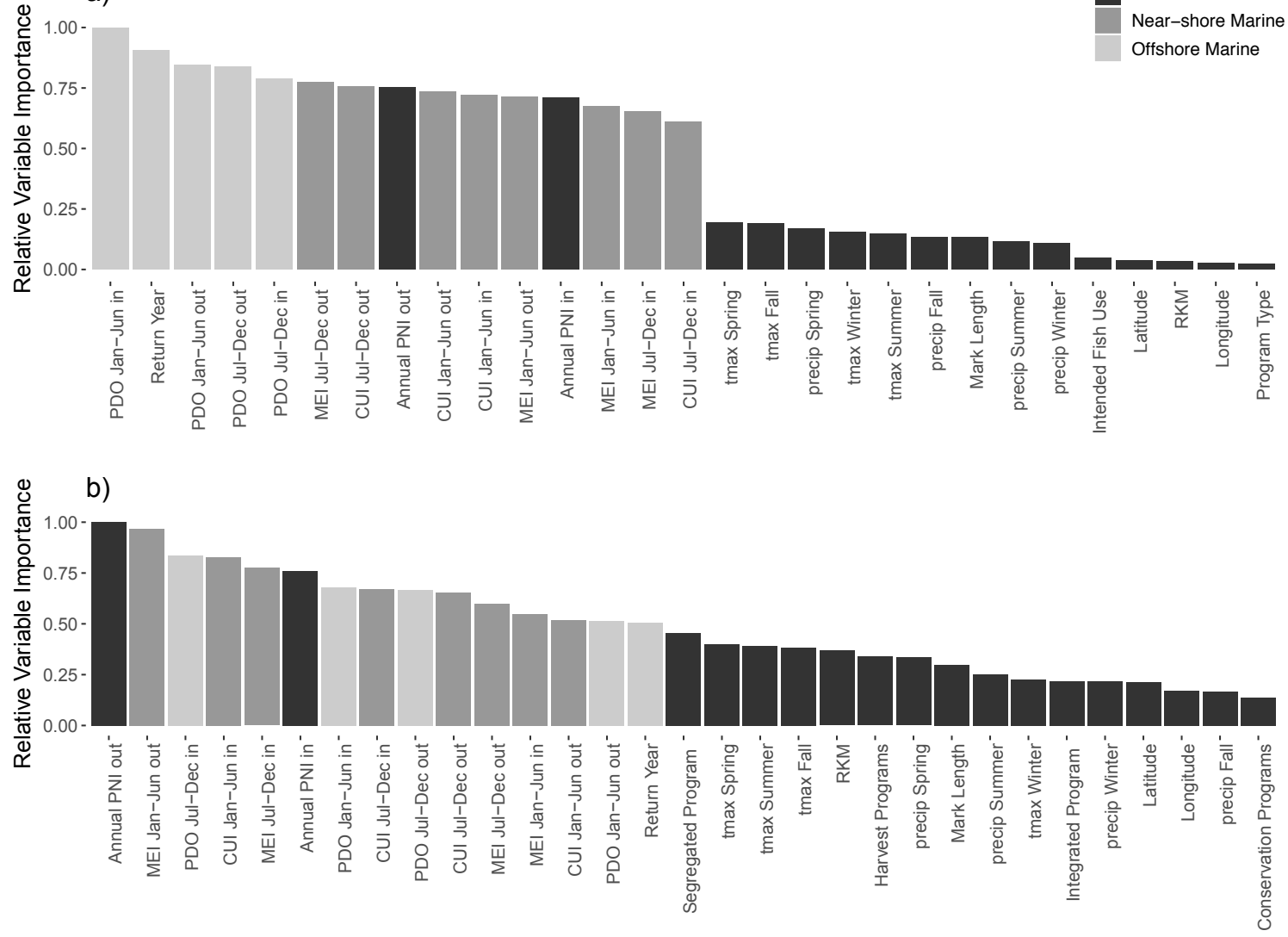

Figure 3.6. Relative variable importance plots for hatchery spring Chinook salmon generated from a) random forest model using the Gini Index and b) artificial neural networks using Garson Weights, grouped by environment. MEI = Multivariate El Niño Southern Oscillation Index, CUI = Coastal Upwelling Index, PDO = Pacific Decadal Oscillation, $\operatorname{tmax}=$ mean maximum temperature, precip $=$ mean precipitation, Subbasin: $\mathrm{UCR}=$ upper Columbia River, $\mathrm{SR}=$ Snake River, $\mathrm{RKM}=$ river kilometers. "In" and "out" denote whether fish are immigrating or emigrating from the Columbia River. 

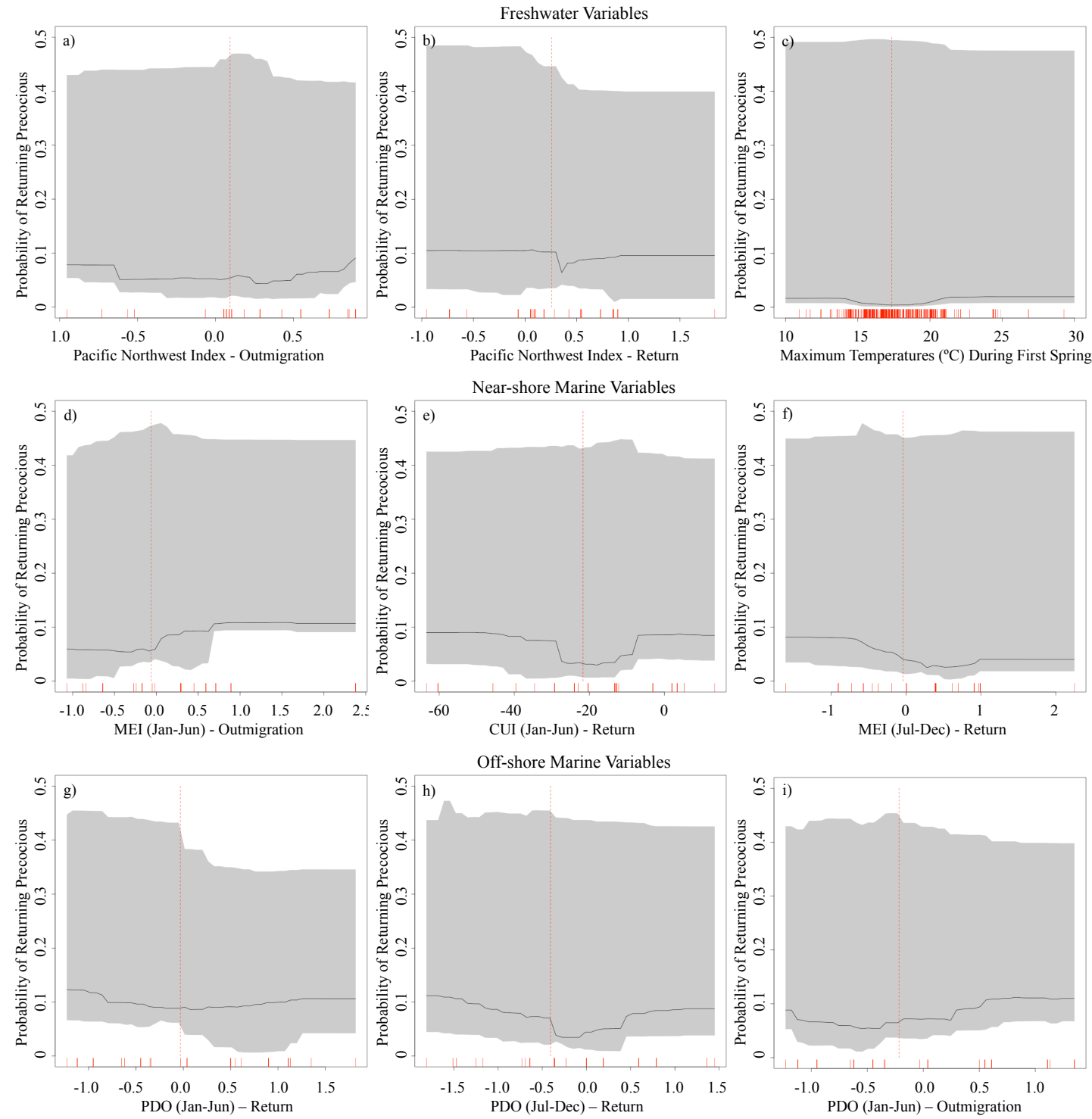

Figure 3.7. Partial dependence plots showing the probability of hatchery origin Chinook salmon returning precociously based on the marginal effect of each variable after averaging out the effects of all other variables. Highest-ranking (a-c) freshwater, (d-f) near-shore, and (g-i) offshore marine variables from random forest and artificial neural network model variable importance measures. Vertical, red dashed lines indicate the mean for each variable and grey represents the interquartile range. 

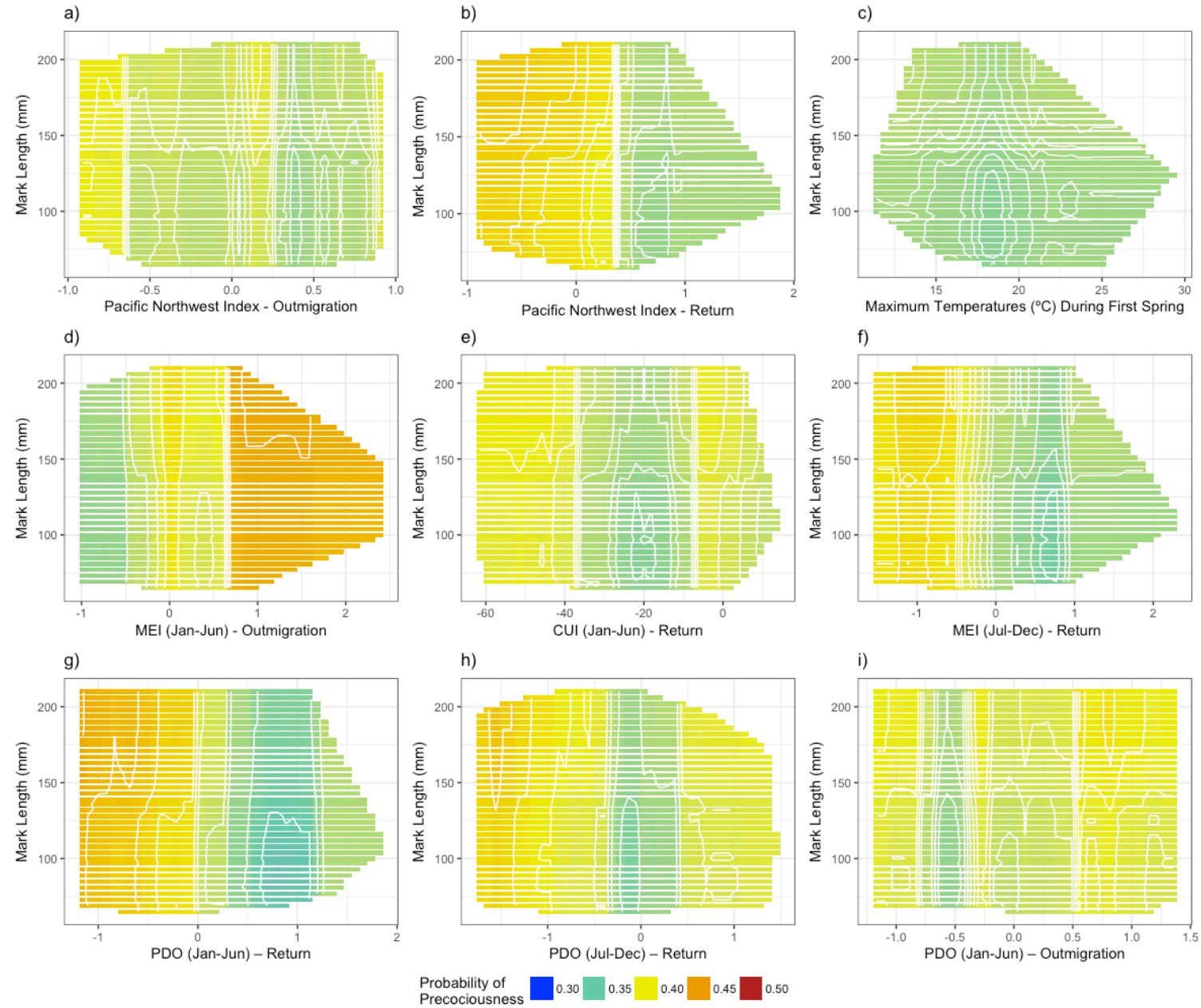

Figure 3.8. Two-way partial dependence plots for hatchery origin fish, showing the interaction of the marginal effect of fish length at the time of marking $(\mathrm{mm})$ and $(\mathrm{a}-\mathrm{c})$ freshwater, (d-f) near-shore, and (g-i) offshore marine predictor variables that ranked high in random forest and artificial neural network variable importance. Color represents the probability of precocious maturation (note the difference in range between this plot and Figure 3.5). 
Chapter 4 - Morphometric differences between wild and hatchery salmonids:

Effects of rearing environment and smoltification 


\section{Introduction}

Over the past century, there have been substantial declines of salmonid populations throughout the Pacific Ocean (Radchenko 1998, Gresh et al. 2000, Chittenden et al. 2010). The Columbia River basin drains into the eastern Pacific Ocean, and once had the largest runs of Chinook salmon in the world but has since seen extensive declines. These declines are related to large-scale changes in climatic patterns and anthropogenic alterations within the river environments (Schaller et al. 1999, Schaller and Petrosky 2007, Haeseker et al. 2012). Specifically, hydroelectric power development, habitat loss and alteration, and commercial fisheries harvest have had dramatic effects on nearly all Pacific salmonid populations in the Columbia Basin (Petrosky and Schaller 2010). Hatchery programs have emerged as the main management strategy used to offset salmonid declines and to bolster threatened and endangered populations (Kostow 2009). Annually, there are an average of 338 million hatchery fish released into the Columbia River basin from federal and state hatcheries (Kostow 2009) and these fish represent 8090\% of all salmon in the river (Williams et al. 1999, NOAA Fisheries 2008).

There has been significant debate over the reliance of management strategies that use hatchery origin salmon to supplement wild populations (Myers et al. 2004, Brannon et al. 2004, Kostow 2009). While the use of artificially propagated salmon can conserve genetic lineages and preserve localized adaptations of populations on the verge of extinction, the long-term effects of domestication selection and inevitable introgression between wild and hatchery fish remains in question (Reisenbichler and Rubin 1999, Kostow 2009). In general, hatchery-origin fish are characterized by increased agonistic 
behaviors, reduced ability to avoid predators, decreased survival rates, decreased spawning success, and altered morphology compared to wild fish (Einum and Fleming 2001, Kostow 2009).

Fish morphology is an important trait that can influence swimming performance, predator avoidance, feeding efficiency, migration, competition and overall fitness (Webb 1984, Hard et al. 1999, Chittenden et al. 2010). Both genetic and environmental factors are known to influence morphology of salmon (Hard et al. 1999). Salmonids, in general, show tremendous phenotypic plasticity that allows populations to quickly adapt to complex and dynamic environments (Unwin and Glova 1997, Einum and Fleming 2001, Chittenden et al. 2010). Fish morphology is an adaptive trait that responds to local prevailing environmental conditions. Because salmonids, in general, have complex anadromous life cycles that demand different morphological optima in different environments, there is conflicting selection pressures on body shape (Swain et al. 1991). During early life stages in freshwater, juvenile salmon have deeper bodies (increased dorsal to ventral distance) and a more robust caudal peduncle (Swain et al. 1991, Chittenden et al. 2010). This robust body shape is adapted to burst swimming and affords advantages for predator avoidance and increased feeding efficiency for drift food by increasing thrust. During freshwater migration and in the marine environment, salmon morphology is predicted to be more streamlined and fusiform (reduced body depth and longer caudal peduncle), which reduces drag and allows more efficient sustained swimming performance (Fleming and Gross 1989, Pakkasmaa and Piironen 2000). Due to high phenotypic plasticity and conflicting selection pressures experienced by 
salmonids with different early life experiences, I believe that rearing environment is likely to have considerable influence on morphology.

Because the purpose of most hatchery-produced fish is to be a proxy replacement for wild populations that have been extirpated or reduced, I sought to compare morphological differences that arise during early life experiences. The objective of this research was to compare shape variation in wild and hatchery Oncorhynchus tshawytscha (henceforth Chinook salmon) and O. mykiss (henceforth steelhead) within the Columbia River basin. Morphological comparisons have been conducted on salmonids in the past (Atlantic salmon: Pakkasmaa and Piironen 2000; Chinook salmon: Hard et al. 1999, Wessel et al. 2006; Chinook salmon and steelhead: Currens et al. 1989; Coho salmon: Swain et al. 1991), but relatively recent advancements in morphometric analysis techniques have the potential for improved analyses (Mitteroecker and Gunz 2009, Adams 2013). I employed geometric morphometrics, a methodology that uses Cartesian coordinates of pertinent, anatomical landmarks to statistically describe shape variation among individuals (Adams 2010). This shape variation can then be used to compare individuals from different populations and environments. I predicted that based on different environmental histories, there will be significant morphological differences between hatchery and wild Chinook and steelhead. I hypothesized that hatchery fish would have reduced body depth (i.e. dorsal to ventral distance), reduced caudal peduncles, and generally more fusiform body shapes compared to wild fish, based on the relatively constant water velocities, lack of predators and different foraging requirements in the hatchery setting (Wessel et al. 2006). Additionally, I hypothesized that hatchery 
fish would have less overall morphological variation compared to wild fish as a result of artificial breeding practices and homogeneous rearing environments. A loss of morphological variation may be caused by domestication selection and loss of localized adaptation to dynamic environments. Loss in shape variation may cause substantial economic losses for both Chinook and steelhead fisheries and ecological loss of rare or important phenotypes adapted to complex environments.

\section{Methods}

\section{Study Site and Data Collection}

The Columbia River basin covers an approximate area of $660,000 \mathrm{~km}^{2}$ across western North America and is the second largest river by volume in the United States.

Historically, this system was dominated by high flows during the spring runoff, followed by decreased flows during the summer months. Anthropogenic influences have altered many of the physical and chemical processes within the Columbia basin such as flow volumes, temperatures, dissolved gas concentrations, and sediment flows, such that salmonids have been extirpated from much of their historical habitats (Smith et al. 2003, Williams et al. 2008).

Run of the river, yearling spring Chinook salmon and steelhead were collected at the John Day Dam smolt monitoring facility between April 25 - May 28, 2011. Fish collection was part of the 2008 Federal Columbia River Power System Biological Opinion Compliance Monitoring, facilitated by Pacific Northwest National Laboratories. As part of compliance monitoring, each fish was anesthetized with tricaine methanesulfonate (MS-222) and surgically implanted with 1) passive integrated 
transponder (PIT; HPT12, BioMark, Boise, ID) and 2) Juvenile Salmon Acoustic Telemetry Systems acoustic micro-transmitter (AT; Model SS130, Advanced Telemetry Systems, Isanti, MN). While anesthetized and prior to tagging, photographs were taken of the lateral sides of each fish with a mounted, high resolution digital camera (Cannon EOS 5D Mark III). Each photograph contained $1 \mathrm{~cm}^{2}$ grid cells, used as a reference in geometric analyses to account for differences in camera height throughout the tagging process. Each fish was identified as wild (i.e. adipose intact) or hatchery (i.e. adipose removed) origin by the presence or absence of the adipose fin. Details specific to the experimental design for compliance monitoring, fish collection, and tagging methodologies can be found in (Johnson et al. 2012, Ploskey et al. 2012, Skalski et al. 2012c, 2012a, 2012b, Weiland et al. 2013).

I employed a stratified random sampling procedure to subsample from the pool of approximately 2,500 photographs taken in 2011. Randomly selected images were stratified by species (Chinook salmon $n=514$, steelhead $n=276$ ), fish origin (Chinook wild $n=253$, Chinook hatchery $n=261$, steelhead wild $n=76$, steelhead hatchery $n=$ 199), and Julian day (Chinook = Julian day 117 - 150; steelhead = Julian day 117 - 129). I identified 21 biologically relevant, fixed anatomical landmarks to describe the shape variation of both species of salmonid following procedures of Fraser et al. (2010) (Figure 4.1; Appendix C.1). These landmarks, in concert, show variation in fish shape that may be linked to feeding (i.e. mouth position: landmarks 1 and 18) and swimming ability (i.e. thickness of the caudal peduncle: landmarks 7 - 10). 
Using the program TpsDig ( $v 2.31$; Rohlf 2001), all landmark coordinates were located on each digital photograph by the same individual. Using the statistical platform $\mathrm{R}(v 3.5 .0 ; 2018)$ and the package geomorph (v3.0.4: Adams et al. 2017) I performed a Generalized Procrustes Analysis (GPA; Rohlf and Slice 1990) on each species separately (Figure 4.2). GPA is used to: 1) translate the coordinates of all specimens to the mean; 2) scale coordinates to unit centroid size; and 3) rotate coordinates using least-squares criteria to minimize the deviations of each landmark configuration compared to the mean configuration (Rohlf and Slice 1990, Adams 2013). Centroid size for each fish is calculated as the square root of summed, squared distances from the center of each landmark configuration to each landmark. Following this superimposition, the aligned specimens are in the form of Procrustes shape coordinates and are used for all subsequent multivariate analysis (Adams 2013).

\section{Statistical Analyses}

In geometric morphometric analyses, multivariate analyses of covariance (MANCOVA) are frequently used to test for shape differences between operational taxonomic units (i.e. wild and hatchery fish) and other covariates (Collyer and Adams 2007). In our analysis of Chinook salmon, the assumptions of MANCOVA were met (i.e. independence, normality, levels and homogeneity of variance) based on visual inspection of residual diagnostic plots. For steelhead, all assumptions were met, except for equal variance, based on visual inspection of residual diagnostic plots. Wild steelhead had more variation than hatchery steelhead, which is likely due to differences in sample size. For 
each species, I performed a homogeneity of slopes test of the Procrustes aligned shape coordinates (i.e. shape $=$ dependent variable), with log-transformed centroid size and fish origin as independent covariates. If slopes are homogeneous (i.e. wild and hatchery fish shape changes with size in a similar way), then an allometric correction can be applied that accounts for shape change as a function of size. If slopes are heterogeneous, there are no allometric corrections that can be applied (Collyer and Adams 2007). The homogeneity of slopes procedure uses a randomized residual permutation procedure that employs resampling of residuals from a reduced model to estimate the effects of a full model (Collyer and Adams 2007, Collyer et al. 2015). These models include 9999 random permutations along with the observed value and assess the significance of the observed value as the probability of finding a more extreme value by chance from the 10000 values generated (Collyer and Adams 2007). A significant interaction between fish origin and centroid size indicates that as size changes, shape changes in wild fish differently than hatchery fish (Collyer and Adams 2007). I compared the direction (positive or negative) and magnitude (length) of allometric vectors to determine if heterogeneous slopes would lead to biologically relevant differences in shape between wild and hatchery fish.

In order to better understand the relationship between shape and biological predictor variables and to visualize the shape variation across these gradients, I performed a redundancy analysis (RDA) in R using shape variables (i.e. Procrustes aligned landmark configurations) and predictor variables with vegan (v2.5-2). Each model contained the dependent shape variables and the independent variables condition 
factor, centroid size, Julian day and biologically relevant interaction terms size $\mathrm{x}$ condition factor, size x Julian day, condition factor x Julian day. All numeric predictors were scaled to have a mean of 0 prior to analysis. Condition factor is an index variable that relates the weight of a fish relative to its length and can represent the physiological condition of a fish, with heavier fish at a given length having better nutritional condition (Jones et al. 1999). Condition factor was calculated as:

$$
\text { Eq 4.1. } \quad K=\left(W^{*} L^{-3}\right) * 10^{2}
$$

where $W=$ mass $(\mathrm{g}), L=$ length $(\mathrm{mm})$ (Shearer and Swanson 2000). Centroid size essentially represents the area of a fish. Julian day accounts for differences in shape that may arise due to different degrees of smoltification for migrating juveniles. I compared full models that contained all predictor variables and interactions with reduced models for Chinook salmon and steelhead separately. I performed step AIC model reduction to identify models that had the lowest AIC scores. Variable inflation factor (threshold $>5$ ) was used to identify multicollinearity between predictor variables and interaction terms, which resulted in the removal of all interactions in reduced models. I performed a partial RDA, using fish origin and conditioning all other predictor variables, in order to partition the amount of shape variation explained by the effect of rearing environment.

I assessed the amount of error associated with digitizing landmarks (i.e. digitizing error) by randomly selecting four photographs of each species and replicated the digitizing process for each of the four photographs five times (e.g. Chinook salmon: 4 photographs digitized 5 time each). I then averaged the standard deviation for each landmark from the replicates and compared the average digitizing error to the average 
standard deviation of each landmark for all fish (Chinook $n=514$; steelhead $n=276$ ).

For both species, the posterior dorsal fin insertion point (landmark 5) in the replicates had higher standard deviation than the averaged standard deviation of all fish (Appendix C.2 and C.3). Most of the variation in this landmark comes from forward or backward movements (anterior - posterior; $\mathrm{x}$ axis) not up or down movements (dorsal - ventral; y axis). Visual inspection of photographs suggests that this landmark is more difficult to accurately place because of a combination of dorsal fin erosion or stubbing in hatchery fish and obscuration of insertion point from folded or flopped dorsal fin (Figure 4.1).

\section{Results}

\section{Summary Statistics}

Wild Chinook salmon were significantly smaller (i.e. centroid size, length, weight), but had comparable condition factor to hatchery Chinook based on a Welch's $t$-test (Table 4.1). Hatchery Chinook salmon had significantly more overall shape variation than wild Chinook based on a pair-wise comparison of Procrustes distances $(p=0.01)$. Wild steelhead were significantly smaller in centroid size, length and weight but had significantly higher condition factor than hatchery steelhead (Table 4.1). Wild steelhead had significantly more overall shape variation compared to hatchery steelhead based on a comparison of Procrustes distances $(p=0.03)$. High correlations between condition factor, length, and weight (Chinook salmon $r>0.99$; steelhead $r>0.96$ ) dictated the removal of length and weight so that all further analyses were performed with the independent predictor variables origin, centroid size, condition factor, and Julian day. 


\section{Chinook Salmon}

The shape of wild Chinook salmon was significantly different from the shape of hatchery salmon with increased body size (homogeneity of slopes test; Table 4.2). The relationship between shape variation and size can be visualized as vectors with different slopes and magnitudes (Collyer and Adams 2007). If the angular difference between slopes is near $0^{\circ}$ (i.e. parallel), then wild and hatchery fish will have the same allometric trajectories. Slope vectors for wild and hatchery Chinook are both negative but significantly differ by an angle of $37.1^{\circ}$ (effect size calculated from randomized residual permutation procedure is given in standard deviations as the likelihood of finding a more extreme value; $Z=7.82, p<0.001$; Figure 4.3). Slope vector magnitude is the amount of shape change per unit of covariate change (i.e. natural log-transformed centroid size; Collyer and Adams 2007). Although the shape of wild fish appeared to change more per unit change in size than hatchery fish, the difference was not significant $(Z=-0.14, p=$ 0.476; Figure 4.3).

I performed a redundancy analysis to determine how much of the variation in shape was attributable to variation in my predictor variables. A reduced model contained the predictor variables size, origin, condition factor, Julian day and explained $15.7 \%$ of the shape variation in Chinook salmon (Table 4.3). After conditioning all other variables, fish origin explained $4.5 \%$ of the total shape variation in Chinook salmon. Shape variation across RDA axis 1 was most explained by size, and condition factor (Figure 4). Landmark positions that positively correlated with size were the left and right movements 
of the anterior point of the eye (landmark number 21) and up and down movements of the dorsal terminus of the caudal flexure (landmark 8) and the most anterior point of the lower jaw (landmark 18). Fish with higher condition factor were more robust with positive correlations with up and down movements of dorsal landmarks (landmarks 4, 5 and 6; Figure 4.4). Furthermore, smaller wild fish had downward oriented mouths and were concave on their ventral sides compared to large hatchery fish that had upward oriented mouths and convex ventral sides. Shape variation across RDA axis 2 was most correlated with overall shape differences between wild and hatchery fish (Figure 4.4). Hatchery fish had more streamlined bodies, with slightly downturned mouths and thinner tails (Figure 4.2). Condition factor explained most of the variation along the RDA axis 3. As fish attained higher condition factor, dorsal landmarks moved upwards. Julian day was most correlated with RDA axis 4. Early migrating fish were more robust with slightly downturned mouths compared to later migrants that were more streamlined with slightly upturned eyes.

\section{Steelhead}

Shape variation in wild steelhead differed significantly from that of hatchery steelhead along a gradient of size (homogeneity of slopes test; Table 4.2). Slope vectors for wild and hatchery steelhead were both negative and differ significantly by an angle of $55.3^{\circ}(Z=6.70, p=<0.001$; Figure 4.5). Again, although the shape of wild fish appeared to change more per unit change in size (i.e. magnitude) than hatchery fish, the difference was not significant $(Z=0.86, p=0.187$ Figure 4.5$)$. 
The full model containing all variables and interactions in my redundancy analysis explained $20.5 \%$ of steelhead shape variation. The reduced model contained origin, size, condition factor and explained $19.2 \%$ of the shape variation. Interaction terms were removed based on high degrees of multicollinearity with main effects. After conditioning all other variables, fish origin explained $6.8 \%$ of the total steelhead shape variation. RDA axis 1 of the reduced model was most correlated with fish origin and size (Table 4.3). Wild steelhead were negatively correlated with size and had larger heads and more robust tails (Table 4.3; Figure 4.6). RDA axis 2 was most correlated with size and condition factor and wild fish were smaller but had higher condition factor (Figure 4.6). As steelhead increased in condition factor dorsal landmarks (landmarks 3-6) moved upwards, increasing dorsal-ventral distance. Wild fish on the second RDA axis had more robust bodies and thicker tails, compared to hatchery fish that were thinner (Figure 4.6). RDA axis 3 was positively correlated with size and negatively correlated with condition factor, indicating that as fish increased in size, condition factor decreased.

\section{Discussion}

My comparison of morphological variation in wild and hatchery salmonids provides new insight into how shapes change in fish dependent on early life experiences (i.e. rearing environment). My analyses support my hypothesis that there were significant differences in body shape between wild and hatchery origin fish that can be partially explained by rearing environment and variables influenced by smoltification. Hatchery fish of both species were significantly larger (i.e. centroid size, length, weight) than wild fish but had 
comparable or lower condition factor (Table 4.1). In general, hatchery fish have smaller heads and longer, thinner tails (i.e. fusiform) compared to wild fish (Figure 4.2).

Allometric trajectories indicate that the shape of wild and hatchery fish are significantly different at small and large sizes (Figures 3, 4). Wild and hatchery Chinook salmon became more morphologically different as size increased, while steelhead became more similar. While the amount of shape variation explained by fish origin was significant, other variables may play a role in the phenotypic expression of juvenile body shapes (Table 4.2). Inconsistent with my prediction, the overall amount of Procrustes shape variation (i.e. overall variation) was not significantly different between wild and hatchery Chinook salmon. This finding suggests that regardless of significant differences in the way shapes vary, hatchery fish have not lost overall shape variation. Consistent with my prediction, the total amount of Procrustes shape variation was significantly greater in wild compared to hatchery steelhead, indicating that hatcheries may have a homogenizing effect on steelhead shape.

Morphological variation arises, in part, from physiological adaptation to local environmental conditions and can greatly influence the swimming performance of fish (Webb 1984, Pakkasmaa and Piironen 2000). For phenotypically plastic salmonids, there are conflicting selection pressures between morphological optima, and body shapes generally differ between two swimming modes, burst and sustained swimming (Fleming and Gross 1989, Swain et al. 1991). During freshwater residence, juvenile morphology selects for deeper bodies and thicker tails that help produce thrust, leading to the burst swimming mode. This mode aids in quick escapes from predators, increased feeding 
efficiency, and a competitive advantage for attaining drift food (Fleming and Gross 1989, Swain et al. 1991, Wessel et al. 2006). During migration and ocean residence, salmonid morphology is selected towards more streamlined, fusiform shape that produces less drag and allows sustained, energetically efficient swimming performance in open waters (Fleming and Gross 1989, Swain et al. 1991, Pakkasmaa and Piironen 2000). My findings indicate that wild smolt shapes are closer to the burst swimming mode (deeper dorsal-ventral distance, larger head and thicker caudal peduncle) optimized for complex and dynamic environments, while hatchery fish are closer to streamline, fusiform shapes, optimized for spatially homogeneous, open water (Figure 4.2).

Because salmonids are so phenotypically plastic and can physiologically and behaviorally respond to their environments, I predicted that rearing environment would play a major role in the early life experiences that shape Chinook salmon and steelhead. Swain et al (1991) investigated the effects of rearing environment versus genetics by comparing morphological differences in hatchery Coho salmon $(O$. kisutch) reared in a hatchery setting to wild Coho reared in the wild and in a hatchery setting. These authors found that the morphology of wild and hatchery Coho reared in a hatchery setting was more similar to each other than to wild Coho reared in a natural setting and concluded that morphological differences were due to rearing environment more than genetics (Swain et al. 1991). In another study that compared the effects of rearing environment and genotype, Chittenden et al (2010) found no differences in growth, survival, predator avoidance or migratory behavior in wild and hatchery Coho reared in a hatchery environment but significant differences between these groups compared to wild Coho 
reared in a natural environment. Again, rearing environment had a greater effect on fish morphology and other measured traits than genetics (Chittenden et al. 2010). In my study, fish origin was a significant predictor of morphology and explained $4.5 \%$ and $6.8 \%$ of the total shape variation observed in Chinook salmon and steelhead respectively.

Fish size, condition factor, and Julian day (Chinook only) were significant predictors of fish shape (Table 4.3). For hatchery fish, these variables are almost certainly affected by rearing environment, but also by natural conditions experienced after release, including the physiological process of smoltification. Smoltification is the process by which freshwater fish prepare for saltwater and includes physiological, biochemical, and behavioral changes (Winans 1984). In terms of morphology, smoltification in Chinook and steelhead involves gradual changes away from the burst swimming optima, beneficial during freshwater residence, to the streamlined, fusiform optima beneficial for long-during ocean residence (Winans 1984). For Chinook salmon, Julian day was a significant predictor of shape and explained the majority of shape variation along RDA axis 4 and likely represents morphological effects of smoltification (Table 4.3)

Morphological and behavioral responses to the novel river environment will likely have a lag period, where hatchery fish acclimate to the new environment (Einum and Fleming 2001). I found that hatchery fish of both species were larger in size but had lower or comparable condition factor to wild fish. Hatchery fish are, in general, longer and weigh more than their wild counterparts (Larsen et al. 2013). My finding of larger hatchery fish with lower condition factor supports the postulation of Einum and Fleming 
(2001), who suggest that hatchery salmonids (Atlantic salmon - Salmo salar and brown trout - S. trutta) require a period of acclimation in the wild to adapt to the novel diets. Condition factor mostly affected fish shape along dorsal landmarks, with better condition moving those landmarks upwards. This finding is supported by Currens et al (1989) who found that the areas of greatest fat deposition were in the trunk and dorsal region of Coho salmon. The landmarks most correlated with Julian day were the lips of the upper and lower jaw and the orientation of the eyes. Later migrants had eyes that were slightly oriented upwards, which may be an adaptation for avian predators. Steelhead smolts have been found to be more susceptible to surface-feeding avian predators than Chinook smolts (i.e. size selection by birds for larger fish) and hatchery fish of both species are much more likely to be consumed than wild fish (Collis et al. 2001). Collis et al (2001) suggested that hatchery fish are more vulnerable to surface-feeding avian predators because they spend more time migrating and foraging near the surface compared to wild fish. My finding that later migrants had eyes more oriented upward, may reflect changes in predation rates by avian predators. In 2010 , it was estimated that 98,000 smolts were consumed by avian predators at the Dalles Dam alone (Zorich et al. 2011). Avian predation tends to increase over the migration season suggesting that fish with upward oriented eyes may have a selective advantage because they recognize predators sooner.

One limitation of my study is that I do not know how long hatchery fish were in the river environment prior to sampling. Based on results from other salmonid morphology studies, I suspect that the morphological variation attributable to rearing environment would be greater between wild and hatchery fish prior to hatchery release 
into the common river environment (Swain et al. 1991, Cramon-Taubadel et al. 2007). Because most hatcheries release fish as they begin the smoltifacation process and most hatchery smolt initiate migration quickly after release, I feel that the morphological variation found in hatchery fish reflects hatchery environment but fish may have begun adapting to new river environment (Kostow 2009).

\section{Conclusion}

Hatchery fish are, in general, produced to support recreational and commercial harvests and are intended to mimic wild populations that have been extirpated due to anthropogenic factors until wild populations are again self-sustaining (Galbreath et al. 2008, Kostow 2009). Hatchery fish inevitably spawn with wild populations and there are serious concerns about the impact of artificially produced fish on already threatened or endangered wild populations (Unwin and Glova 1997, Brannon et al. 2004, Dahl et al. 2006, Kostow 2009, Fraser et al. 2010). My investigation into the morphological variation that arises between wild and hatchery fish based on rearing environment, indicates significant differences between naturally and artificially reared individuals. Several factors related to rearing environment likely contribute to this finding: 1) domestication selection in hatcheries, 2) hatchery rearing practices, and 3) physical rearing environment. Domestication selection in the hatchery environment is caused by a combination of random artificial broodstock selection and the removal of natural selection forces (Reisenbichler and Rubin 1999, Araki et al. 2008). Egg-to-smolt mortality in hatcheries is less than $15 \%$, compared to $95 \%$ in wild populations 
(Reisenbichler et al. 2008). Selection for traits that occur in the artificial hatchery environment often become deleterious because those traits are not advantageous in a natural setting (Ford 2002). This may be one reason for the $95 \%$ mortality of hatchery fish after release (Reisenbichler and Rubin 1999, Ford 2002, Araki et al. 2008). Steelhead appear to be more susceptible to domestication selection than Chinook and have been shown to have reduced fitness after 1-2 generations in captivity (Araki et al. 2008). My findings indicate that steelhead have lost morphological variability compared to their wild counterparts. Hatchery rearing practices including elevated water temperatures, feeding of high lipid diets, feeding to satiation, surface broadcast of food and lack of predators all contribute to the morphological variation in hatchery fish and other lifer history changes such as precocious maturation (Wessel et al. 2006, Elder and Strecker in review). The physical environment of hatcheries are generally spatially homogeneous, linear concrete raceways, with unvaried low water velocities and no physical structures (Wessel et al. 2006). There are virtually no similarities between the average hatchery raceway and natural rearing areas that juvenile salmonids evolved.

Hatcheries, in general, were intended to be a short-term solution to anthropogenically related declines in wild populations, while the factors that caused population declines were ameliorated (Dahl et al. 2006). In the Columbia River basin, hydroelectric development not only has major effects on the survival of migrating smolt and adults but has substantially reduced spawning and rearing habitat (Reeves et al. 1995, Elder et al. 2016). Hydroelectric dams that are impassable to salmonids restrict access to spawning and rearing habitat to approximately $60 \%$ of historical range (Sheer and Steel 
2006). For example, aquatic barriers in the Willamette River watershed have caused a $42 \%$ loss of accessible stream habitats, equating to $14,931 \mathrm{~km}$ of high quality habitat that is now inaccessible to salmonids (Sheer and Steel 2006).

Restoring critical habitat to wild salmonids will be the ultimate solution to many of the anthropogenically related declines in salmonid populations throughout the Pacific Northwest. Until then, hatcheries will likely plan an important role in maintaining population abundances. Relatively minor alterations to hatchery facilities have the potential to have major, positive effects in terms of bringing hatchery and wild populations closer together in morphology and behavior (Pakkasmaa and Piironen 2000, Berejikian et al. 2010). Hatcheries that mimic natural salmonid rearing habitat will likely have immediate positive effects. Pakkasmaa and Piironen (2000) found that by altering water velocity to levels found in natural rearing habitats for 1 month, salmonids morphologically adapted to have deeper, more robust bodies than fish held in low velocity tanks. Enriched hatchery rearing environments (i.e. in-water structure, underwater feeding apparatus and overhead cover) have been shown to reduce some of the deleterious behavioral effects of conventional hatchery environments including social dominance and agonistic behavior and fish from enriched tanks grew faster and outcompeted conventional hatchery fish in quasi-natural environments after release (Berejikian et al. 2010). I recommend a coordinated effort between federal, state and tribal hatcheries to incorporate elements of the natural rearing environment into conventional hatcheries. These elements include in-water structure to promote the burst swimming mode, increased water velocities to increase dorsal-ventral distance, under- 
water feeding apparatus to reduce surface feeding behavior, overhead cover and mimicked predators to teach escape behavior (Pakkasmaa and Piironen 2000, Collis et al. 2001, Kostow 2009, Berejikian et al. 2010). There will need to be a paradigm shift, where the goal of salmonid production is not numerical, but based on scientifically defensible morphological, behavioral and genetic similarities between artificial and wild populations. 


\section{References}

Adams, D. 2013. A field comes of age: Geometric morphometrics in the 21st century. Hystrix, 24: 7-14.

Adams, D. C. 2010. Parallel evolution of character displacement driven by competitive selection in terrestrial salamanders. BMC Evolutionary Biology 10:72.

Adams, D. C., M. L. Collyer, A. Kaliontzopoulou, and E. Sherratt. 2017. Geomorph: Software for geometric morphometric analyses. R package.

Araki, H., B. A. Berejikian, M. J. Ford, and M. S. Blouin. 2008. Fitness of hatcheryreared salmonids in the wild. Evolutionary Applications 1:342-355.

Berejikian, B. A., D. M. Van Doornik, R. C. Endicott, T. L. Hoffnagle, E. P. Tezak, M. E. Moore, and J. Atkins. 2010. Mating success of alternative male phenotypes and evidence for frequency-dependent selection in Chinook salmon, Oncorhynchus tshawytscha. Canadian Journal of Fisheries and Aquatic Sciences 67:1933-1941.

Brannon, E. L., D. F. Amend, M. A. Cronin, J. E. Lannan, S. LaPatra, W. J. McNeil, R. E. Noble, C. E. Smith, A. J. Talbot, G. A. Wedemeyer, and H. Westers. 2004. The controversy about salmon hatcheries. Fisheries 29:12-31.

Chittenden, C. M., C. A. Biagi, J. G. Davidsen, A. G. Davidsen, H. Kondo, A. McKnight, O.-P. Pedersen, P. A. Raven, A. H. Rikardsen, J. M. Shrimpton, B. Zuehlke, R. S. McKinley, and R. H. Devlin. 2010. Genetic versus rearing-environment effects on phenotype: hatchery and natural rearing effects on hatchery- and wild-born Coho salmon. PLOS ONE 5:e12261. 
Collis, K., D. D. Roby, D. P. Craig, B. A. Ryan, and R. D. Ledgerwood. 2001. Colonial waterbird predation on juvenile salmonids tagged with passive integrated transponders in the Columbia river estuary: vulnerability of different salmonid species, stocks, and rearing types. Transactions of the American Fisheries Society 130:385-396.

Collyer, M. L., D. J. Sekora, and D. C. Adams. 2015. A method for analysis of phenotypic change for phenotypes described by high-dimensional data. Heredity $115: 357$.

Collyer, M. L., and D. C. Adams. 2007. Analysis of two-state multivariate phenotypic change in ecological studies. Ecology 88:683-692.

Currens, K. P., C. S. Sharpe, R. Hjort, C. B. Schreck, and H. W. Li. 1989. Effects of different feeding regimes on the morphometrics of Chinook salmon (Oncorhynchus tshawytscha) and Rainbow Trout (O. mykiss). Copeia 1989:689695.

Dahl, J., E. Pettersson, J. Dannewitz, T. Järvi, and A. Löf. 2006. No difference in survival, growth and morphology between offspring of wild-born, hatchery and hybrid brown trout (Salmo trutta). Ecology of Freshwater Fish 15:388-397.

Einum, S., and I. Fleming. 2001. Implications of stocking: Ecological interactions between wild and released salmonids. Nordic Journal of Freshwater Research, $75,56-70$. 
Elder, T., C. M. Woodley, M. A. Weiland, and A. L. Strecker. 2016. Factors influencing the survival of outmigrating juvenile salmonids through multiple dam passages: an individual-based approach. Ecology and Evolution 6:5881-5892.

Fleming, I. A., and M. R. Gross. 1989. Evolution of adult female life history and morphology in a Pacific salmon (Coho: Oncorhynchus kisutch). Evolution 43:141-157.

Ford, M. J. 2002. Selection in captivity during supportive breeding may reduce fitness in the wild. Conservation Biology 16:815-825.

Fraser, D. J., A. L. S. Houde, P. V. Debes, P. O’Reilly, J. D. Eddington, and J. A. Hutchings. 2010. Consequences of farmed-wild hybridization across divergent wild populations and multiple traits in salmon. Ecological Applications 20:935953.

Galbreath, P. F., C. A. Beasley, B. A. Berejikian, R. W. Carmichael, D. E. Fast, M. J. Ford, J. A. Hesse, L. L. McDonald, A. R. Murdoch, and C. M. Peven. 2008. Recommendations for broad scale monitoring to evaluate the effects of hatchery supplementation on the fitness of natural salmon and steelhead populations. Final Draft Report of the Ad Hoc Supplementation Monitoring and Evaluation Workgroup.

Gresh, T., J. Lichatowich, and P. Schoonmaker. 2000. An Estimation of historic and current levels of salmon production in the northeast pacific ecosystem: Evidence of a nutrient deficit in the freshwater systems of the pacific northwest. Fisheries $25: 15-21$. 
Haeseker, S. L., J. A. McCann, J. Tuomikoski, and B. Chockley. 2012. Assessing freshwater and marine environmental influences on life-stage-specific survival rates of Snake River spring-summer Chinook salmon and steelhead. Transactions of the American Fisheries Society 141:121-138.

Hard, J. J., G. A. Winans, and J. C. Richardson. 1999. Phenotypic and genetic architecture of juvenile morphometry in chinook salmon. Journal of Heredity 90:597-606.

Johnson, G. E., M. J. Hennen, S. A. Zimmerman, G. Batten, S. M. Carpenter, Z. Deng, T. Fu, J. S. Hughes, J. J. Martinez, and G. R. Ploskey. 2012. Survival and passage of yearling Chinook salmon and steelhead at The Dalles Dam, spring 2011- final report. Pacific Northwest National Laboratory, Richland, WA.

Jones, R. E., R. J. Petrell, and D. Pauly. 1999. Using modified length-weight relationships to assess the condition of fish. Aquacultural Engineering 20:261276.

Kostow, K. 2009. Factors that contribute to the ecological risks of salmon and steelhead hatchery programs and some mitigating strategies. Reviews in Fish Biology and Fisheries 19:9-31.

Larsen, D. A., D. L. Harstad, C. R. Strom, M. V. Johnston, C. M. Knudsen, D. E. Fast, T. N. Pearsons, and B. R. Beckman. 2013. Early life history variation in hatcheryand natural-origin spring Chinook Salmon in the Yakima River, Washington. Transactions of the American Fisheries Society 142:540-555. 
Mitteroecker, P., and P. Gunz. 2009. Advances in Geometric Morphometrics. Evolutionary Biology 36:235-247.

Myers, R. A., S. A. Levin, R. Lande, F. C. James, W. W. Murdoch, and R. T. Paine. 2004. Hatcheries and endangered salmon. Science 303:1980.

NOAA Fisheries. 2008. Biological Opinion (BiOp) on the operation of the Federal Columbia River Power System (FCRPS). U.S. Department of Commerce, National Marine Fisheries Service, Northwest Regional Office, Seattle, WA.

Pakkasmaa, S., and J. Piironen. 2000. Water velocity shapes juvenile salmonids. Evolutionary Ecology 14:721-730.

Petrosky, C. E., and H. A. Schaller. 2010. Influence of river conditions during seaward migration and ocean conditions on survival rates of Snake River Chinook salmon and steelhead. Ecology of Freshwater Fish 19:520-536.

Ploskey, G., M. Weiland, and T. Carlson. 2012. Route-specific passage proportions and survival rates for fish passing through John Day Dam, The Dalles Dam, and Bonneville Dam in 2010 and 2011. Pacific Northwest National Laboratory, Richland, WA, PNNL-21442.

Radchenko, V. 1998. Historical trends of fisheries and stock condition of Pacific salmon in Russia. North Pacific Anadromous Fish Commission Bulletin 1:28-37.

Reeves, G. H., L. E. Benda, K. M. Burnett, P. A. Bisson, and J. R. Sedell. 1995. A disturbance-based ecosystem approach to maintaining and restoring freshwater habitats of evolutionarily significant units of anadromous salmonids in the Pacific Northwest. American Fisheries Society Symposium 17:334-349. 
Reisenbichler, R. R., and S. P. Rubin. 1999. Genetic changes from artificial propagation of Pacific salmon affect the productivity and viability of supplemented populations. ICES Journal of Marine Science 56:459-466.

Reisenbichler, R. R., S. P. Rubin, L. Wetzel, and S. Phelps. 2008. Natural selection after release from a hatchery leads to domestication in steelhead, Oncorhynchus mykiss. Stock Enhancement and Sea Ranching: Developments, Pitfalls and Opportunities (2008): 371.

Rohlf, F. J. 2001. TPSDIG. Department of Ecology and Evolution, State University of New York at Stony Brook, Stony Brook, New York, USA.

Rohlf, F. J., and D. Slice. 1990. Extensions of the Procrustes method for the optimal superimposition of landmarks. Systematic Biology 39:40-59.

Schaller, H. A., and C. E. Petrosky. 2007. Assessing hydrosystem influence on delayed mortality of Snake River stream-type Chinook salmon. North American Journal of Fisheries Management 27:810-824.

Schaller, H. A., C. E. Petrosky, and O. P. Langness. 1999. Contrasting patterns of productivity and survival rates for stream-type Chinook salmon (Oncorhynchus tshawytscha) populations of the Snake and Columbia rivers. Canadian Journal of Fisheries and Aquatic Sciences 56:1031-1045.

Shearer, K. D., and P. Swanson. 2000. The effect of whole body lipid on early sexual maturation of 1+ age male Chinook salmon (Oncorhynchus tshawytscha). Aquaculture 190:343-367. 
Sheer, M. B., and E. A. Steel. 2006. Lost watersheds: Barriers, aquatic habitat connectivity, and salmon persistence in the Willamette and Lower Columbia River basins. Transactions of the American Fisheries Society 135:1654-1669.

Skalski, J. R., R. L. Townsend, A. G. Seaburg, G. E. Johnson, G. R. Ploskey, and T. J. Carlson. 2012a. Compliance monitoring of juvenile yearling Chinook salmon and steelhead survival and passage at The Dalles Dam, spring 2011. Pacific Northwest National Laboratory, Richland, WA.

Skalski, J. R., R. L. Townsend, A. G. Seaburg, G. R. Ploskey, and T. J. Carlson. 2012b. Compliance monitoring of yearling Chinook salmon and juvenile steelhead survival and passage at Bonneville Dam, spring 2011. Pacific Northwest National Laboratory, Richland, WA.

Skalski, J. R., R. L. Townsend, A. G. Seaburg, M. A. Weiland, C. M. Woodley, J. S. Hughes, and T. J. Carlson. 2012c. Compliance monitoring of yearling Chinook salmon and juvenile steelhead survival and passage at John Day Dam, spring 2011. Pacific Northwest National Laboratory, Richland, WA.

Smith, S. G., W. D. Muir, E. E. Hockersmith, R. W. Zabel, R. J. Graves, C. V. Ross, W. P. Connor, and B. D. Arnsberg. 2003. Influence of river conditions on survival and travel time of Snake River sub-yearling fall Chinook Salmon. North American Journal of Fisheries Management 23:939-961.

Swain, D. P., B. E. Riddell, and C. B. Murray. 1991. Morphological differences between hatchery and wild populations of Coho salmon (Oncorhynchus kisutch): 
Environmental versus genetic origin. Canadian Journal of Fisheries and Aquatic Sciences 48:1783-1791.

Unwin, M. J., and G. J. Glova. 1997. Changes in life history parameters in a naturally spawning population of chinook salmon (Oncorhynchus tshawytscha) associated with releases of hatchery-reared fish. Canadian Journal of Fisheries and Aquatic Sciences 54:1235-1245.

Webb, P. W. 1984. Body form, locomotion and foraging in aquatic vertebrates. American Zoologist 24:107-120.

Weiland, M. A., C. M. Woodley, G. R. Ploskey, J. S. Hughes, J. A. Kim, Z. Deng, T. Fu, E. S. Fischer, J. Skalski, and R. L. Townsend. 2013. Acoustic telemetry evaluation of juvenile salmonid passage and survival at John Day Dam, 2010. Pacific Northwest National Laboratory, Richland, WA. PNNL 22177.

Wessel, M. L., W. W. Smoker, and J. E. Joyce. 2006. Variation of morphology among juvenile Chinook salmon of hatchery, hybrid, and wild origin. Transactions of the American Fisheries Society 135:333-340.

Williams, J. G., R. W. Zabel, R. S. Waples, J. A. Hutchings, and W. P. Connor. 2008. Potential for anthropogenic disturbances to influence evolutionary change in the life history of a threatened salmonid. Evolutionary Applications 1:271-285.

Winans, G. A. 1984. Multivariate morphometric variability in Pacific salmon: Technical demonstration. Canadian Journal of Fisheries and Aquatic Sciences 41:11501159. 
Zorich, N. A., M. R. Jonas, and P. L. Madson. 2011. Avian predation at Jonh Day and The Dalles Dams 2010: Estimating fish consumption using direct observation with diet analysis. U.S. Army Corps of Engineers. 
Table 4.1. Summary statistics showing the mean and standard deviation for juvenile Chinook salmon and steelhead migrating through the Columbia River.

\begin{tabular}{lllll}
\hline \multicolumn{1}{c}{ Species } & \multicolumn{1}{c}{ Centroid Size } & \multicolumn{1}{c}{ Length $(\mathbf{m m})$} & \multicolumn{1}{c}{ Weight $(\mathrm{g})$} & \multicolumn{1}{c}{ Condition Factor } \\
\hline Chinook salmon & & & & \\
$\quad$ Wild & $23.45( \pm 3.88)$ & $143.9( \pm 23.68)$ & $29.88( \pm 15.07)$ & $0.921( \pm 0.06)$ \\
$\quad$ Hatchery & $25.34( \pm 3.31)$ & $156.1( \pm 19.71)$ & $37.03( \pm 15.07)$ & $0.923( \pm 0.06)$ \\
Welch Two & $t=-5.945$ & $t=-6.332$ & $t=-5.378$ & $t=-0.359$ \\
Sample t-test & $d f=494$ & $d f=490$ & $d f=511$ & $d f=511$ \\
& $p<0.001$ & $p<0.001$ & $p<0.001$ & $p=0.719$ \\
Steelhead & & & & \\
Wild & $30.91( \pm 4.79)$ & $192.3( \pm 27.76)$ & $62.65( \pm 33.18)$ & $0.846( \pm 0.06)$ \\
Hatchery & $33.43( \pm 3.34)$ & $206.5( \pm 19.18)$ & $74.29( \pm 23.98)$ & $0.816( \pm 0.06)$ \\
Welch Two & $t=-4.250$ & $t=-4.687$ & $t=-2.807$ & $t=3.650$ \\
Sample t-test & $d f=105.9$ & $d f=105.3$ & $d f=108.1$ & $d f=128.3$ \\
& $p<0.001$ & $p<0.001$ & $p=0.006$ & $p<0.001$ \\
\hline
\end{tabular}


Table 4.2. Individual general linear model comparison of shape variation as a function of size, origin and the interaction of size and origin of juvenile Chinook salmon and steelhead in the Columbia River. Results indicate significant effects of centroid size (size), fish origin (wild or hatchery), and the interaction of centroid size and origin. Significant interaction of centroid size and origin indicates that shape changes differently for hatchery and wild fish with size (i.e. heterogeneity of slope vectors with size).

\begin{tabular}{|c|c|c|c|}
\hline Model & df & $\boldsymbol{F}$ & $\boldsymbol{P}$ \\
\hline \multicolumn{4}{|l|}{ Chinook salmon } \\
\hline Shape $\sim \log ($ Size $)$ & 1 & 44.42 & 0.001 \\
\hline Shape $\sim$ Origin & 1 & 34.98 & 0.001 \\
\hline Shape $\sim \log ($ Size $):$ Origin & 1 & 4.05 & 0.001 \\
\hline Total & 513 & & \\
\hline \multicolumn{4}{|l|}{ Steelhead } \\
\hline Shape $\sim \log ($ Size $)$ & 1 & 34.68 & 0.001 \\
\hline Shape $\sim$ Origin & 1 & 64.07 & 0.001 \\
\hline Shape $\sim \log ($ Size $):$ Origin & 1 & 4.58 & 0.001 \\
\hline Total & 275 & & \\
\hline
\end{tabular}


Table 4.3. Results from reduced redundancy analysis models of shape variation and selected predictor variables. All listed RDA axis were statistically significant $(p<0.05)$. Bold numbers represent correlations between shape variables and predictor variables that were $>0.4$.

\begin{tabular}{|c|c|c|c|c|c|}
\hline Species & $\begin{array}{l}\text { Predictor } \\
\text { Variables } \\
\end{array}$ & RDA1 & RDA2 & RDA3 & RDA4 \\
\hline \multicolumn{6}{|l|}{ Chinook } \\
\hline Eigenvalues & & 3.63 & 1.89 & 0.77 & 0.30 \\
\hline \multirow[t]{5}{*}{$\%$ of Constrained Variance Explained } & & $8.6 \%$ & $4.5 \%$ & $1.8 \%$ & $0.7 \%$ \\
\hline & Origin & 0.384 & -0.919 & 0.034 & -0.085 \\
\hline & Size & -0.898 & -0.062 & 0.362 & -0.242 \\
\hline & Condition Factor & -0.587 & -0.266 & -0.758 & 0.107 \\
\hline & Julian Day & -0.081 & -0.086 & 0.061 & 0.991 \\
\hline \multicolumn{6}{|l|}{ Steelhead } \\
\hline Eigenvalues & & 5.01 & 2.30 & 0.77 & \\
\hline \multirow{4}{*}{$\%$ of Constrained Variance Explained } & & $11.9 \%$ & $5.5 \%$ & $1.8 \%$ & \\
\hline & Origin & 0.912 & -0.257 & 0.319 & \\
\hline & Size & -0.653 & -0.550 & 0.520 & \\
\hline & Condition Factor & 0.081 & -0.950 & -0.303 & \\
\hline
\end{tabular}




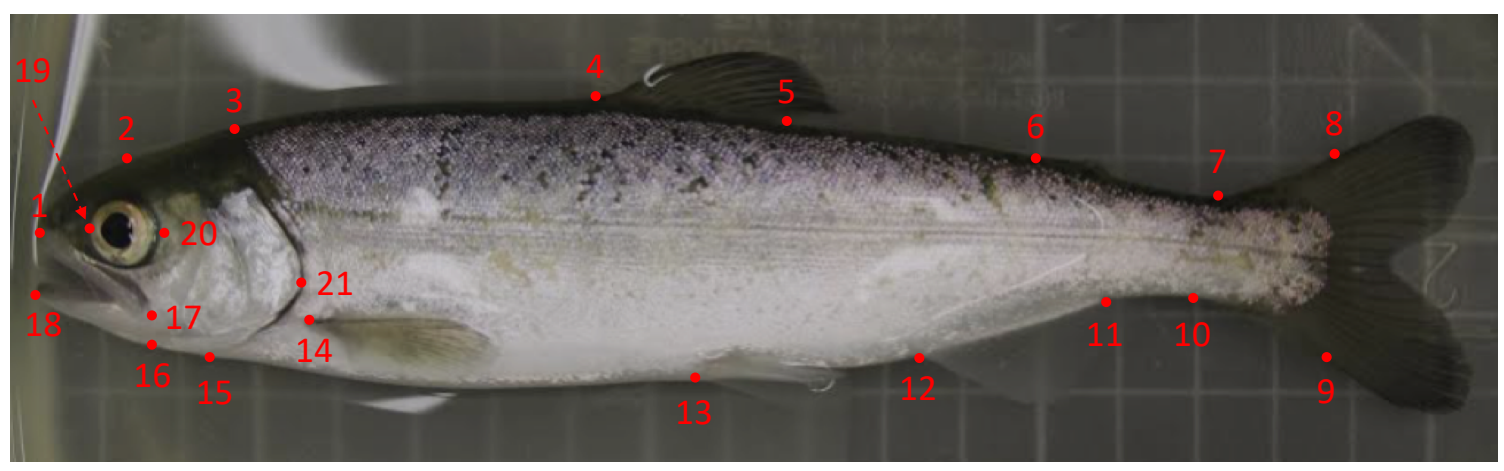

Figure 4.1. Landmark locations used in geometric morphometric analysis of juvenile Chinook salmon and steelhead. Landmark locations are from Fraser et al. (2010). 


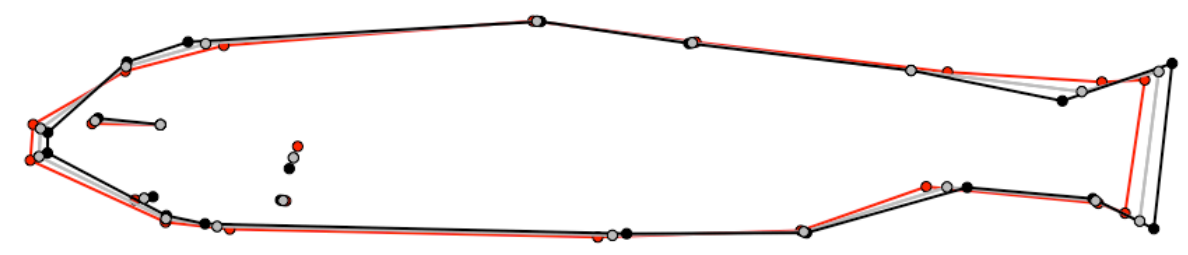

(b

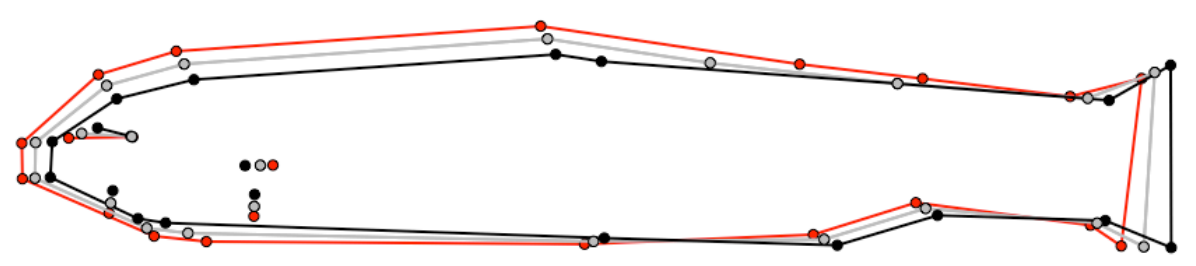

Figure 4.2. Generalized Procrustes aligned consensus shapes (grey circles and grey links), average hatchery shape (black circles and black links), and average wild shape (red circles and red links) in a) Chinook salmon and b) steelhead. Shape differences are magnified by a factor of 5 to aid visual interpretation. 


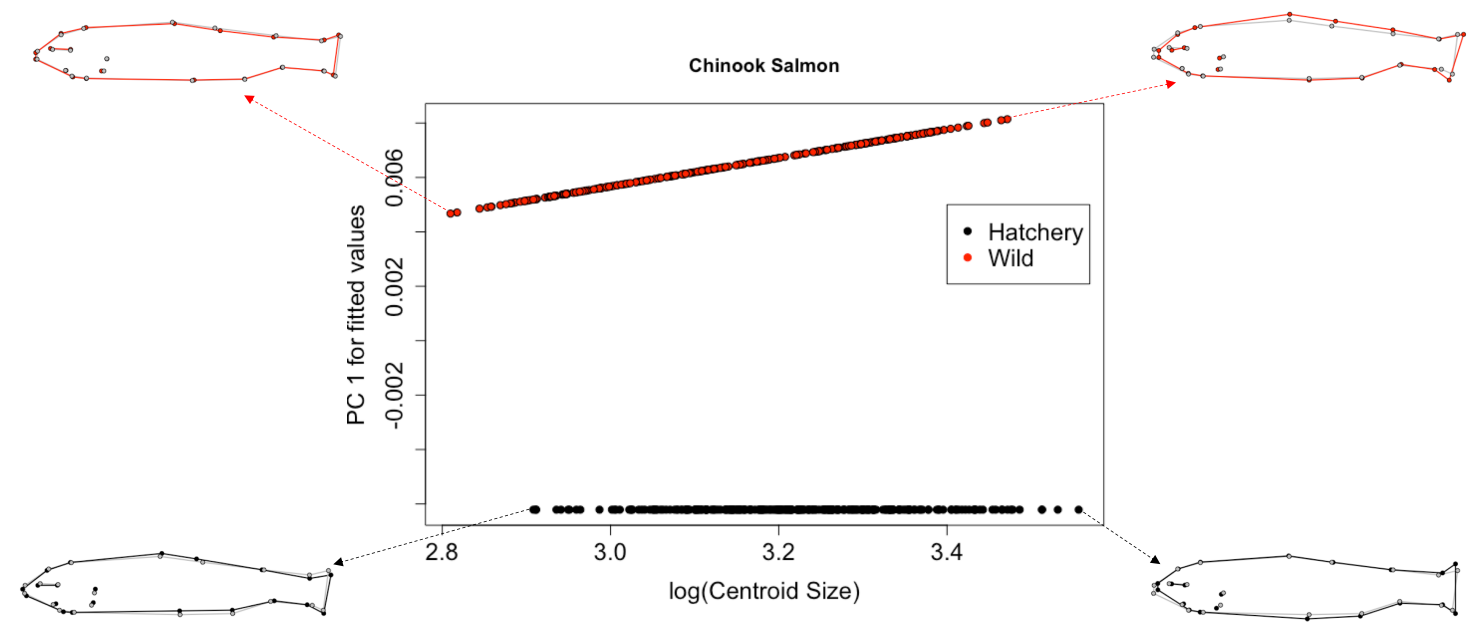

Figure 4.3. Allometric vectors for wild (red) and hatchery (black) Chinook salmon showing heterogeneous slopes of shape across sizes. Slope vector magnitude (i.e. shape change per $\mathrm{mm}$ of size change) is not significant but angles between slope vectors $\left(37.1^{\circ}\right)$ is significantly different between wild and hatchery fish. Differences between consensus and referenced shapes are magnified by a factor of 2 to aid visual interpretation. 


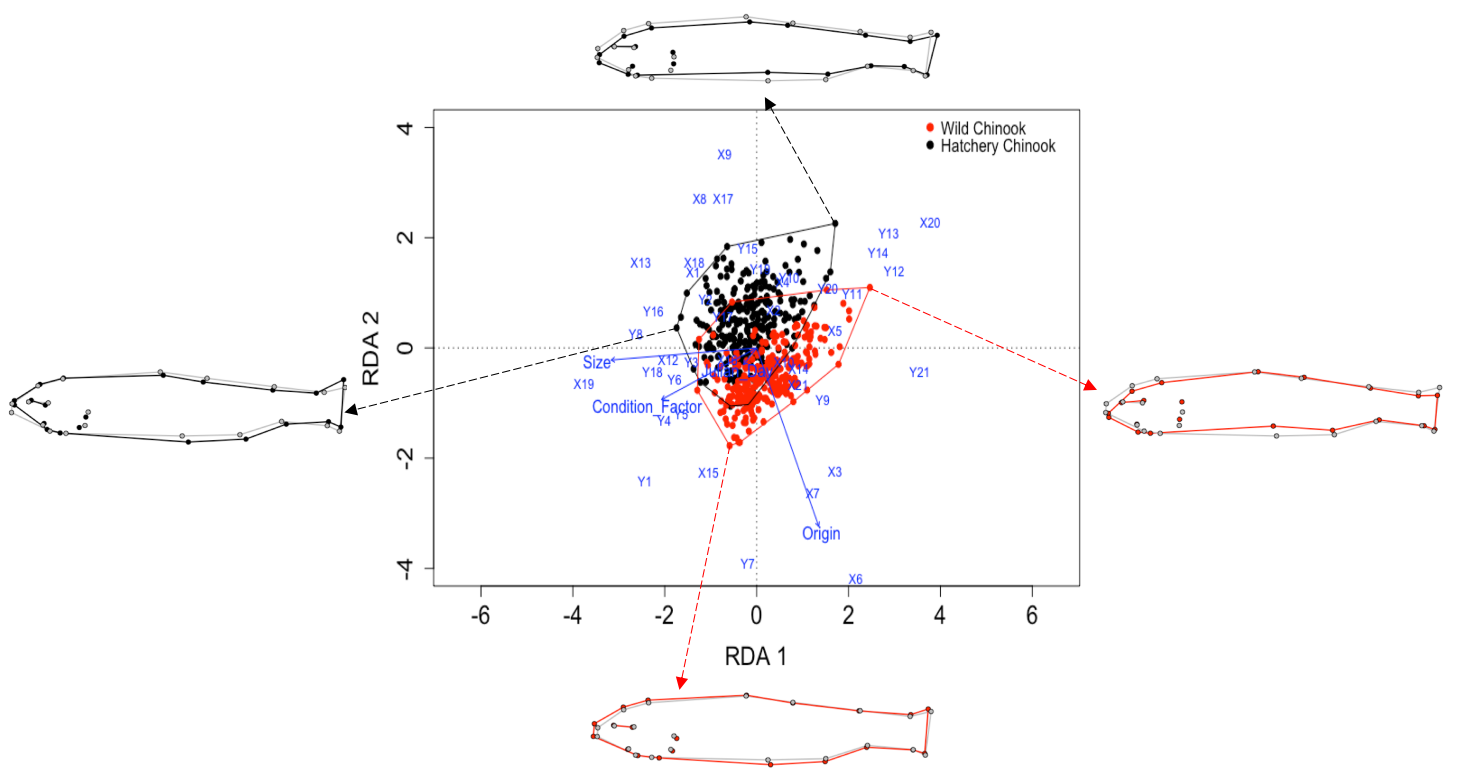

Figure 4.4. Constrained ordination plot for Chinook salmon with wild (red points and lines) and hatchery (black points and lines) fish, as well as correlations with predictor variables (blue vectors and text). Landmark numbers are plotted in blue. Fish shapes (red $=$ wild, black $=$ hatchery and grey $=$ consensus $)$ are the maximum and minimum shapes found along each axis. Differences between consensus and referenced shapes are magnified by a factor of 2 to aid visual interpretation. 


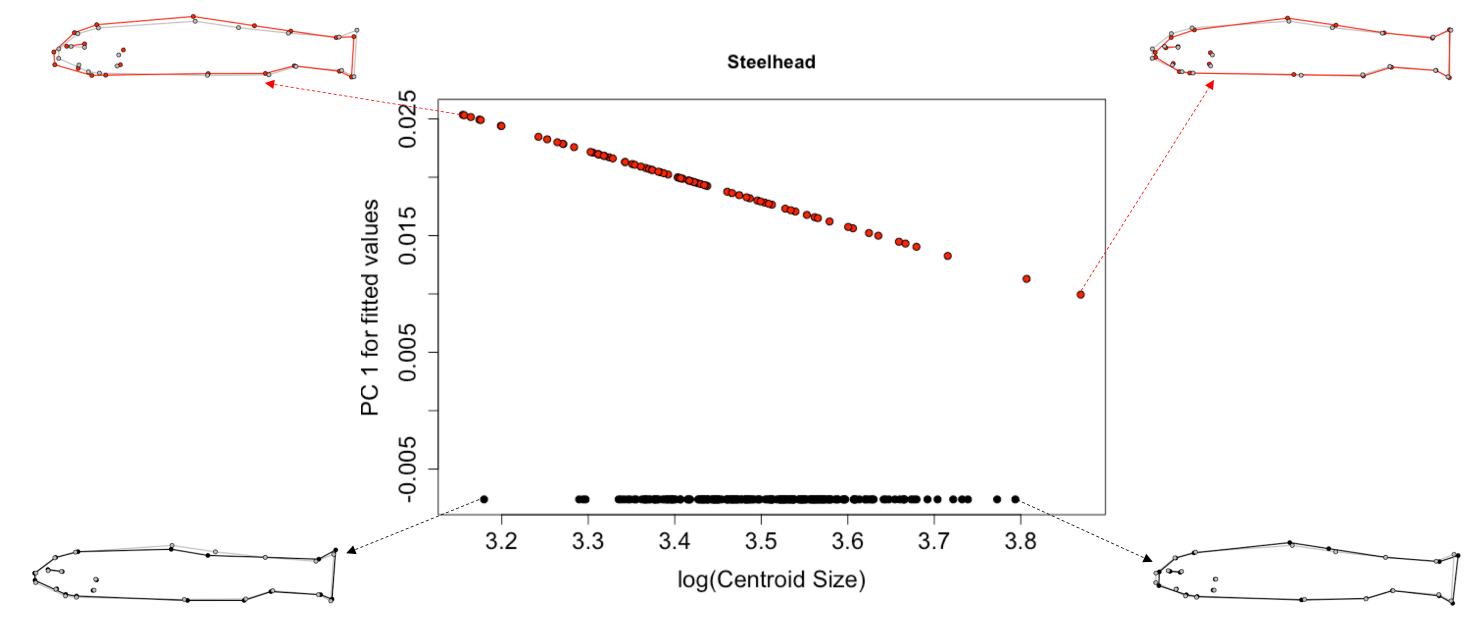

Figure 4.5. Allometric vectors for wild (red) and hatchery (black) steelhead showing heterogeneous slopes. Slope vector magnitude is not significant but angles between slope vectors $\left(55.3^{\circ}\right)$ is significantly different between wild and hatchery fish. Differences between consensus and referenced shapes are magnified by a factor of 2 to aid visual interpretation. 


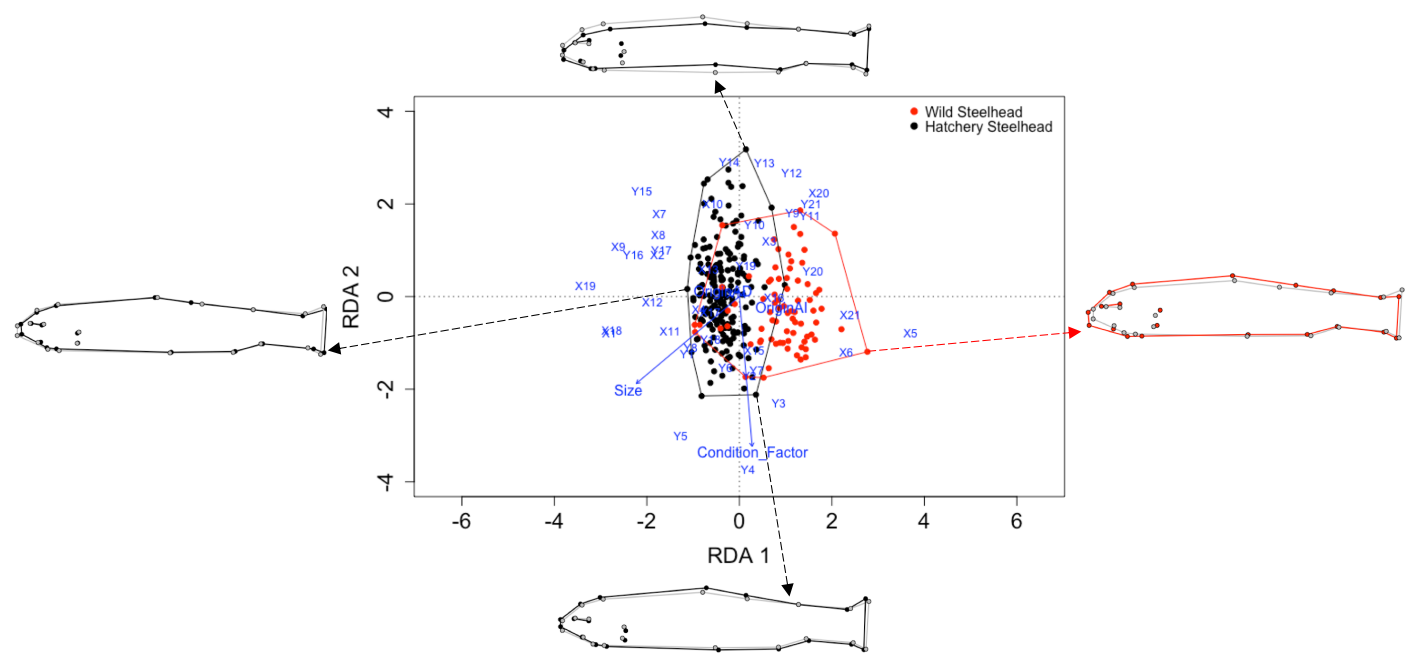

Figure 4.6. Constrained ordination plot for steelhead with wild (red points and lines) and hatchery (black points and lines) fish and correlations with predictor variables (blue vectors and text). Landmark numbers are plotted in blue. Fish shapes (red = wild, black $=$ hatchery and grey $=$ consensus) are the maximum and minimum shapes found along each axis. Differences between consensus and referenced shapes are magnified by a factor of 2 to aid visual interpretation. 


\section{Chapter 5 - Conclusion}

The broad breadth of my research investigated how human-caused alterations, within and adjacent to the Columbia River, have affected salmonid species within the context of a large riverscape. This work has been conducted through a lens of biotic and abiotic connectivity across spatial and temporal scales. While all of my data consisted of observations at the individual level, my focus has always been on the big picture and population-level effects. While salmon exhibit a staggering amount of plasticity and can vary from one watershed to another, there are a great many lessons to learn at the level of the population (Reeves et al. 1995, Greene et al. 2005). I tested the effects on migrating smolt of multiple dam passages versus a single dam passage to determine if this anthropogenic alteration creates a pulse-type ecological disturbance, or if there are cumulative and additive effects more akin to a press-type disturbance (Chapter 2). I investigated the biological and environmental factors that influence the precocious lifehistory strategy and compared fish of wild and hatchery origin (Chapter 3). Finally, I described morphological variation in smolt and compared the effects of rearing environment (i.e. hatchery vs. wild origin) on body shape (Chapter 4). The following discussion summarizes and integrates the findings of each of my chapters across salmonid habitats and life-cycle.

Rearing Environment and Early Life Experiences (Hatchery vs. Wild) Approximately $40 \%$ of historical habitat, including rearing habitat, is no longer accessible to wild fish due to anthropogenic alterations (Sheer and Steel 2006). 
Hatcheries were developed to off-set the declines in wild salmon abundance that resulted from habitat loss and over-harvesting. Hatchery rearing environments are generally spatially homogeneous, linear concrete raceways, with unvaried low water velocities, no physical structures and no predators (Wessel et al. 2006). By contrast, wild rearing environments are generally spatially heterogeneous, dynamic and varied in regards to water velocities, substrate size and composition, in-water structure, and aquatic and terrestrial predators. Generally, egg to smolt survival in hatcheries is very high (85$95 \%)$, whereas in the wild, survival over this period is typically very low (1-5\%; Waples 1999, Araki et al. 2008). Lack of this type of purifying selection in hatcheries has been cited as a contributor to rapid domestication selection (Waples 1999, Araki et al. 2008).

The environment in which salmon are reared can affect many aspects of fish behavior, physiology, life stage transitions (Chapter 3) and morphology (Chapter 4). These effects can follow individuals across environments and life stages (Chapter 3 and 4, Waples 1999, Kostow 2009). Behaviorally, hatchery-reared fish exhibit increased agonistic and dominance behavior, reduced predator avoidance, and use habitats differently than wild fish (Reisenbichler and Rubin 1999, Berejikian et al. 2001, Kostow 2009). Conditions within the hatchery setting that influence these behaviors include high fish densities, lack of predators, and food delivery methods (Berejikian et al. 2001). Physiologically, hatchery salmonids differ from wild fish in size, coloring, amount of external damage (i.e. stubbing or erosion of dorsal fin), and parasite levels (Kostow 2009, Chittenden et al. 2010). Hatchery conditions that influence physiology include high fish 
densities, and uniform feeding regimes and food type (Pakkasmaa and Piironen 2000, Brannon et al. 2004).

Morphologically, hatchery fish are longer and thinner, have smaller heads and thinner caudal peduncles compared to wild fish (Fleming and Gross 1989, Swain et al. 1991, Chapter 4). This morphological variation is suspected to reflect differences in swimming modes used in hatcheries compared to in the wild. Hatchery juveniles tend to use the sustained swimming mode that is more energetically efficient in open water with no complexity (i.e. hatchery raceway), while wild juveniles use the burst swimming mode that allows quick predator avoidance and food acquisition in dynamic environments (Fleming and Gross 1989, Swain et al. 1991, Wessel et al. 2006, Chapter 4). My research suggests that there are significant morphological differences between hatchery and wild salmonids and less overall shape variation in hatchery compared to wild steelhead (Chapter 4).

Life history strategies, such as age of maturation, differ in hatchery-reared and wild fish (Larsen et al. 2004, Harstad et al. 2014, Chapter 3). Generally, wild Chinook salmon reach sexual maturity between age 4-6 years (from fertilization to spawning), with a small proportion precociously maturing at ages $<4$ years (Gross 1991, Larsen et al. 2013, Chapter 3). In recent years, some hatcheries in the Columbia Basin have documented precocious maturation rates as high as 70\% (Harstad et al. 2014). I found that in some years $>70 \%$ of returning spring-run, hatchery Chinook salmon matured precociously compare to wild fish, whose precocious proportions never exceeded $30 \%$ in any year (Chapter 3). Precociousness in wild Chinook salmon appears to be influenced 
by density dependent processes in freshwater, with a positive relationship between the number of returning adults and the probability of maturing precociously the following broodyear (Chapter 3). This relationship may be a result of the amount of marine-derived nutrients entering the freshwater ecosystem in the form of adult salmon that increase juvenile salmon size directly (e.g. as a food source) or indirectly (e.g. increasing trophic productivity; Gresh et al. 2000).

\section{Migration Corridor}

As juvenile salmon grow, they tend to move downstream to larger streams and rivers. On average, yearling spring Chinook salmon in the Columbia Basin undergo the parr-smolt transformation around their second spring (i.e. 14-18 months post fertilization). This physiological process involves preparation for entry into salt water and affects blood chemistry, morphology, schooling behavior, color changes, and initiation of downstream migration (McCullough 1999). Hatchery fish are generally released into the river environment at the onset of smoltification. The post-release mortality rate for hatchery fish is estimated to be $>95 \%$, due in part to maladaptation to the hatchery environment that becomes deleterious in the natural environment (Reisenbichler and Rubin 1999). Once hatchery fish are released into the natural river setting they mix with wild populations and begin the process of outmigration. Depending on the location of the natal stream, flow volume, and release date, migration to the ocean may take up to one month, with some fish passing as many as eight large-scale, hydroelectric dams (Schaller and Petrosky 2007, Haeseker et al. 2012, Chapter 2). There 
has been ongoing debate about how experiences within the migration corridor, specifically dam passages, affect later life stages (see Schaller and Petrosky 2007, Rechisky et al. 2013). A growing body of evidence suggests that dam passage experiences influence survival rates of salmonids at later life stages (i.e. delayed or latent mortality; Budy et al. 2002, Schaller and Petrosky 2007, Petrosky and Schaller 2010, Haeseker et al. 2012, Rechisky et al. 2013). I found that in the lower Columbia River hydrosystem, the close spatial proximity of dams (i.e. John Day, The Dalles, and Bonneville dams within 229 river $\mathrm{km}$ ) created a press-type of ecological disturbance for fish passing all three dams. The deleterious environmental conditions created by the dams persisted through the hydrosystem and prevented physiological recovery between passages leading to lower survival (Chapter 2).

Fish passing more dams during periods of deleterious environmental conditions, such as high levels of supersaturated dissolved gas concentrations, had lower survival than fish passing a single dam during the same conditions. Fish velocity through the entire hydrosystem had a positive relationship with survival during these deleterious conditions, whereas velocity had little effect on survival for fish passing a single dam (Chapter 2). Chinook salmon and steelhead had statistically similar survival rates through the lower Columbia River hydrosystem, despite differences in body size and life history patterns (Chapter 2).

Marine Environment 
The period of salt water entry, following migration through the Columbia River hydrosystem, is increasingly understood to be a critical period for salmonids (Beamish and Mahnken 2001, Tomaro et al. 2012, Tucker et al. 2012). Historically, the marine phase of salmonid life cycles has been extremely difficult to study, but long-term data sets and new technologies (e.g. microsatellite DNA, hydro-acoustic telemetry along the continental shelf, PIT Tag Information System) have been shedding light (Beamish and Mahnken 2001, Tucker et al. 2012, Teel et al. 2015). Variation exists between populations, but in general, migrating spring-run Chinook salmon smolt arrive in the lower Columbia River estuary and river plume between April - May of each year (Tomaro et al. 2012). Following saltwater transition, marine trophic conditions (i.e. abundance and composition of secondary production) during the early stages of salmon ocean residence are thought to affect growth (Tomaro et al. 2012). Fisher et al (2014) found that the average northward dispersal rate of recent ocean emigrants near the mouth of the Columbia River was slower than juveniles caught farther north and suggested that this slower dispersal rate likely reflects a period of acclimation to seawater and directional orientation, but also foraging in productive inshore waters (Fisher et al. 2014). I found evidence that precocious maturation in wild fish is influenced by trophic conditions experienced in the marine environment. For wild Chinook salmon that surpassed a maturation size threshold $(>150 \mathrm{~mm})$ during freshwater residence, productive marine conditions (i.e. cold, high salinity, nutrient rich water) increase the probability of precocious maturation (Chapter 3). Hatchery Chinook salmon were generally influenced by marine conditions but displayed a tremendous amount of variability and displayed no 
relationship between juvenile size and productive marine conditions. I concluded that hatchery fish, in general, attain the critical sizes required to initiate maturation prior to hatchery release and earlier than wild fish, resulting in physiological asynchrony from the environmental cues that affect wild fish (Chapter 3).

\section{Spawning}

Following the marine phase, returning adults between the ages 2 and 6 re-enter freshwater and begin their migrations back towards their natal streams. In one long-term study (1998-2006), fewer than 1\% of hatchery released smolt survived to adulthood (release and return at Lower Granite Dam; Haeseker et al. 2012). In 2003, a target of 4\% survival for the smolt to adult life stage was set; however, this target has rarely been met by Snake River and Upper Columbia fishes (Haeseker et al. 2012). Fish migrating upstream face anthropogenic challenges including fish ladder bottlenecks that slow migration and increased novel predation pressures. For semelparous Chinook salmon, precociousness is thought to be more prevalent in stream-type populations that spend extended periods ( $\sim 18$ months) growing in low productivity, low order streams before initiating migration seaward as smolt (Taylor 1990, Mullan et al. 1992, Clarke and Blackburn 1994, Johnson et al. 2012, Schroder et al. 2012). Reproductive success for female salmon is proportional to body size and thus it is always advantageous for females to achieve larger sizes (Jonsson et al. 2013). Males compete with other large males to maximize fertilization success with multiple females. Schroder et al (2012) found that large, anadromous males on the spawning grounds produced $89 \%$ of fry, while 
precocious strategies produced only $11 \%$ (Schroder et al. 2012). The prevalence of the anadromous adult strategy in the Columbia basin suggests that the competitive strategy has historically been the most successful reproductive strategy despite facing the forces of mortality associated with freshwater migration and ocean residence (Unwin and Glova 1997).

In their seminal paper, Wilbur and Collins (1973) reported strong density dependent effects on amphibian Rana sylvatica larva; higher densities resulted in significantly lower mean body weights and an inverse relationship between size and age at metamorphosis. The authors interpreted the density dependent effects as a result of competition for limited food resources and an emergent size advantage for larger individuals (Wilbur and Collins 1973). My research found that the probability of precociousness increased in larger fish in years preceding high densities of adult returns (Chapter 3). The effect of subbasin (Lower Columbia, Upper Columbia, Snake River) on precociousness ranked low in importance, suggesting that density dependent responses resulting from adult returns may be ubiquitous within wild Chinook salmon regardless of genetic isolation between populations. In years following high adult returns, I assume that more juveniles would be produced, thus competition for limited resources in rearing areas and in the migration corridor would increase. In these years, there may be an advantage conferred to larger individuals that mature early, based on limiting competition throughout subsequent life stages. From an evolutionary perspective, the precocious strategy may be a mechanism to limit this type of density-dependent competition between 
conspecifics (or other stocks) in resource limited rearing streams and throughout the migration corridor (Weitkamp et al. 2015, Chapter 3).

\section{Implications}

Over the past 150 years the major anthropogenic stressors to salmonid populations in the Columbia River have changed (i.e. 4H's; Gresh et al. 2000). In the late 1800 s and early 1900 s, commercial fish harvest was the major force impacting salmonids. Coinciding with the decline of the most productive harvest period, hydroelectric power facilities began blocking salmon passage to large sections of historical habitat and preventing movement of fishes between critical habitats (Gresh et al. 2000). To help struggling salmon populations, the industrial hatchery industry was created to supplement salmon numbers to ensure continued commercial harvest. Currently, $80-90 \%$ of salmon in the Columbia River are of hatchery origin (Williams et al. 1999, Brannon et al. 2004).

While major advancements have been made in identifying and ameliorating negative effects of anthropogenic alterations within the Columbia Basin, many wild populations continue to decline (Kareiva et al. 2000). My research and the findings of others, suggests that physical and operational alterations within the lower Columbia hydrosystem have substantially improved conditions for migrating smolt (Chapter 2, Muir et al. 2001, Schaller and Petrosky 2007, Petrosky and Schaller 2010). While voluntary spill at dams has played an important role in improving conditions, harmful dissolved gas levels remain an ongoing challenge for dam managers. Dissolved gas 
concentrations exceeded the State of Oregon water quality standards in 9 of 10 years between 2001-2011 (Chapter 2). Riverscape-scale management strategies that recognize biotic and abiotic connectivity between dams (i.e. press disturbance) will likely benefit migrating smolt. Climate change has altered the timing and magnitude of the spring freshet in the Columbia River compared to conditions before the 1900s and will likely continue to add environmental uncertainty (Naik and Jay 2011). High flow conditions during the spring freshet, as seen in 2011, may become less frequent but strategies that can mitigate involuntary spill and the associated deleterious environmental conditions that result will benefit salmonids (Chapter 2).

Large-scale habitat restoration and recovery remain the most likely management tools to improve wild salmonid populations in the Columbia River (Reeves et al. 1995, Williams et al. 1999). For habitat restoration and recovery to be effective, it must address all critical habitats required by the life history constraints of salmonids including spawning, rearing, migration, estuary, and marine habitats (Schlosser 1991). In terms of habitat restoration, the majority of management attention in the Columbia Basin has been on reducing the effects of hydropower on migrating smolt. While improvements to this habitat and to this life stage have been relatively successful, these actions mainly just stem loss of hatchery fish to hydropower related mortality and do little to rebuild selfsustaining wild populations. In recent years, dam removal has been more seriously considered as a means to reconnect historical habitat and wild populations. The removal of the Condit Dam on the Little White Salmon river, a tributary of the Columbia River, is widely accepted as a success story. In 2012, one year after the removal of this $38 \mathrm{~m}$ tall, 
100-year-old dam, $>200$ spawned salmon carcasses were found upstream of the breach site. Of those spawned salmon, 93\% were wild fish (Allen et al. 2016). Dam removal studies indicate that rivers are resilient and often exhibit quick physical, ecological and biological recoveries within months and years, not decades, following dam removals (O'Connor et al. 2015). With over $50 \%$ of the 85,000 dams in the United States no longer serving their intended purpose, dam removal and upstream habitat reclamation may be a tool used increasingly to manage fisheries (O'Connor et al. 2015, Allen et al. 2016).

The potential for deleterious effects arising from hatchery inputs within the Columbia River Basin continues to be a critical issue (Galbreath et al. 2008). The current available information regarding genetic, demographic, and ecological risks of hatchery fish on wild populations is insufficient to adequately manage the myriad possible negative effects (Galbreath et al. 2008). However, there is substantial evidence that interactions between hatchery and wild fish are detrimental to wild populations (i.e. agonistic behavior, density dependent mortality, increased predation pressures, size at release, long freshwater residency, introgression and reduced fitness of offspring; Brannon et al. 2004, Araki et al. 2008, Kostow 2009). Artificial rearing practices are incredibly successful at raising salmonids in captivity and will continue to play an important conservation role in the Columbia Basin, but these fish rarely meet the varied outcomes desired upon release into the wild environment. My research indicates that hatchery fish are not currently equal or adequate replacements for wild fish (Chapters 3 and 4). While hatcheries vary greatly in their stated goals and desired outcomes, several 
changes to general hatchery practices may help produce more fish that are more similar to wild fish. These include: 1) changing the goals away from producing as many, large individuals as possible to producing fish that resemble the targeted wild populations they supposedly support, 2) altering the hatchery environment to reflect the rearing environments in which salmon evolved and into which they will be released, and 3) reducing the number of hatchery fish released annually into the Columbia Basin for the sole purpose of harvest.

An additional danger exists in how policymakers regard wild and hatchery fish. For example, hatchery fish produced from wild ESU broodstock may be included within that ESU, resulting in delisting of threatened and endangered populations based on large numbers of hatchery origin fish (Myers et al. 2004). In 2001, a U.S. District Court Judge removed the ESA listing of Oregon coast Coho salmon, citing that abundant hatchery fish produced with this broodstock were genetically associated with the ESU (Myers et al. 2004). Lastly, hatchery supplementation has never been intended to be a long-term solution and does not address the root causes of salmonid declines (Dahl et al. 2006). Hatchery fish perpetuate a perception that salmon populations are healthier and more robust than they actually are. Reducing hatchery supplementation may help inform public perception about the true state of salmonid imperilment in the Columbia River Basin and help tip the scales regarding policy actions that address the root causes of salmon declines. 


\section{References}

Allen, M. B., Engle, R. O., Zendt, J. S., Shrier, F. C., Wilson, J. T., \& Connolly, P. J. 2016. Salmon and steelhead in the White Salmon River after the removal of Condit Dam-Planning efforts and recolonization results. Fisheries, 41: 190-203.

Araki, H., B. A. Berejikian, M. J. Ford, and M. S. Blouin. 2008. Fitness of hatcheryreared salmonids in the wild. Evolutionary Applications 1:342-355.

Beamish, R. J., and C. Mahnken. 2001. A critical size and period hypothesis to explain natural regulation of salmon abundance and the linkage to climate and climate change. Progress in Oceanography 49:423-437.

Berejikian, B. A., E. P. Tezak, T. A. Flagg, A. L. LaRae, and E. R. Kummerow. 2001. Social dominance, growth, and habitat use of age-0 steelhead. Development of a Natural Rearing System to Improve Supplemental Fish Quality, 96.

Brannon, E. L., D. F. Amend, M. A. Cronin, J. E. Lannan, S. LaPatra, W. J. McNeil, R. E. Noble, C. E. Smith, A. J. Talbot, G. A. Wedemeyer, and H. Westers. 2004. The controversy about salmon hatcheries. Fisheries 29:12-31.

Budy, P., G. P. Thiede, N. Bouwes, C. E. Petrosky, and H. Schaller. 2002. Evidence linking delayed mortality of snake river salmon to their earlier hydrosystem experience. North American Journal of Fisheries Management 22:35-51.

Chittenden, C. M., C. A. Biagi, J. G. Davidsen, A. G. Davidsen, H. Kondo, A. McKnight, O.-P. Pedersen, P. A. Raven, A. H. Rikardsen, J. M. Shrimpton, B. Zuehlke, R. S. McKinley, and R. H. Devlin. 2010. Genetic versus rearing-environment effects on 
phenotype: hatchery and natural rearing effects on hatchery- and wild-born Coho salmon. PLOS ONE 5:e12261.

Clarke, W. C., and J. Blackburn. 1994. Effect of growth on early sexual maturation in stream-type chinook salmon (Oncorhynchus tshawytscha). Aquaculture 121:95103.

Dahl, J., E. Pettersson, J. Dannewitz, T. Järvi, and A. Löf. 2006. No difference in survival, growth and morphology between offspring of wild-born, hatchery and hybrid brown trout (Salmo trutta). Ecology of Freshwater Fish 15:388-397.

Fisher, J. P., L. A. Weitkamp, D. J. Teel, S. A. Hinton, J. A. Orsi, E. Farley Jr, J. Morris, M. Thiess, R. Sweeting, and M. Trudel. 2014. Early ocean dispersal patterns of Columbia River Chinook and coho salmon. Transactions of the American Fisheries Society 143:252-272.

Fleming, I. A., and M. R. Gross. 1989. Evolution of adult female life history and morphology in a pacific salmon (Coho: Oncorhynchus kisutch). Evolution 43:141-157.

Galbreath, P. F., C. A. Beasley, B. A. Berejikian, R. W. Carmichael, D. E. Fast, M. J. Ford, J. A. Hesse, L. L. McDonald, A. R. Murdoch, and C. M. Peven. 2008. Recommendations for broad scale monitoring to evaluate the effects of hatchery supplementation on the fitness of natural salmon and steelhead populations. Final Draft Report of the Ad Hoc Supplementation Monitoring and Evaluation Workgroup. 
Greene, C. M., D. W. Jensen, G. R. Pess, E. A. Steel, and E. Beamer. 2005. Effects of environmental conditions during stream, estuary, and ocean residency on chinook salmon return rates in the Skagit River, Washington. Transactions of the American Fisheries Society 134:1562-1581.

Gresh, T., J. Lichatowich, and P. Schoonmaker. 2000. An estimation of historic and current levels of salmon production in the northeast pacific ecosystem: Evidence of a nutrient deficit in the freshwater systems of the pacific northwest. Fisheries $25: 15-21$.

Gross, M. R. 1991. Salmon breeding behavior and life history evolution in changing environments. Ecology 72:1180-1186.

Haeseker, S. L., J. A. McCann, J. Tuomikoski, and B. Chockley. 2012. Assessing freshwater and marine environmental influences on life-stage-specific survival rates of snake river spring-summer chinook salmon and steelhead. Transactions of the American Fisheries Society 141:121-138.

Harstad, D. L., D. A. Larsen, and B. R. Beckman. 2014. Variation in minijack rate among hatchery populations of Columbia River Basin Chinook salmon. Transactions of the American Fisheries Society 143:768-778.

Johnson, J., T. Johnson, and T. Copeland. 2012. Defining life histories of precocious male parr, minijack, and jack Chinook salmon using scale patterns. Transactions of the American Fisheries Society 141:1545-1556. 
Jonsson, B., N. Jonsson, and A. G. Finstad. 2013. Effects of temperature and food quality on age and size at maturity in ectotherms: an experimental test with Atlantic salmon. Journal of Animal Ecology 82:201-210.

Kareiva, P., M. Marvier, and M. McClure. 2000. Recovery and management options for spring/summer Chinook salmon in the Columbia River Basin. Science 290:977979.

Kostow, K. 2009. Factors that contribute to the ecological risks of salmon and steelhead hatchery programs and some mitigating strategies. Reviews in Fish Biology and Fisheries 19:9-31.

Larsen, D. A., B. R. Beckman, K. A. Cooper, D. Barrett, M. Johnston, P. Swanson, and W. W. Dickhoff. 2004. Assessment of high rates of precocious male maturation in a spring Chinook salmon supplementation hatchery program. Transactions of the American Fisheries Society 133:98-120.

Larsen, D. A., D. L. Harstad, C. R. Strom, M. V. Johnston, C. M. Knudsen, D. E. Fast, T. N. Pearsons, and B. R. Beckman. 2013. Early life history variation in hatcheryand natural-origin spring Chinook Salmon in the Yakima River, Washington. Transactions of the American Fisheries Society 142:540-555.

McCullough, D. A. (1999). A review and synthesis of effects of alterations to the water temperature regime on freshwater life stages of salmonids, with special reference to Chinook salmon. U.S. Environmental Protection Agency, Region 10.

Muir, W. D., S. G. Smith, J. G. Williams, and B. P. Sandford. 2001. Survival of juvenile salmonids passing through bypass systems, turbines, and spillways with and 
without flow deflectors at Snake River dams. North American Journal of Fisheries Management 21:135-146.

Mullan, J. W., A. Rockhold, and C. R. Chrisman. 1992. Communications: Life histories and precocity of Chinook salmon in the mid-Columbia River. The Progressive Fish-Culturist 54:25-28.

Myers, R. A., S. A. Levin, R. Lande, F. C. James, W. W. Murdoch, and R. T. Paine. 2004. Hatcheries and endangered salmon. Science 303:1980.

Naik, P. K., and D. A. Jay. 2011. Distinguishing human and climate influences on the Columbia River: Changes in mean flow and sediment transport. Journal of Hydrology 404:259-277.

O'Connor, J. E., Duda, J. J., \& Grant, G. E. 2015. 1000 dams down and counting. Science 348: 496-497.

Pakkasmaa, S., and J. Piironen. 2000. Water velocity shapes juvenile salmonids. Evolutionary Ecology 14:721-730.

Petrosky, C. E., and H. A. Schaller. 2010. Influence of river conditions during seaward migration and ocean conditions on survival rates of Snake River Chinook salmon and steelhead. Ecology of Freshwater Fish 19:520-536.

Rechisky, E. L., D. W. Welch, A. D. Porter, M. C. Jacobs-Scott, and P. M. Winchell. 2013. Influence of multiple dam passage on survival of juvenile Chinook salmon in the Columbia River estuary and coastal ocean. Proceedings of the National Academy of Sciences, 201219910. 
Reeves, G. H., L. E. Benda, K. M. Burnett, P. A. Bisson, and J. R. Sedell. 1995. A disturbance-based ecosystem approach to maintaining and restoring freshwater habitats of evolutionarily significant units of anadromous salmonids in the Pacific Northwest. American Fisheries Society Symposium 17:334-349.

Reisenbichler, R. R., and S. P. Rubin. 1999. Genetic changes from artificial propagation of Pacific salmon affect the productivity and viability of supplemented populations. ICES Journal of Marine Science: Journal du Conseil 56:459-466.

Schaller, H. A., and C. E. Petrosky. 2007. Assessing hydrosystem influence on delayed mortality of Snake River stream-type Chinook salmon. North American Journal of Fisheries Management 27:810-824.

Scheuerell, M. D. 2005. Influence of juvenile size on the age at maturity of individually marked wild Chinook salmon. Transactions of the American Fisheries Society 134:999-1004.

Schroder, S. L., C. M. Knudsen, T. N. Pearsons, T. W. Kassler, E. P. Beall, S. F. Young, and D. E. Fast. 2012. Breeding success of four male life history types of spring Chinook salmon spawning in an artificial stream. Environmental Biology of Fishes 94:231-248.

Schlosser, I. J. 1991. Stream fish ecology: a landscape perspective. BioScience, 41(10), 704-712.

Sheer, M. B., and E. A. Steel. 2006. Lost watersheds: Barriers, aquatic habitat connectivity, and salmon persistence in the Willamette and lower Columbia River Basins. Transactions of the American Fisheries Society 135:1654-1669. 
Swain, D. P., B. E. Riddell, and C. B. Murray. 1991. Morphological differences between hatchery and wild populations of Coho salmon (Oncorhynchus kisutch): Environmental versus genetic origin. Canadian Journal of Fisheries and Aquatic Sciences 48:1783-1791.

Taylor, E. 1990. Environmental correlates of life-history variation in juvenile chinook salmon, Oncorhynchus tshawytscha (Walbaum). Journal of Fish Biology 37:1-17.

Teel, D. J., B. J. Burke, D. R. Kuligowski, C. A. Morgan, and D. M. Van Doornik. 2015. Genetic identification of Chinook salmon: stock-specific distributions of juveniles along the Washington and Oregon coasts. Marine and Coastal Fisheries 7:274300.

Tomaro, L. M., D. J. Teel, W. T. Peterson, and J. A. Miller. 2012. When is bigger better? Early marine residence of middle and upper Columbia River spring Chinook salmon. Marine Ecology Progress Series, 452, 237-252.

Tucker, S., M. Trudel, D. Welch, J. Candy, J. Morris, M. Thiess, C. Wallace, and T. Beacham. 2012. Annual coastal migration of juvenile Chinook salmon: Static stock-specific patterns in a highly dynamic ocean. Marine Ecology Progress Series 449:245-262.

Unwin, M. J., and G. J. Glova. 1997. Changes in life history parameters in a naturally spawning population of chinook salmon (Oncorhynchus tshawytscha) associated with releases of hatchery-reared fish. Canadian Journal of Fisheries and Aquatic Sciences 54:1235-1245.

Waples, R. S. 1999. Dispelling some myths about hatcheries. Fisheries 24:12-21. 
Weitkamp, L. A., D. J. Teel, M. Liermann, S. A. Hinton, D. M. Van Doornik, and P. J. Bentley. 2015. Stock-specific size and timing at ocean entry of Columbia River juvenile Chinook salmon and steelhead: Implications for early ocean growth. Marine and Coastal Fisheries 7:370-392.

Wessel, M. L., W. W. Smoker, and J. E. Joyce. 2006. Variation of morphology among juvenile Chinook salmon of hatchery, hybrid, and wild origin. Transactions of the American Fisheries Society 135:333-340.

Wilbur, H. M., and J. P. Collins. 1973. Ecological aspects of amphibian metamorphosis. Science 182:1305.

Williams, R. N., P. A. Bisson, D. L. Bottom, L. D. Calvin, C. C. Coutant, M. W. Erho, C. A. Frissell, J. A. Lichatowich, W. J. Liss, W. E. McConnaha, P. R. Mundy, J. A. Stanford, and R. R. Whitney. 1999. Return to the river: Scientific issues in the restoration of salmonid fishes in the Columbia River. Fisheries 24:10-19. 
Appendix A - Supplementary materials for Chapter 2

A.1. Mean acoustic transmitter life span

A.2. Environmental variable summary statistics by dam

A.3. Generalized least squares analysis between environmental variables at The Dalles Dam compared to Bonneville Dam and John Day Dam (i.e. test between dams)

A.4. Generalized least squares analysis of environmental variables at The Dalles Dam (i.e. test between variables at a single dam)

A.5. Explanation of survival estimates and boxplot of mean survival estimates for both species

A.6. Principal component analysis for Chinook salmon passing one dam

A.7. Dissolved gas and outflow discharge between 2001-2011

A.8. Differential pressure $(\Delta \mathrm{P})$ 


\begin{abstract}
A.1. Acoustic Transmitter Life Spans
Mean tag life for randomly selected acoustic transmitters was significantly different based on manufacturing lots (Skalski et al. 2012b); however the travel time that fish passed through the study area made differences between tag lots inconsequential (mean travel time for Chinook salmon and steelhead passing three dams was 3.17 days, SD \pm 1.73 and 3.01 days, $\mathrm{SD} \pm 1.87$ respectively).
\end{abstract}


A.2. Summary statistics (minimum, maximum and median) for each environmental variable by dam.

Table A2. - Minimum, maximum and mean (from raw hourly measurements) values for each environmental variable at each dam in the Lower Columbia River hydrosystem.

\begin{tabular}{|c|c|c|c|c|c|c|}
\hline & & $\begin{array}{c}\text { Outflow } \\
\text { Discharge } \\
\left(\mathbf{m}^{3} \cdot \mathbf{s}^{-1}\right)\end{array}$ & $\begin{array}{c}\text { Spillway } \\
\text { Discharge } \\
\left(\mathrm{m}^{3} \cdot \mathbf{s}^{-1}\right)\end{array}$ & $\begin{array}{c}\text { Temperature } \\
\left({ }^{\circ} \mathbf{C}\right)\end{array}$ & $\begin{array}{c}\text { Dissolved } \\
\text { Gas (\%) }\end{array}$ & $\begin{array}{c}\text { Barometric } \\
\text { Pressure } \\
(\mathrm{mmHg})\end{array}$ \\
\hline \multirow{3}{*}{$\begin{array}{c}\text { Bonneville } \\
\text { Dam }\end{array}$} & Min & 5623.7 & 716.4 & 7.1 & 103.9 & 749.0 \\
\hline & $\operatorname{Max}$ & 14475.5 & 8999.1 & 15.8 & 124.7 & 773.0 \\
\hline & Median & 11248.9 & 5132.4 & 11.8 & 116.6 & 760.0 \\
\hline \multirow{3}{*}{$\begin{array}{c}\text { The Dalles } \\
\text { Dam }\end{array}$} & Min & 4479.7 & 0.0 & 7.1 & 104.9 & 746.0 \\
\hline & Max & 14427.4 & 7750.3 & 15.8 & 126.2 & 769.0 \\
\hline & Median & 10972.8 & 4202.2 & 11.9 & 113.3 & 756.0 \\
\hline \multirow{3}{*}{$\begin{array}{c}\text { John Day } \\
\text { Dam }\end{array}$} & Min & 4989.4 & 852.3 & 6.6 & 102.9 & 742.0 \\
\hline & Max & 15265.5 & 7662.5 & 15.6 & 131.0 & 766.0 \\
\hline & Median & 11370.6 & 3982.7 & 11.8 & 112.7 & 753.0 \\
\hline
\end{tabular}


A.3. Generalized least squares regression between environmental variables at The Dalles Dam compared to the same variables at Bonneville Dam and John Day. The intent of this analysis is to show the relationship between predictor variables at each dam.

Table A.3. Results from generalized least squares regression between the average daily means of each environmental variable recorded at The Dalles Dam compared to daily means at Bonneville Dam and John Day Dam. The high correlations indicate that environmental variables are statistically similar between dams and support my use of random forest analysis over logistic regression.

\begin{tabular}{|c|c|c|}
\hline & $\begin{array}{c}\text { The Dalles Dam } \\
\text { X } \\
\text { Bonneville Dam }\end{array}$ & $\begin{array}{c}\text { The Dalles Dam } \\
\text { X } \\
\text { John Day Dam }\end{array}$ \\
\hline $\begin{array}{c}\text { Outflow } \\
\text { Discharge }\end{array}$ & $\begin{array}{c}r=0.96 \\
t=108.08 \\
p<0.001\end{array}$ & $\begin{array}{c}r=0.96 \\
t=117.63 \\
p<0.001\end{array}$ \\
\hline $\begin{array}{l}\text { Spillway } \\
\text { Discharge }\end{array}$ & $\begin{array}{l}r=0.15 \\
t=11.09 \\
p<0.001\end{array}$ & $\begin{array}{l}r=0.34 \\
t=15.51 \\
p<0.001\end{array}$ \\
\hline $\begin{array}{c}\text { Total } \\
\text { Dissolved Gas }\end{array}$ & $\begin{array}{c}r=0.99 \\
t=21.80 \\
p<0.001\end{array}$ & $\begin{array}{c}r=0.99 \\
t=20.13 \\
p-<0.001\end{array}$ \\
\hline $\begin{array}{c}\text { Water } \\
\text { Temperature }\end{array}$ & $\begin{array}{c}r=0.97 \\
t=157.59 \\
p<0.001\end{array}$ & $\begin{array}{c}r=0.97 \\
t=203.28 \\
p<0.001\end{array}$ \\
\hline
\end{tabular}


A.4. Generalized least squares analysis of environmental variables at The Dalles Dam. The intent of this analysis is to show the relationship between predictor variables at a dam.

A generalized least squares (GLS) analysis for non-independent variables was conducted between the average daily environmental variables at The Dalles Dam in order to determine the strength of correlation among predictor variables. We examined the relationships between project outflow discharge (kcfs) and spillway discharge ( $\mathrm{kcfs})$, spillway discharge (kcfs) and total dissolved gas $(\%)$, and water temperature $\left({ }^{\circ} \mathrm{C}\right)$ and total dissolved gas (\%). Due to high degrees of autocorrelation within environmental variables $($ Durbin Watson Test; DW statistic $=0.27-0.79)$ time series models were run in order to determine the lag time required to account for temporal autocorrelation. The GLS models were run using the identified lag time component in order to remove autocorrelation and determine the true relationship between environmental variables.

The results of the generalized least squares analysis for non-independent variables, accounting for temporal autocorrelation, indicated that averaged daily outflow and spillway discharge were significantly correlated $(t=13.65 ; p<0.001)$, spillway discharge and dissolved gas were significantly correlated $(t=3.91 ; p<0.001)$ and temperature and dissolved gas were significantly correlated $(t=2.94 ; p=0.004)$ at The Dalles Dam during my study period. 
A.5. Survival estimates for acoustically tagged salmonids.

Survival estimates were calculated using the Active Tag-Life-Adjusted Survival program (ATLAS v 1.5.3; Lady, Westhagen \& Skalski 2010). The ATLAS program uses acoustic tag lifespan curves to estimate tag failure rates and produces adjusted and unbiased survival estimates that account for the probability of tag failure and incorporates Cormack-Jolly-Seber model assumptions (Townsend et al. 2006). Because a large fraction (99\%) of fish passed through the study area in less than 20 days, all analyses other than survival estimates used data that were not adjusted by ATLAS for tag life failure and therefore differ from those reported elsewhere (Skalski et al. 2012a-c).

a) Chinook

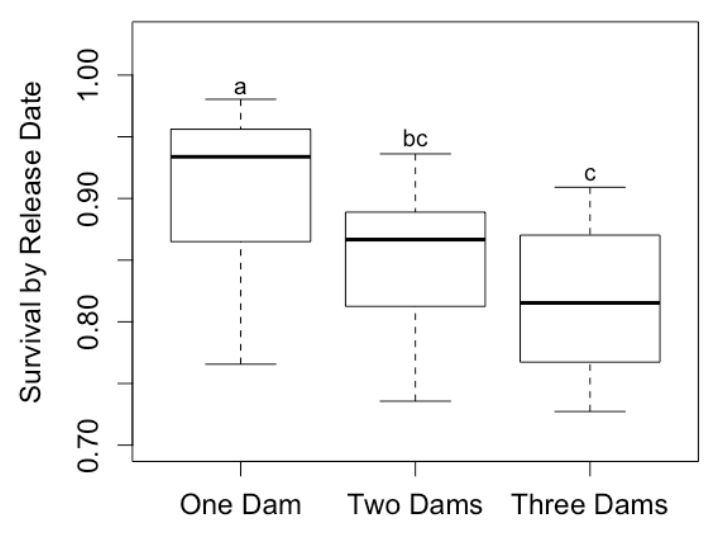

b) Steelhead

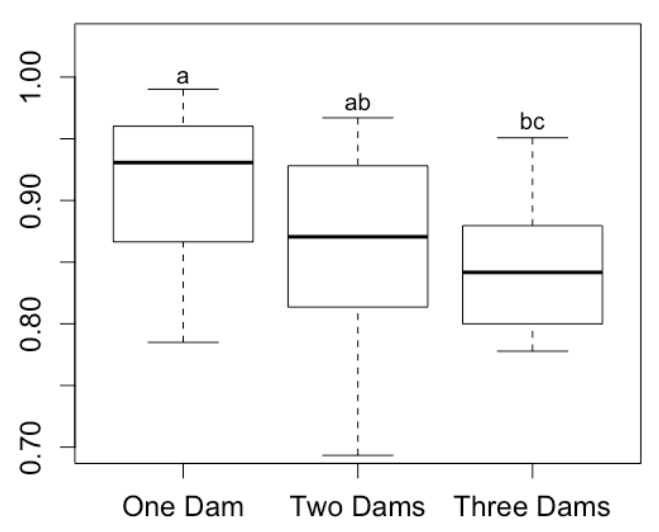

Figure A5. Boxplots of the mean survival estimates of a) Chinook and b) steelhead passing one, two and three dams. Each species' survival was assessed with a block design analysis of variance using number of dam passages as a treatment $(n=3)$ and blocked by released date $(\mathrm{n}=16)$. Survival means with different letters are statistically significant (Tukey's HSD, $p<0.05$ ). Whiskers represent the minimum and maximum range and box represents the inner quartiles with the median in bold. 


\section{References}

Lady, J.M.; Westhagen, P. \& Skalski, J.R. (2010) Program ATLAS 1: Active Tag Life Adjusted Survival. http://www.cbr.washington.edu/analysis/apps/atlas

Townsend, R.; Skalski, J.; Dillingham, P. \& Steig, T. (2006) Correcting bias in survival estimation resulting from tag failure in acoustic and radio-telemetry studies. Journal of Agricultural, Biological, and Environmental Statistics, 11, 183-196. 
A.6. Principal component analysis for Chinook salmon passing one dam

Table A.6. Eigenvalues, percent of variance explained and eigenvectors for each principal component for Chinook passing a one dam (BON, TDA and JDA). The first four PC's explained $95.22 \%$ of the environmental variance and were retained following a visual inspection of the associated scree plot. An eigenvector threshold of 0.4 was used as a cut off within each principal component (bold). PC1 is most correlated with release day, outflow volume, spillway volume, water temperature and dissolved gas concentrations. PC2 and PC3 show high correlations with fish length and barometric pressure. PC4 is highly correlated with fish velocity.

\begin{tabular}{llcccc}
\hline & $\begin{array}{l}\text { Principal } \\
\text { Components }\end{array}$ & PC1 & PC2 & PC3 & PC4 \\
& Eigenvalue & 5.20 & 1.04 & 0.96 & 0.42 \\
$\begin{array}{l}\text { Predictor } \\
\text { Variables }\end{array}$ & $\begin{array}{l}\text { Variance } \\
\text { Explained }\end{array}$ & $65.02 \%$ & $12.97 \%$ & $11.95 \%$ & $5.27 \%$ \\
\hline $\begin{array}{l}\text { Release Day } \\
\text { Fish Length }\end{array}$ & & $\mathbf{0 . 4 3}$ & -0.04 & 0.03 & -0.11 \\
$\begin{array}{l}\text { Outflow } \\
\text { Volume }\end{array}$ & -0.07 & $\mathbf{0 . 7 0}$ & $\mathbf{0 . 7 2}$ & -0.15 \\
$\begin{array}{l}\text { Spillway } \\
\text { Volume }\end{array}$ & & $\mathbf{0 . 4 2}$ & 0.01 & 0.02 & -0.15 \\
$\begin{array}{l}\text { Water } \\
\text { Temperature }\end{array}$ & & $\mathbf{0 . 4 1}$ & 0.15 & -0.12 & -0.28 \\
$\begin{array}{l}\text { Barometric } \\
\text { Pressure }\end{array}$ & & $\mathbf{0 . 4 1}$ & -0.12 & 0.12 & 0.02 \\
$\begin{array}{l}\text { Dissolved Gas } \\
\text { Fish Velocity }\end{array}$ & & -0.19 & $\mathbf{0 . 6 1}$ & $-\mathbf{0 . 6 5}$ & -0.24 \\
\hline
\end{tabular}




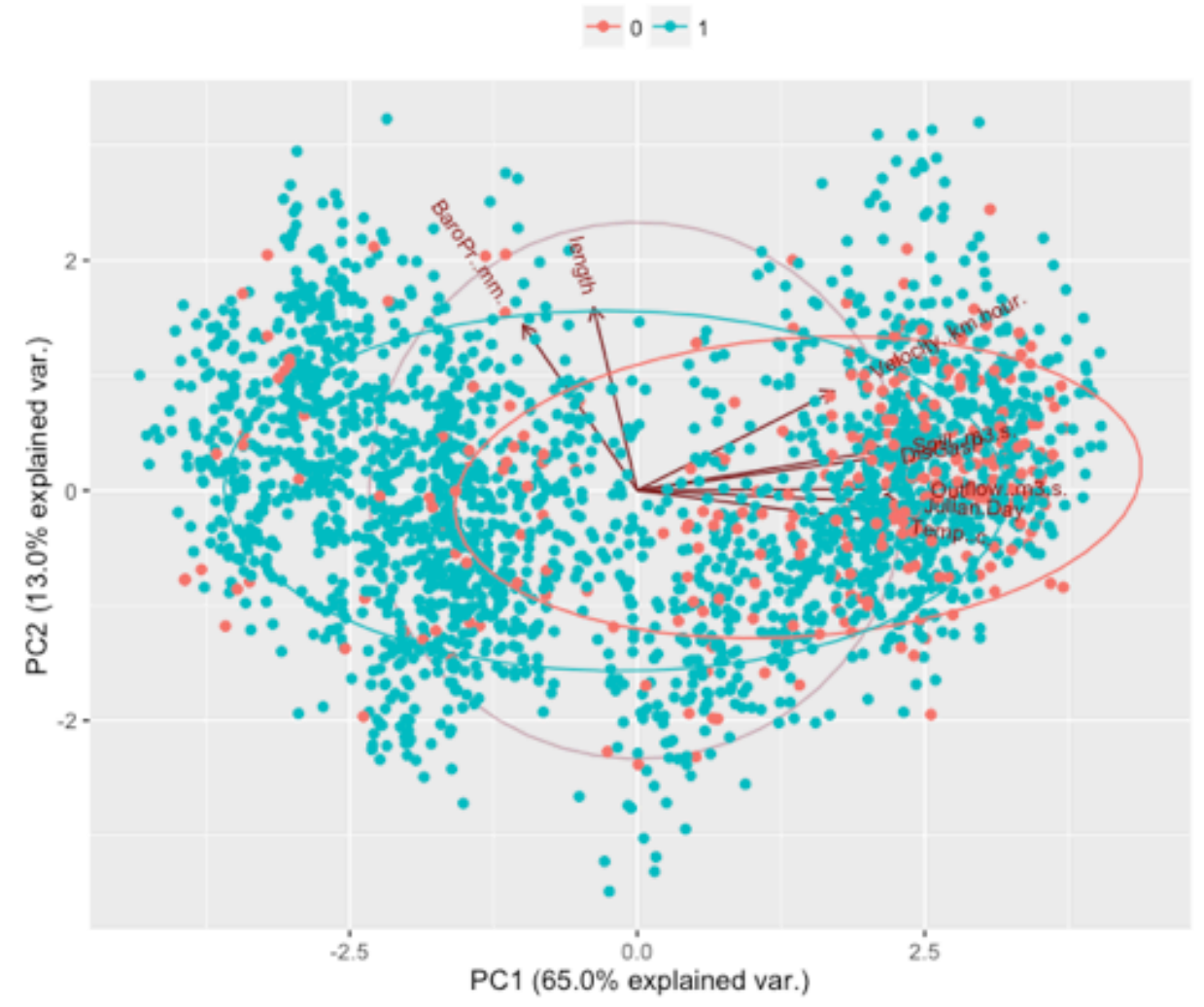

Figure A.6. Bi-plot showing the first and second principal components for Chinook salmon passing one dam in the Lower Columbia River. Eigenvectors for PC1 indicate that release day, outflow volume, spillway volume, water temperature and dissolved gas explain the $65.02 \%$ of the measured variance. PC2 and PC3 explain $12.97 \%$ and $11.95 \%$ of the variance and both are driven by fish length and barometric pressure. PC4 explains $5.27 \%$ of the variance and is explained by fish velocity. Green dots represent fish that survival, while red dots indicate fish mortality. 
A.7. Dissolved gas and outflow discharge between 2001-2011

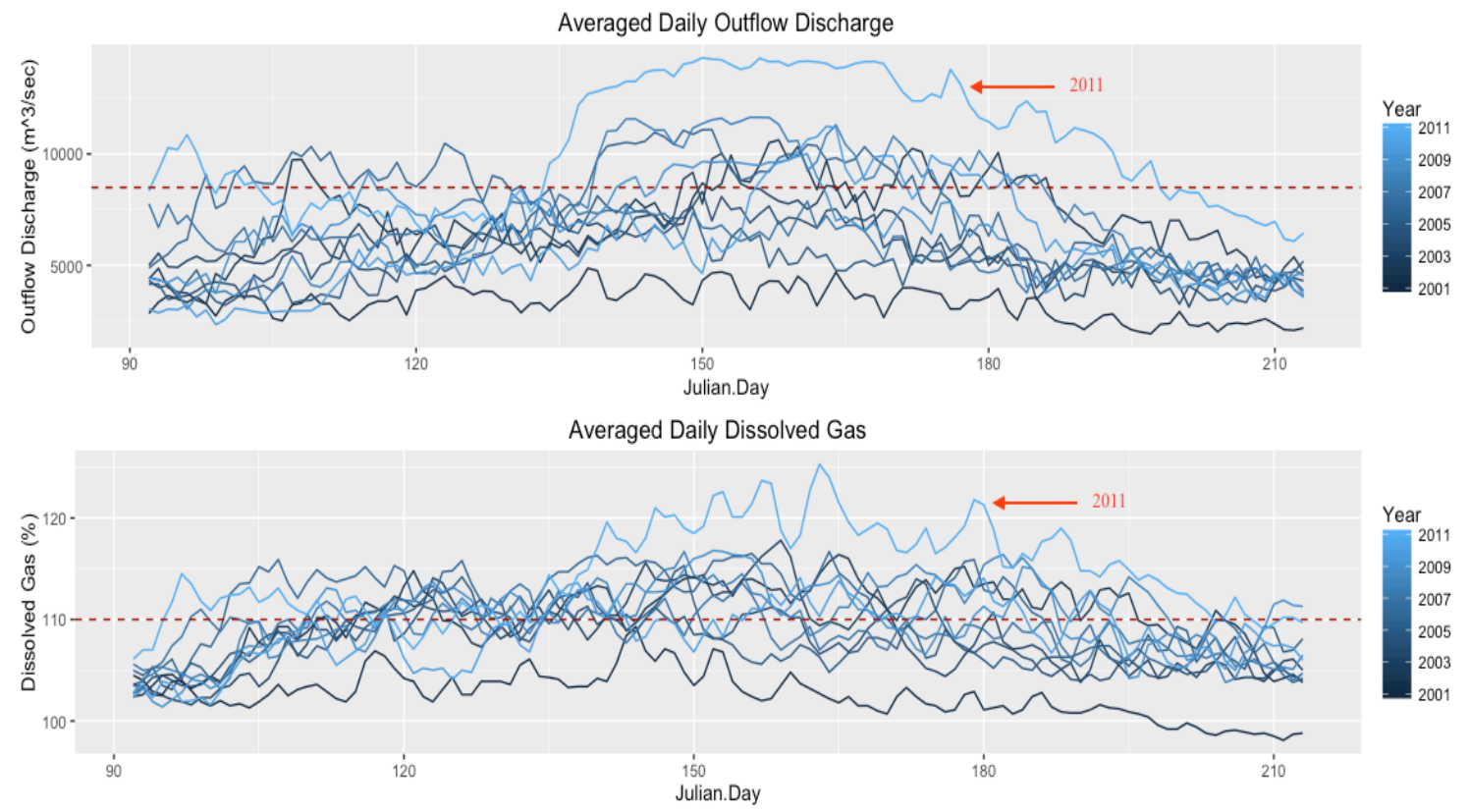

Figure A.7. Averaged dissolved gas (\%) and outflow discharge $\left(\mathrm{m}^{3} \cdot \mathrm{sec}^{-1}\right)$ in the Lower Columbia River hydrosystem over the past ten years. Hourly measurements from each dam (BON, TDA and JDA) averaged from April 1 - July 31 (day of year 92 - 213). Horizontal red lines represent outflow volumes (upper panel) that would initiate involuntary spill by exceeding hydro-capacity at BON dam $\left(>8495 \mathrm{~m}^{3} \cdot \mathrm{sec}^{-1}\right)$ and the State of Oregon's dissolved gas concentrations water quality standard $(110 \%)$. 
A.8. Differential pressure $(\Delta \mathrm{P})$

Appendix A.8 shows the daily averaged differential pressure $(\Delta \mathrm{P})$ that would be experienced by smolt migrating at the surface, $1 \mathrm{~m}$ and $2 \mathrm{~m}$ depths at each of the Lower Columbia River dams. Differential pressure is calculated as the difference between total dissolved gas pressures in river and atmospheric barometric pressure (see Colt 1983). Differential pressures $>38 \mathrm{mmHg}$ (shaded grey) have been shown to cause chronic gas bubble trauma and pressures $>76 \mathrm{mmHg}$ cause acute gas bubble trauma. Salmonid smolt can avoid harmful $\Delta \mathrm{P}$ levels through hydrostatic compensation (swimming at deeper depths). Throughout my study period, migration depths of $2 \mathrm{~m}$ should compensate for all elevated $\Delta \mathrm{P}$ levels in 2011.

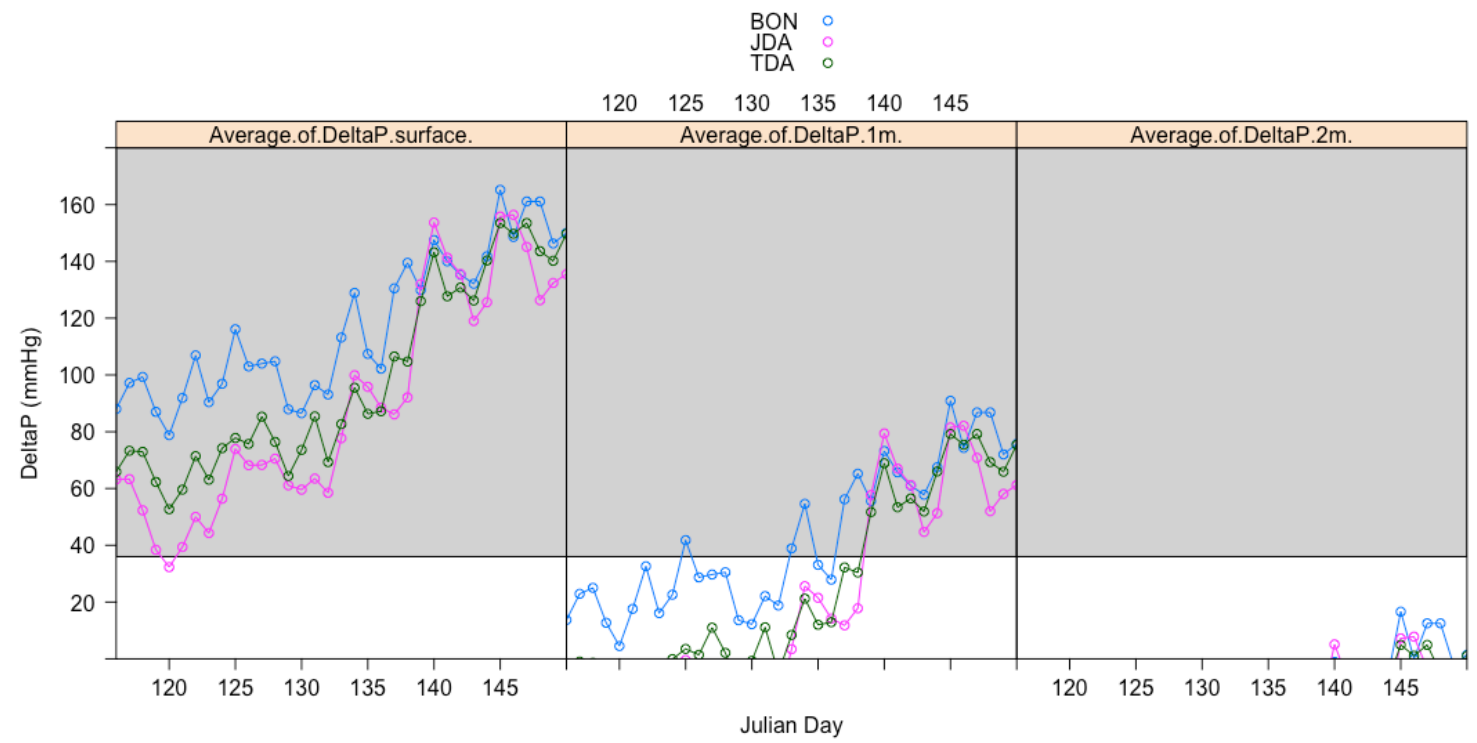

Figure A.8. Averaged daily differential pressure $(\Delta \mathrm{P})$ experienced by smolt migrating at the (a) surface, (b) 1-m and (c) 2-m depths at each of the Lower Columbia River dams. Differential pressures $>38 \mathrm{mmHg}$ (shaded grey) have been shown to cause chronic gas bubble trauma and pressures $>76 \mathrm{mmHg}$ cause acute gas bubble trauma. 


\section{Appendix B - Supplementary materials for Chapter 3}

B.1. Length at the time of marking by year for wild Chinook salmon.

B.2. Marine predictor variables included in statistical models showing the median, standard deviation and the scale of influence for Columbia River salmon.

B.3. Freshwater predictor variables included in statistical models showing the median, standard deviation, and the scale of influence for Columbia River salmon.

B.4. Adult return counts by subbasin and brood year. 
B.1. Length at the time of marking by year for wild Chinook salmon.

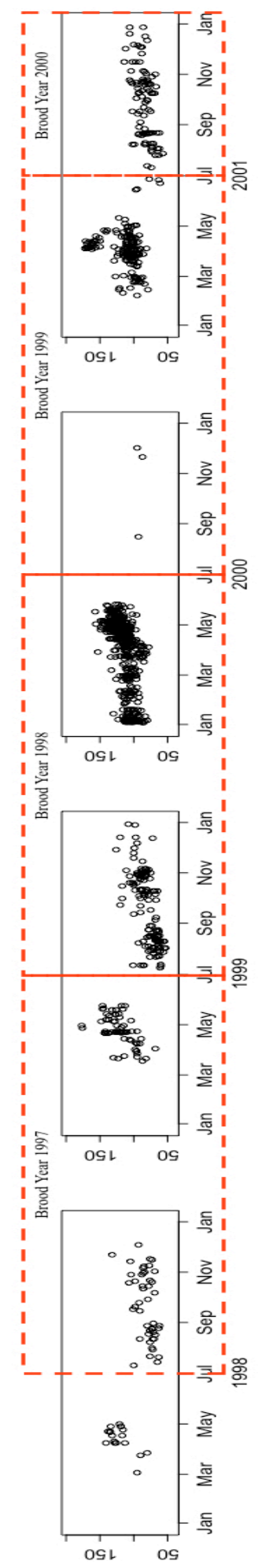

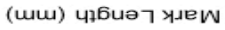
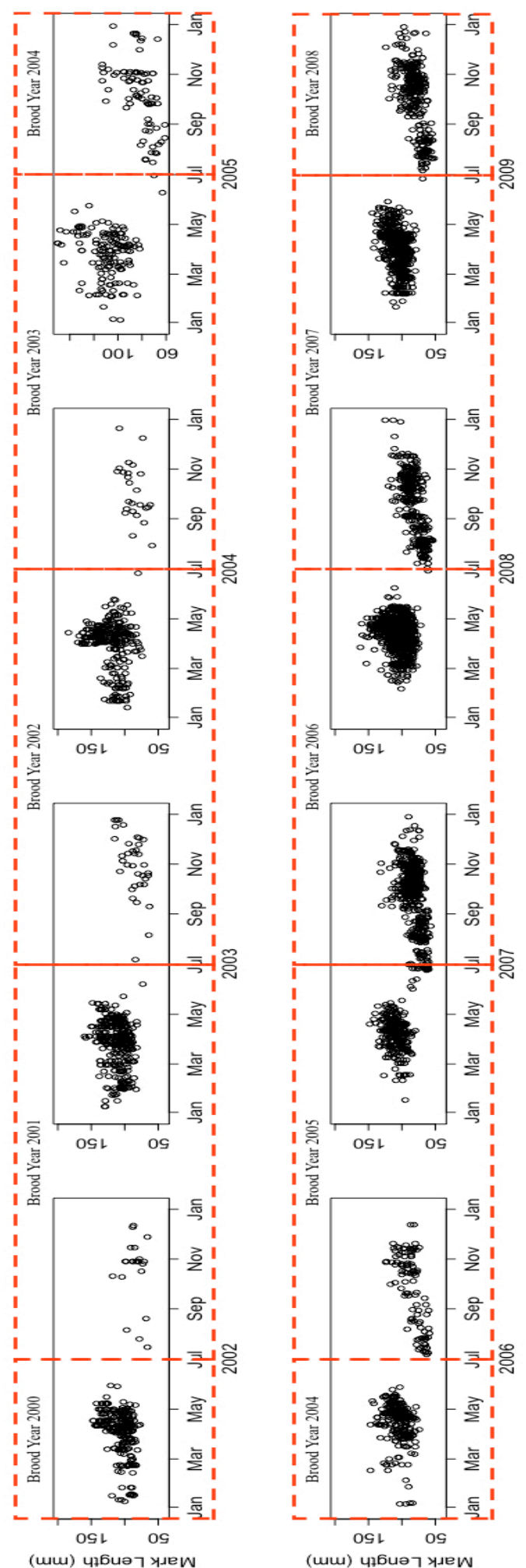
Figure B.1. Length at the time of marking by year for wild Chinook salmon. Brood years were determined by subtracting two years from the year of release for fish that were caught and tagged before July and subtracting one year from the release year for fish tagged after July. 
B.2. Marine predictor variables included in statistical models showing the median, standard deviation and the scale of influence for Columbia River salmon.

Table B.2. Marine predictor variables included in statistical models showing the median, standard deviation and the scale of influence for Columbia River salmon. CUI $=$ Coastal Upwelling Index, MEI = Multivariate E1 Niño - Southern Oscillation Index, PDO = Pacific Decadal Oscillation.

\begin{tabular}{|c|c|c|c|}
\hline Variable & $\begin{array}{c}\text { Wild } \\
\text { Median } \pm \underline{\text { SD }}\end{array}$ & $\begin{array}{c}\text { Hatchery } \\
\text { Median } \pm \text { SD }\end{array}$ & $\begin{array}{c}\text { Scale of Influence } \\
\text { (Spatial and Temporal) }\end{array}$ \\
\hline $\begin{array}{l}\text { Mean CUI } \\
\text { (Jan-Jun - Year of } \\
\text { Outmigration) }\end{array}$ & $-13.25 \pm 21.23$ & $-20.33 \pm 19.86$ & Near-shore - Bi-annual \\
\hline $\begin{array}{l}\text { Mean CUI } \\
\text { (Jul-Dec - Year of } \\
\text { Outmigration) }\end{array}$ & $-4.17 \pm 11.85$ & $-6.42 \pm 14.06$ & Near-shore - Bi-annual \\
\hline $\begin{array}{l}\text { Mean CUI } \\
\text { (Jan-Jun - Year of } \\
\text { Return) }\end{array}$ & $-24.00 \pm 19.89$ & $-20.33 \pm 19.54$ & Near-shore - Bi-annual \\
\hline $\begin{array}{l}\text { Mean CUI } \\
\text { (Jul-Dec - Year of } \\
\text { Return) }\end{array}$ & $-4.17 \pm 14.32$ & $-4.17 \pm 14.62$ & Near-shore - Bi-annual \\
\hline $\begin{array}{l}\text { Mean MEI } \\
\text { (Jan-Jun - Year of } \\
\text { Outmigration) }\end{array}$ & $-0.17 \pm 0.65$ & $-0.05 \pm 0.61$ & $\begin{array}{c}\text { eastern Pacific Ocean - } \\
\text { Annual }\end{array}$ \\
\hline $\begin{array}{l}\text { Mean MEI } \\
\text { (Jul-Dec - Year of } \\
\text { Outmigration) }\end{array}$ & $-0.37 \pm 0.81$ & $0.00 \pm 0.78$ & $\begin{array}{c}\text { eastern Pacific Ocean - } \\
\text { Annual }\end{array}$ \\
\hline $\begin{array}{l}\text { Mean MEI } \\
\text { (Jan-Jun - Year of } \\
\text { Return) }\end{array}$ & $-0.02 \pm 0.63$ & $0.29 \pm 0.57$ & $\begin{array}{c}\text { eastern Pacific Ocean - } \\
\text { Annual }\end{array}$ \\
\hline $\begin{array}{l}\text { Mean MEI } \\
\text { (Jul-Dec - Year of } \\
\text { Return) }\end{array}$ & $0.00 \pm 0.86$ & $0.39 \pm 0.80$ & $\begin{array}{c}\text { eastern Pacific Ocean - } \\
\text { Annual }\end{array}$ \\
\hline $\begin{array}{l}\text { Mean PDO } \\
\text { (Jan-Jun - Year of } \\
\text { Outmigration) }\end{array}$ & $-0.45 \pm 0.79$ & $-0.35 \pm 0.77$ & $\begin{array}{c}\text { eastern Pacific Ocean - } \\
\text { Annual }\end{array}$ \\
\hline $\begin{array}{l}\text { Mean PDO } \\
\text { (Jul-Dec - Year of } \\
\text { Outmigration) }\end{array}$ & $-0.73 \pm 0.74$ & $-0.73 \pm 0.83$ & $\begin{array}{c}\text { eastern Pacific Ocean - } \\
\text { Annual }\end{array}$ \\
\hline $\begin{array}{l}\text { Mean PDO } \\
\text { (Jan-Jun - Year of } \\
\text { Return) }\end{array}$ & $-0.34 \pm 0.82$ & $0.04 \pm 0.84$ & $\begin{array}{c}\text { eastern Pacific Ocean - } \\
\text { Annual }\end{array}$ \\
\hline $\begin{array}{l}\text { Mean PDO } \\
\text { (Jul-Dec - Year of } \\
\text { Return) }\end{array}$ & $-0.69 \pm 1.01$ & $-0.36 \pm 0.89$ & $\begin{array}{c}\text { eastern Pacific Ocean - } \\
\text { Annual }\end{array}$ \\
\hline
\end{tabular}


B.3. Freshwater predictor variables included in statistical models showing the median, standard deviation, and the scale of influence for Columbia River salmon.

Table B.3. Freshwater predictor variables included in statistical models showing the median, standard deviation, and the scale of influence for Columbia River salmon. PNI = Pacific Northwest Index.

\begin{tabular}{|c|c|c|c|}
\hline Variable & $\begin{array}{c}\text { Wild } \\
\text { Median } \pm \text { SD }\end{array}$ & $\begin{array}{c}\text { Hatchery } \\
\text { Median } \pm \text { SD }\end{array}$ & $\begin{array}{c}\text { Scale of Influence } \\
\text { (Spatial and Temporal) }\end{array}$ \\
\hline $\begin{array}{l}\text { Mean Annual PNI } \\
\text { (Year of Outmigration) }\end{array}$ & $0.09 \pm 0.59$ & $0.10 \pm 0.57$ & Basin - Seasonal \\
\hline $\begin{array}{l}\text { Mean Annual PNI } \\
\text { (Year of Return) }\end{array}$ & $0.18 \pm 0.45$ & $0.18 \pm 0.54$ & Basin - Seasonal \\
\hline $\begin{array}{l}\text { Adult Return Count of } \\
\text { Brood year by } \\
\text { Subbasin }\end{array}$ & $60899 \pm 46504$ & -- & Watershed - Annual \\
\hline $\begin{array}{l}\text { Mean Maximum } \\
\text { Temperature Fall } 1 \\
(\text { Oct-Dec })\left({ }^{\circ} \mathrm{C}\right)\end{array}$ & $6.74 \pm 2.80$ & $5.24 \pm 1.67$ & Basin - Seasonal \\
\hline $\begin{array}{l}\text { Mean Maximum } \\
\text { Temperature Winter } 1 \\
\text { (Jan-Mar) }\left({ }^{\circ} \mathrm{C}\right)\end{array}$ & $9.04 \pm 2.75$ & $7.68 \pm 1.53$ & Basin - Seasonal \\
\hline $\begin{array}{l}\text { Mean Maximum } \\
\text { Temperature Spring } 1 \\
\text { (Apr-Jun) }\left({ }^{\circ} \mathrm{C}\right)\end{array}$ & $18.70 \pm 3.41$ & $16.99 \pm 2.23$ & Basin - Seasonal \\
\hline $\begin{array}{l}\text { Mean Maximum } \\
\text { Temperature Summer } 1 \\
\text { (Jul-Sept) }\left({ }^{\circ} \mathrm{C}\right)\end{array}$ & $27.86 \pm 2.72$ & $26.08 \pm 2.17$ & Basin - Seasonal \\
\hline $\begin{array}{l}\text { Mean Precipitation } \\
\text { Fall } 1 \\
(\text { Oct-Dec })(\mathrm{mm})\end{array}$ & $1.22 \pm 1.20$ & $0.11 \pm 3.85$ & Basin - Seasonal \\
\hline $\begin{array}{l}\text { Mean Precipitation } \\
\text { Winter } 1 \\
\text { (Jan-Mar) (mm) }\end{array}$ & $1.50 \pm 1.46$ & $0.11 \pm 3.96$ & Basin - Seasonal \\
\hline $\begin{array}{l}\text { Mean Precipitation } \\
\text { Spring } 1 \\
\text { (Apr-Jun) (mm) }\end{array}$ & $0.95 \pm 0.84$ & $0.08 \pm 1.33$ & Basin - Seasonal \\
\hline $\begin{array}{l}\text { Mean Precipitation } \\
\text { Summer } 1 \\
\text { (Jul-Sept) }(\mathrm{mm})\end{array}$ & $0.30 \pm 0.32$ & $0.02 \pm 0.40$ & Basin - Seasonal \\
\hline $\begin{array}{l}\text { Distance to Ocean } \\
(\mathrm{Rkm})\end{array}$ & $778 \pm 313.06$ & $811 \pm 251.14$ & $\operatorname{Basin}-\mathrm{n} / \mathrm{a}$ \\
\hline Mark Length (mm) & $100 \pm 20.04$ & $118 \pm 15.19$ & Individual - Annual \\
\hline
\end{tabular}


B.4. Adult return counts by subbasin and brood year.

Density dependent effects on early life stages were modeled for wild fish using coarsescale adult return counts by subbasin and brood year. We accessed Columbia River $D A R T$ (University of Washington, accessed 2014) adult passage daily counts and queried annual returns $(1997$ - 2015) of all spring-run Chinook salmon retuning through Bonneville, Ice Harbor and Priest Rapids Dams. Fish passing Ice Harbor Dam between April 1 - June 11 were considered to be Snake River subbasin fish. Fish passing Priest Rapids Dam between April 15 - June 13 were considered Upper Columbia River subbasin fish. To estimate adult returns to the Lower Columbia, we subtracted the number of fish passing Priest Rapids and Ice Harbor from the total number of fish passing Bonneville between March 15 - May 31. For each fish in my data set, adult return count was assigned to broodyear and subbasin of origin (i.e. in the broodyear 2001, Snake River subbasin had an adult return count of 174,199 fish). 


\section{Appendix C - Supplementary materials for Chapter 4}

C.1. Landmark number and location on fish.

C.2. Digitizing measurement error for Chinook salmon.

C.3. Digitizing measurement error for steelhead. 
C.1. Landmark number and location on fish.

Table C.1. Landmark number and location on fish.

\begin{tabular}{cl}
\hline $\begin{array}{c}\text { Landmark } \\
\text { Number }\end{array}$ & Description of Landmarks \\
\hline 1 & Anterior lip of upper jaw \\
2 & Head at the midpoint of the eye \\
3 & Supraoccipital notch \\
4 & Anterior dorsal fin insertion \\
5 & Posterior dorsal fin insertion \\
6 & Anterior adipose fin insertion (if present) \\
7 & Minimum caudal depth, dorsal \\
8 & Dorsal terminus of the caudal flexure \\
9 & Ventral terminus of the caudal flexure \\
10 & Minimum caudal depth, ventral \\
11 & Posterior insertion of the anal fin \\
12 & Anterior insertion of the anal fin \\
13 & Insertion of the pelvic fin \\
14 & Insertion of the pectoral fin \\
15 & Meeting point of the gill plate on the ventral midline \\
16 & Midpoint of the gill plate on the ventral midline \\
17 & Most posterior point of the maxillary \\
18 & Most anterior point of the lower jaw \\
19 & Most anterior point of the eye \\
20 & Most posterior point of the eye \\
21 & Posterior edge of the operculum \\
\hline
\end{tabular}


C.2. Digitizing measurement error for Chinook salmon.

a) Total Error

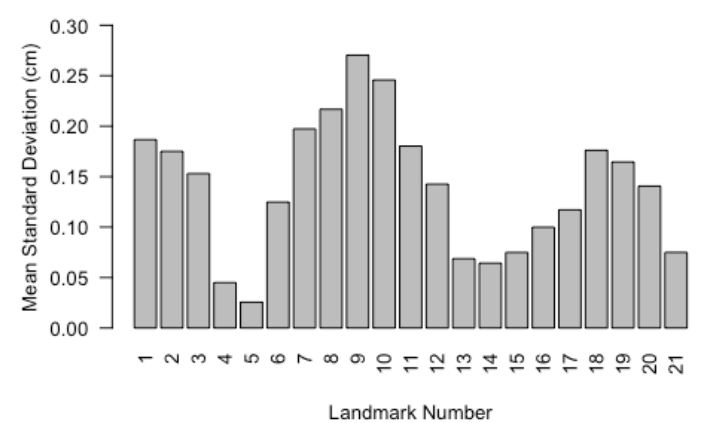

c) Total Error - Measurement Error b) Measurement Error
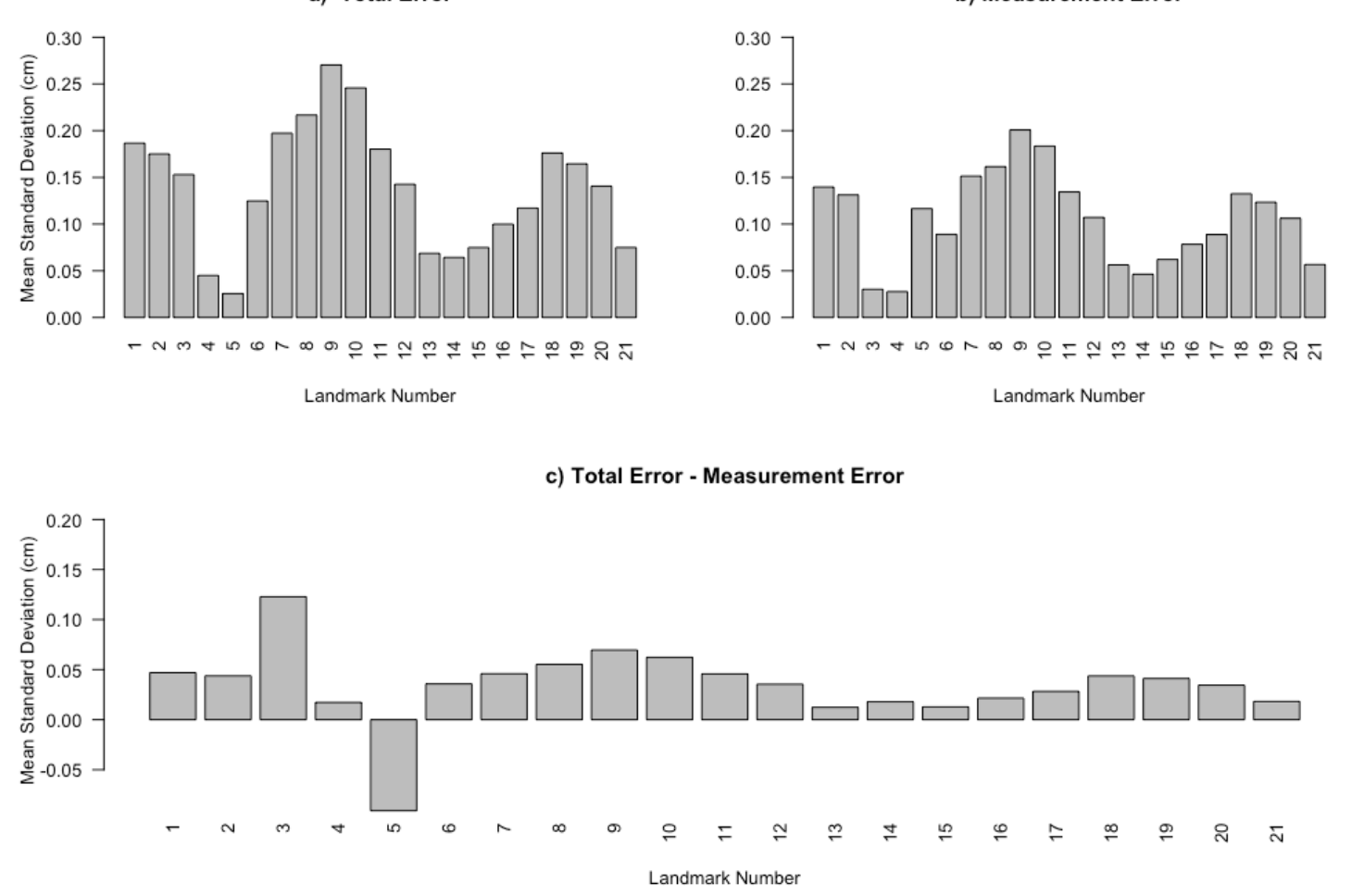

Figure C.2. Standard deviation of each set of landmark coordinates in a) all Chinook salmon $(n=513), b)$ mean replicated digitizing error (4 photographs digitized 5 times) and c) total error minus measurement error. 
C.3. Digitizing measurement error for steelhead.

a) Total Error

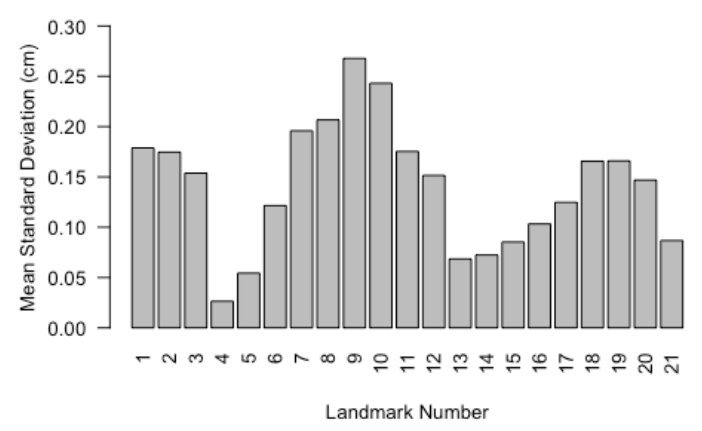

b) Measurement Error

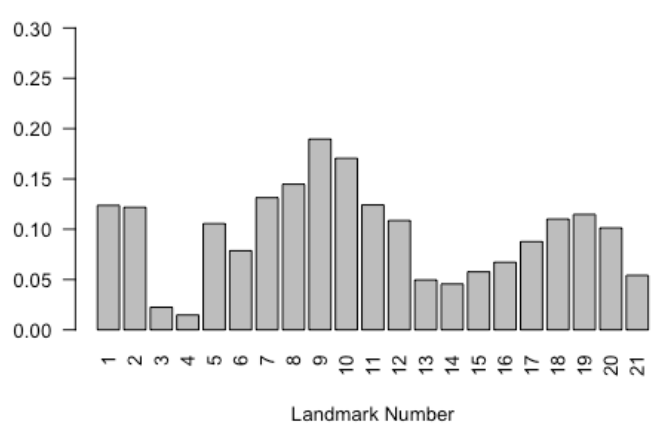

c) Total Error - Measurement Error

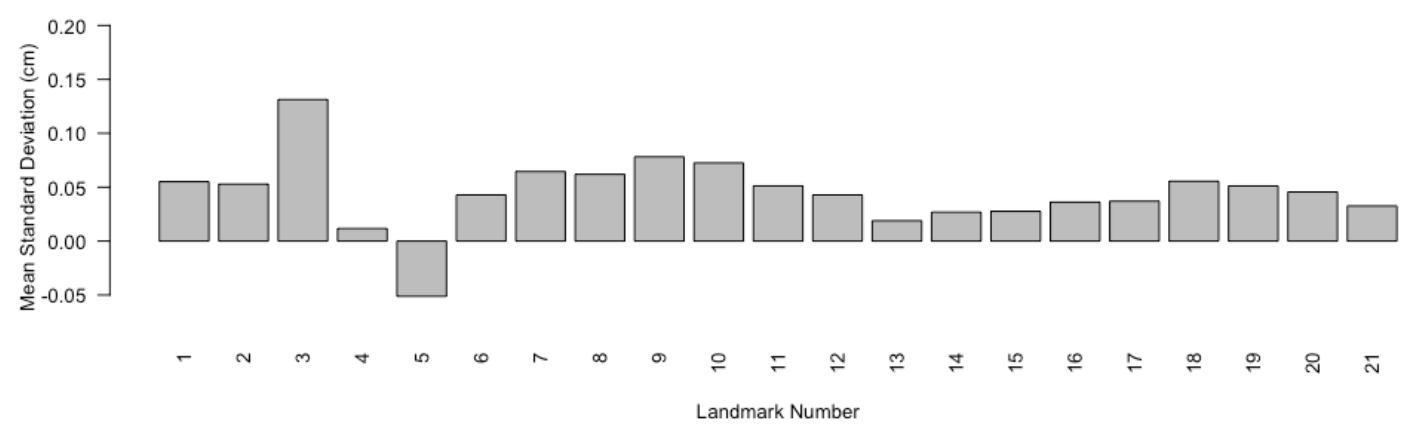

Figure C.3. Standard deviation of each set of landmark coordinates in a) all steelhead ( $n$ $=276$ ), b) mean replicated digitizing error (4 photographs digitized 5 times) and c) total error minus measurement error. 